\title{
WestVirginiaUniversity
}

THE RESEARCH REPOSITORY @ WVU

Graduate Theses, Dissertations, and Problem Reports

2008

\section{Evaluation of skin factor from single-rate gas well test}

Fahad M. Al Mutairi

West Virginia University

Follow this and additional works at: https://researchrepository.wvu.edu/etd

\section{Recommended Citation}

Al Mutairi, Fahad M., "Evaluation of skin factor from single-rate gas well test" (2008). Graduate Theses, Dissertations, and Problem Reports. 1968.

https://researchrepository.wvu.edu/etd/1968

This Thesis is protected by copyright and/or related rights. It has been brought to you by the The Research Repository @ WVU with permission from the rights-holder(s). You are free to use this Thesis in any way that is permitted by the copyright and related rights legislation that applies to your use. For other uses you must obtain permission from the rights-holder(s) directly, unless additional rights are indicated by a Creative Commons license in the record and/ or on the work itself. This Thesis has been accepted for inclusion in WVU Graduate Theses, Dissertations, and Problem Reports collection by an authorized administrator of The Research Repository @ WVU. For more information, please contact researchrepository@mail.wvu.edu. 


\title{
EVALUATION OF SKIN FACTOR FROM SINGLE-RATE GAS WELL TEST
}

\author{
Fahad M. Al Mutairi
}

\author{
Thesis submitted to the \\ College of Engineering and Mineral Resources \\ at West Virginia University \\ in Partial fulfillment of the requirements \\ for the degree of \\ Master of Science \\ in \\ Petroleum and Natural Gas Engineering
}

Khashayar Aminian, Chair

Samuel Ameri, M.S.

H. Ilkin Bilgesu, Ph.D.

Department of Petroleum and Natural Gas Engineering

\author{
Morgantown, West Virginia \\ 2008
}

Keywords: Pressure Transient Tests, Coefficient of Inertial Resistance, NonDarcy Flow Coefficient, Skin Factor, Permeability 


\section{ABSTRACT \\ EVALUATION OF SKIN FACTOR FROM SINGLE-RATE GAS WELL TEST}

Fahad Almutairi

Skin factor is generally used as an indicator for well flow efficiency and the criterion for performing stimulation treatment to improve well productivity. This skin factor is a composite factor and should be divided into its different components in order to evaluate near-wellbore damage. Therefore, the total skin factor obtained from a gas well pressure transient test has two primary components, rate-independent and rate-dependent skins. Both of these skin factors can be determined directly from the interpretation of pressure transient well tests if several transient tests are performed at different rates. However, the multi-rate tests are time consuming and expensive. It is advantageous to estimate the rateindependent skin factor from a single rate test.

In order to obtain a reliable value for the rate-independent skin from a single-rate test, the rate dependent skin must be evaluated independently. The rate-dependent skin depends on the coefficient of inertial resistance, $\beta$ and other parameters. A number of correlations relating $\beta$ to permeability are available in the literature. These published correlations are derived from limited set of laboratory measurements on various porous media and do not provide consistent results. Alternatively, $\beta$ can be determined from the results of the multi-rate well tests using recorded field data.

The main objective of this study is to generate a dependable and simple technique for estimating the true skin factor from the single rate well tests, such as build-up or fall-off tests, on gas wells. More specifically, the objective is to develop a correlation for $\beta$ from field data. Since, the correlation of turbulence factor, $\beta$ and permeability, $\mathrm{k}$ cannot be applied universally to all reservoirs, so the reservoir-specific correlations will be further developed.

The well tests from several wells in the same reservoir were available and several fieldspecific correlations for $\beta$ were developed. The comparison of skin factor determined from these correlations against the skin factors determined from the well test data indicated that reservoir-specific correlations for $\beta$ provide accurate and consistent results. 


\section{ACKNOWLEDGMENTS}

Although constructing and writing a thesis can be quite frustrating, it's one of the most rewarding experiences. Writing a thesis gives me the challenge and the opportunity of pursue an intriguing intellectual question within my research field. In addition, having an academic advisor provides an assessment that he can identify problematic areas requiring more research, without having to investigate in all areas.

I am extremely grateful to my academic advisor Dr. Kashy Aminian, for all his help and advice. He has provided me with smart, sharp, and useful comments and direction. I would like to thank him for all his assistance and support he has given me in completing my research.

I would also like to extend my heartfelt thanks to Dr. Sam Ameri for his assistance and continuous encouragement during my studies at West Virginia University. I also appreciate his participation to be part of the examining committee. I would like to express my gratitude towards Dr. H. Ilkin Bilgesu for his participation in my committee.

Special thanks to the other faculty of the Petroleum and Natural Gas Engineering Department for providing me the knowledge I need to complete my study.

I dedicate my work to my parents, my wife and son for their love, support and patience. I would like to express special thanks to my friends at Saudi Aramco Company, Nader Al Douhan, Bandar Al Malki, Jamal Al Mufleh and Khalid Al Areekan for their support. 


\section{TABLE OF CONTENTS}

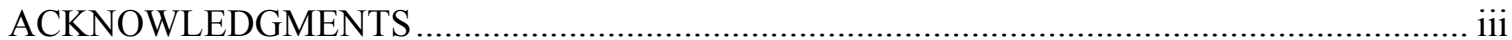

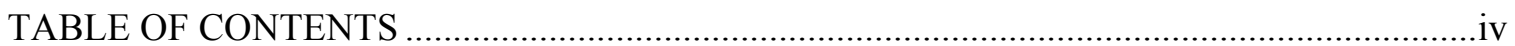

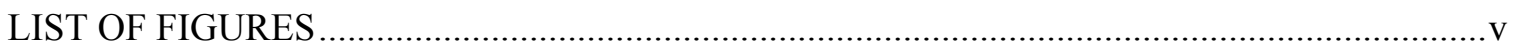

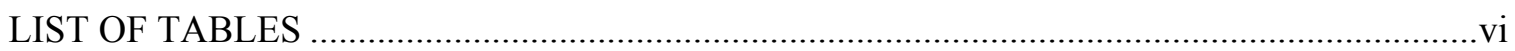

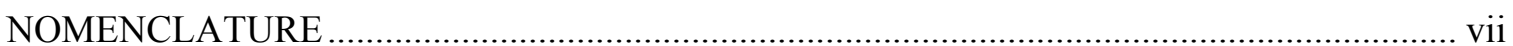

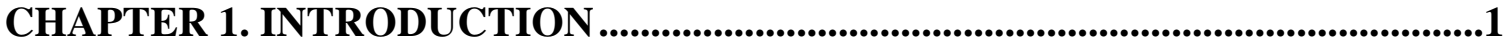

CHAPTER 2. LITERATURE REVIEW ................................................................3

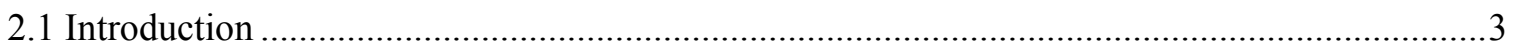

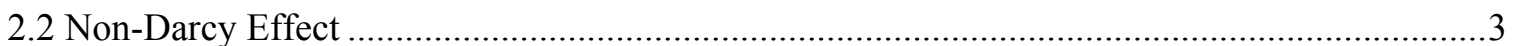

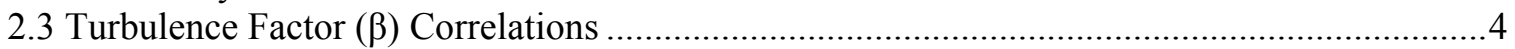

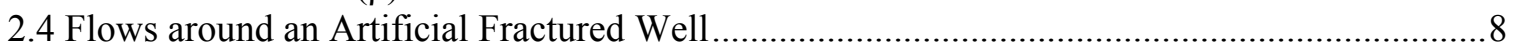

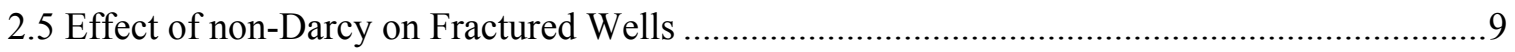

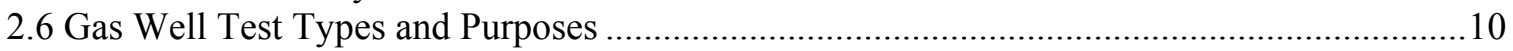

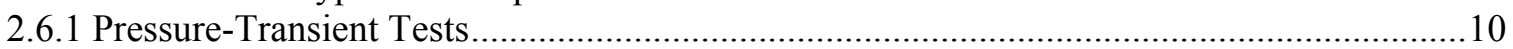

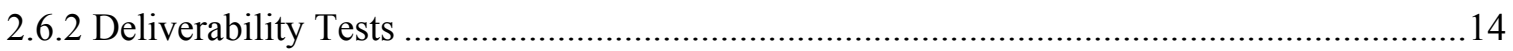

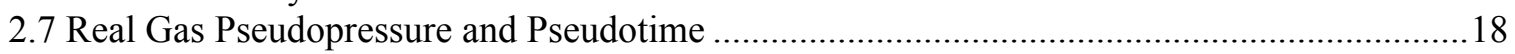

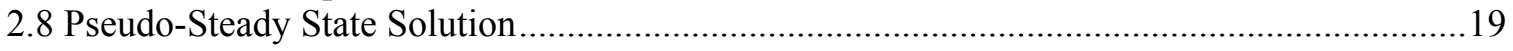

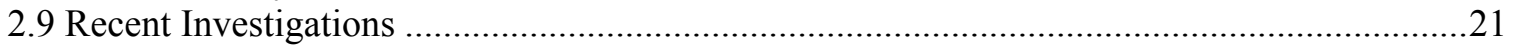

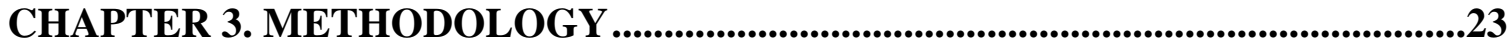

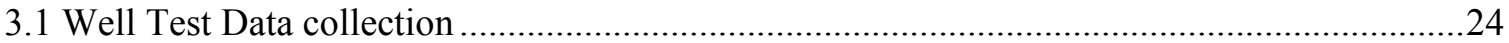

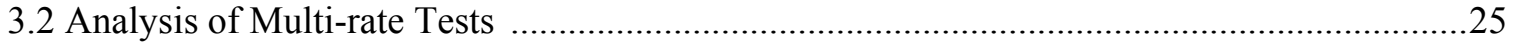

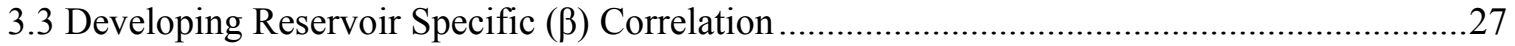

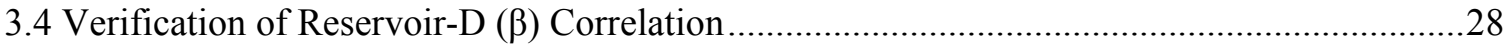

3.5 Evaluation of the Existing $(\beta)$ Correlations for Reservoir-C wells ......................................29

CHAPTER 4. RESULTS AND DISCUSSIONS ...................................................31

CHAPTER 5. CONCLUSIONS AND RECOMMENDATIONS .............................37

REFERENCES

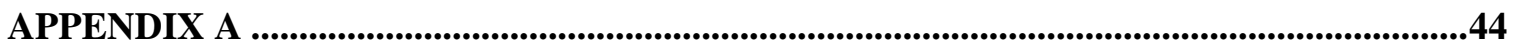

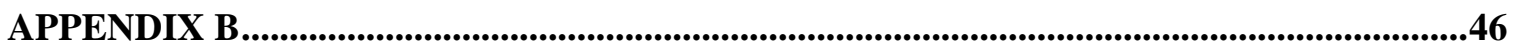

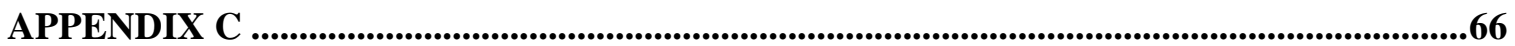




\section{LIST OF FIGURES}

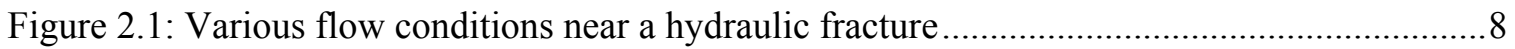

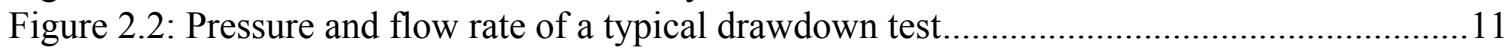

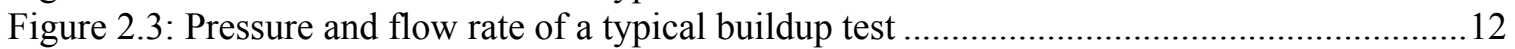

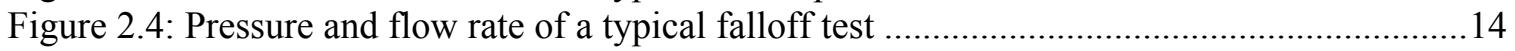

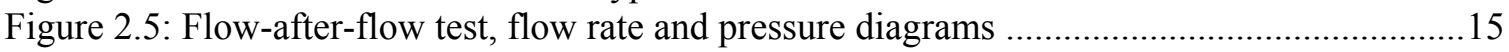

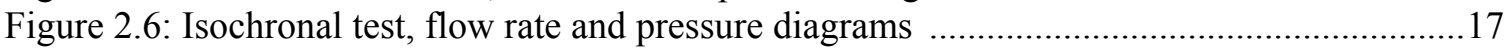

Figure 2.7: Modified Isochronal test, flow rate and pressure diagrams .......................................18

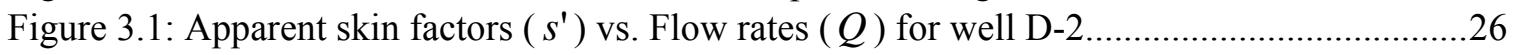

Figure 3.2: $\beta$ Factor vs. Permeability values $(k)$ for reservoir $\mathrm{D}$ wells .....................................28

Figure 4.1: $\beta$ Correlations for different reservoirs (A, B, C \& D) .............................................32

Figure 4.2: $\beta$ General Correlation based on the data from all reservoirs ......................................33

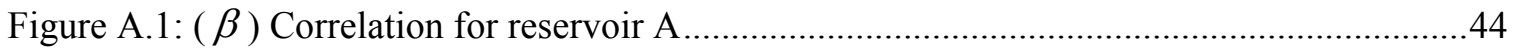

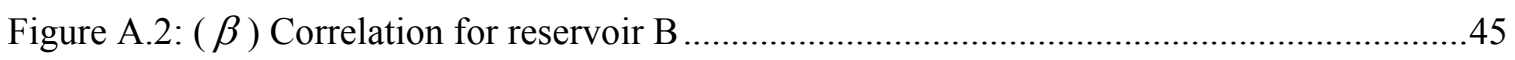

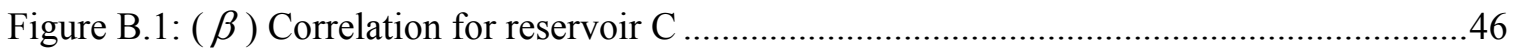

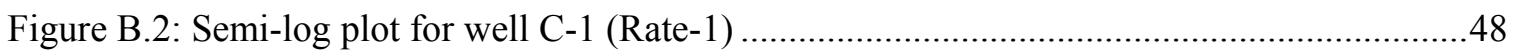

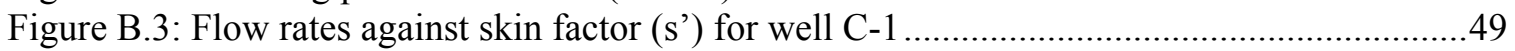

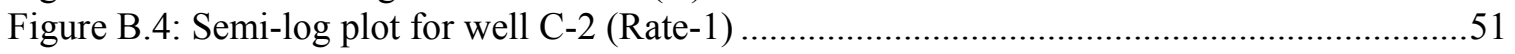

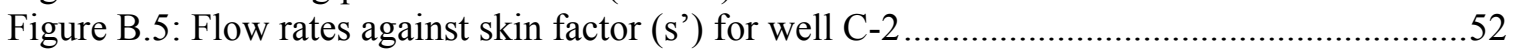

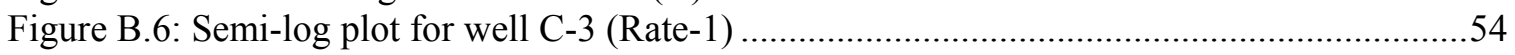

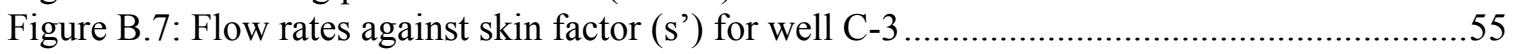

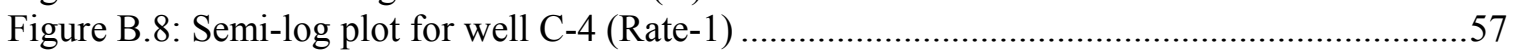

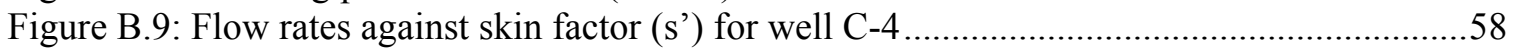

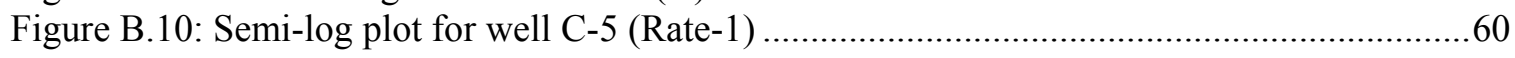

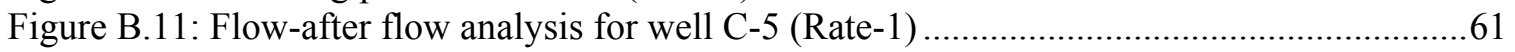

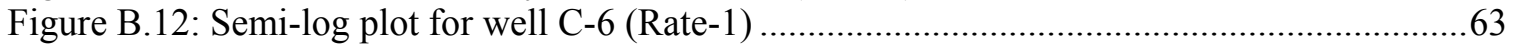

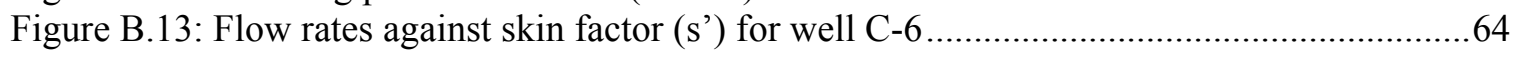

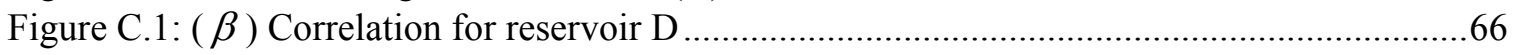

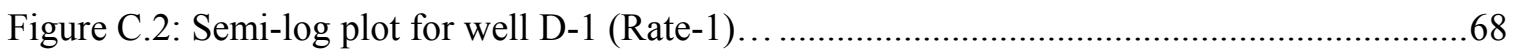

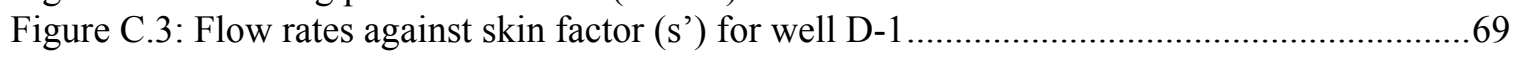

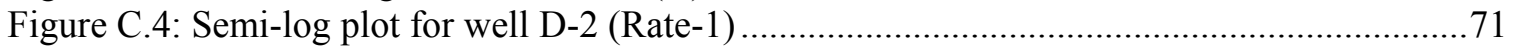

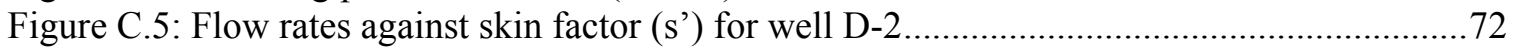

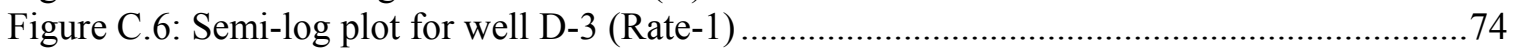

Figure C.7: Flow rates against skin factor (s') for well D-3 ............................... 75 


\section{LIST OF TABLES}

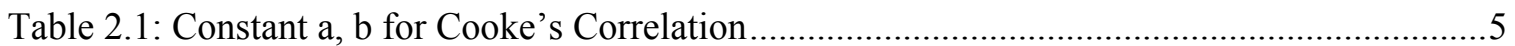

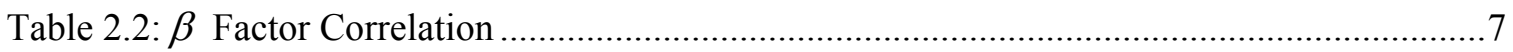

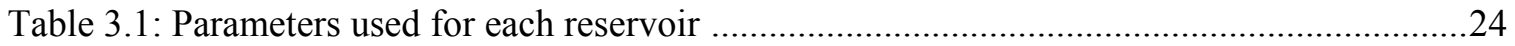

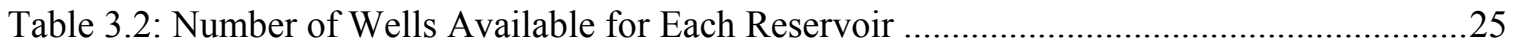

Table 3.3: Permeability and apparent skin factor values for well D-2 ......................................26

Table 3.4: Permeability and $\beta$-factor values for each well in Reservoir-D ................................2

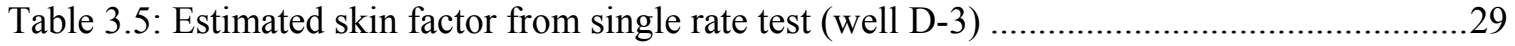

Table 3.6: Evaluation of the Existing $\beta$ Correlation for wells in reservoir-C..........................30

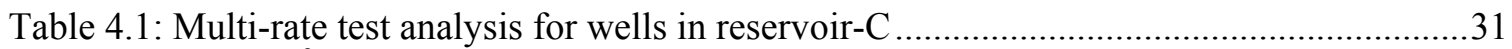

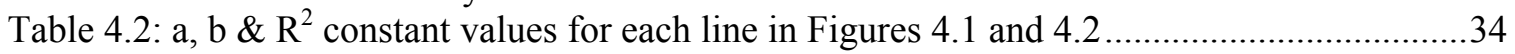

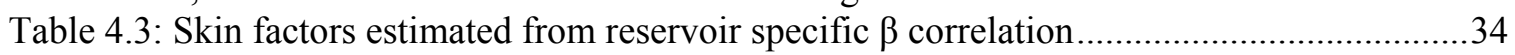

Table 4.4: Skin factors estimated from General $\beta$ correlation (All Reservoirs) ..............................35

Table 4.5: Skin factors estimated from reservoirs A \& B $\beta$ correlations ..........................................

Table A.1: Reservoir A Parameters Obtained from Multi-rate Tests .............................................44

Table A.2: Reservoir B Parameters Obtained from Multi-rate Tests ..........................................45

Table B.1: Reservoir C Parameters Obtained from Multi-rate Tests ..........................................46

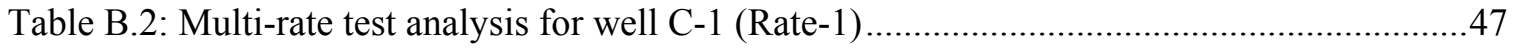

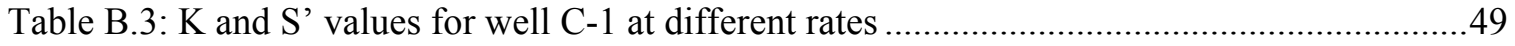

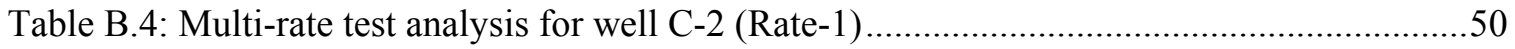

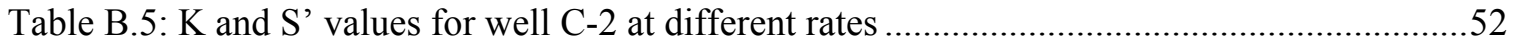

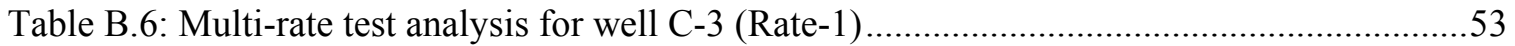

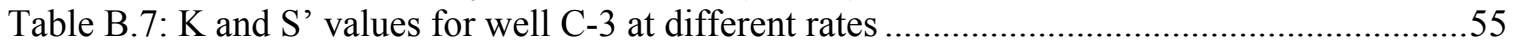

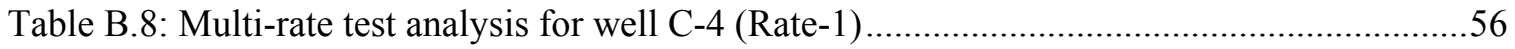

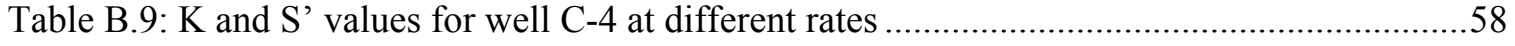

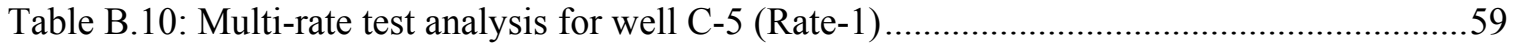

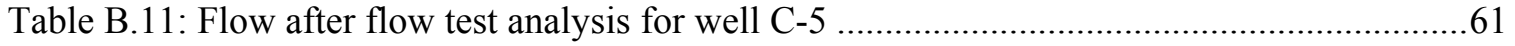

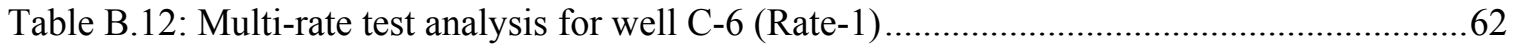

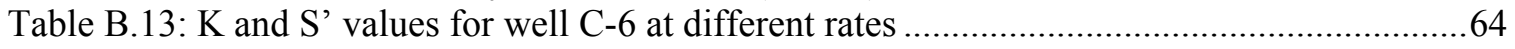

Table C.1: Reservoir D Parameters Obtained from Multi-rate Tests ...........................................66

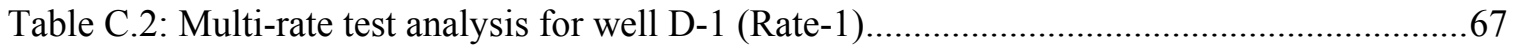

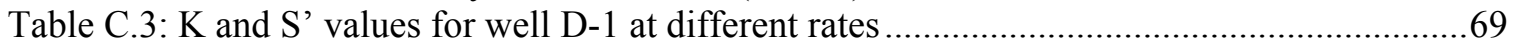

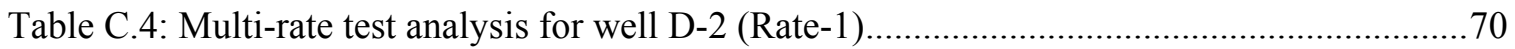

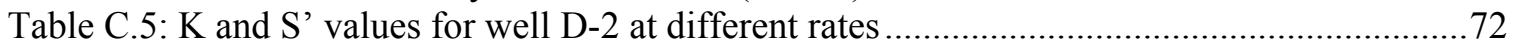

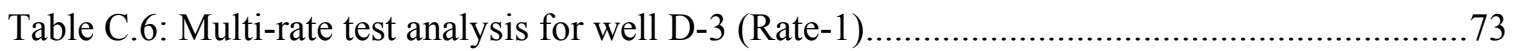

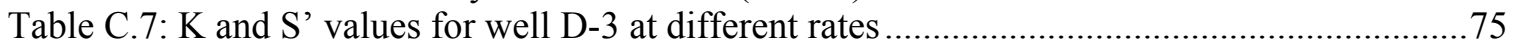


$K=$ permeability (md)

$t=$ Time $(\mathrm{hrs})$

$\phi=$ Porosity $(\%)$

$\mu=$ Gas Viscosity (cp)

$C_{t}=$ Total compressibility $\left(\mathrm{psi}^{-1}\right)$

$r_{d}=$ Transient radius of drainage $(\mathrm{ft})$

$r_{w}=$ Wellbore radius $(\mathrm{ft})$

$m\left(p_{i}\right)=$ Initial pseudo-pressure $\left(\mathrm{psi}^{2} / \mathrm{cp}\right)$

$m\left(p_{w f}\right)=$ Bottomhole pseudo-pressure $\left(\mathrm{psi}^{2} / \mathrm{cp}\right)$

$m\left(p_{R}\right)=$ Reservoir pseudo-pressure $\left(\mathrm{psi}^{2} / \mathrm{cp}\right)$

$h=$ Formation thickness $(\mathrm{ft})$

$T=$ Temperature $(\mathrm{R})$

$q=$ Flow rate $(\mathrm{Mscf} / \mathrm{D})$

$S^{\prime}=$ Apparent skin factor

$S=$ Skin factor

$\mu_{i}=$ Initial gas Viscosity (cp)

$D=$ Non-Darcy turbulence coefficient $(\mathrm{Mscf} / \mathrm{D})^{-1}$

$\bar{\mu}=$ Average gas Viscosity (cp)

$\gamma_{g}=$ Gas specific gravity

$t_{D}=$ Dimensionless time 
$P=$ Pressure (Psia)

$P_{a}=$ Adjusted Bottom hole Pressure (Psia)

$P_{p}=$ Pseudopressure (Psia)

$z=$ Gas compressibility factor

$S-S_{f}=S_{d}=$ Damaged skin

$D_{f}=$ Non-Darcy flow factor for fractured wells

$D_{w}=$ Non-Darcy flow factor for nonfractured wells

$\alpha=$ Factor

$\beta=$ Coefficient of internal resistance

$\rho=$ Density $\left(\mathrm{lbm} / \mathrm{ft}^{3}\right)$

$L_{f}=$ Fracture length $(\mathrm{ft})$

$r_{e}=$ Radius of outer boundary (ft)

$L_{f D}=$ Dimensionless fracture half-length $\left(=\mathrm{L}_{\mathrm{f}} / \mathrm{r}_{\mathrm{e}}\right)$ 


\section{CHAPTER 1}

\section{INTRODUCTION}

Well test data from a gas well can be analyzed using standard pressure transient test interpretation procedures to determine permeability $(k)$ and total skin factor $\left(s^{\prime}\right)$. The total skin factor is a composite factor which is expressed in terms of rate-independent or true skin factor $(s)$ and rate-dependent skin factor $(D q)$ as follows (Ramey, 1965):

$$
s^{\prime}=s+D q
$$

Rate-dependent skin $(D q)$ represents non-Darcy flow pressure drop, however true skin factor $(s)$ represents formation change (stimulation or damage). If a multi-rate test is conducted and analyzed, $\left(s^{\prime}\right)$ can be determined for different values of $(q)$. Plot of $\left(s^{\prime}\right)$ versus $(q)$, which result in straight line, can be utilized to determine $(s)$ and $(D)$ from the intercept and the slope respectively (Ramey, 1965). If only a single rate test is available, the true skin factor $(s)$ could be estimated from equation (1) if the non- Darcy flow coefficient, $D$ can be determined independently. The non-Darcy flow coefficient, $(D)$, could be evaluated by integrating the Forchheimer equation (Ramey, 1965 and Jones et al, 1975) which gives:

$$
D=\frac{2.223 \times 10^{-15} \gamma_{g} k}{\bar{\mu} h_{p} r_{w}} \beta
$$

The term, $\beta$ referred to as the coefficient of inertial resistance originates from Forchheimer equation and is generally correlated with permeability and porosity of the porous media. A number of correlations, which have been derived from limited set of laboratory data, are available in the literature. The predicted value of $\beta$ from these 
correlations varies several orders of magnitude. Therefore, there is need for a reliable consistent procedure to estimate $\beta$ in order to accurately determine the skin factor from a single rate well test. 


\section{CHAPTER 2}

\section{LITERATURE REVIEW}

\subsection{Introduction}

Gas properties are very strong functions of pressure which makes analysis of gas well tests more complicated. Therefore, all the equations controlling pressure transmission through gases are nonlinear.

\subsection{Non-Darcy Effect}

In general, the fluid flow in a porous media at low velocities is governed by Darcy's law (1856), which describes a linear relationship between the velocity and the pressure

gradient, $\left(\frac{d p}{d x}\right)$. However, in case of high flow rate, for an instance, near the wellbore region in gas wells, Darcy's law is inadequate for describing the fluid flow. Therefore, In order to substitute the shortage encountered by Darcy's law for high gas flow rates, Forchheimer (1901) proposed a classical equation and he found that the best equation that could describe his data is as follow.

$$
-\frac{d p}{d x}=\frac{\mu v}{k}+\beta \rho v^{2}
$$

He modified the Darcy flow equation by adding a non-Darcy term $\left(\beta \rho v^{2}\right)$ which is a multiplication of the non-Darcy flow coefficient $(\beta)$, fluid density $(\rho)$ and the second power of velocity $\left(v^{2}\right)$. He noticed that the pressure gradient $\left(\frac{d p}{d x}\right)$ required to sustain a specific high flow rate through a porous media was higher than the one predicted by Darcy's law. The deviation from Darcy's law increases with increasing flow rate and has 
been credited, by Forchheimer, to the surplus gradient required to overcome inertial flow resistance, which is relative to $\rho v^{2}$.

The pressure drop needed to create a desired well production rate is increased by nonDarcy flow $\left(\beta \rho v^{2}\right)$, thus decreasing productivity. It is extremely important to estimate the non-Darcy flow coefficient as precisely as possible as it is the most important factor in determining the non-Darcy effect. The majority of researchers have confirmed that the non-Darcy effect is due to inertial effect and not to turbulence. By analyzing the multirate pressure test results, the non-Darcy flow coefficient can be determined; however these data are not always available.

\subsection{Turbulence Factor ( $\beta$ ) Correlations}

The coefficient, $\beta$, appearing in Forchheimer equation (8) has been referred to by several names such as the coefficient of inertial resistance, turbulence factor, the velocity coefficient, the non-Darcy coefficient, the Forchheimer flow coefficient, and simply the beta factor. In general, $\beta$ is related to the structure of porous media.

The most important factor in evaluating the non Darcy effect is to get a good estimate of the turbulence factor, $\beta$. Many efforts have been made to generate a relationship among laboratory measured $\beta$ factor and rock properties such as porosity and permeability. The first correlation for turbulence factor, $\beta$, was developed by Janicek and Katz (1955) which was a function of porosity and permeability of the porous medium. They have used limestone, sandstone, and dolomite cores for developing the following correlation:

$$
\beta=1.82 \times 10^{8} K^{-5 / 4} \phi^{-3 / 4}
$$


By analyzing both Janicek and Katz data, Tek et al. (1962) proposed a correlation for turbulence factor, $\beta$, which was expressed as following:

$$
\beta=\frac{7.64 \times 10^{8}}{K^{1.72}}
$$

The turbulence factor, $\beta$, in propped fracture at different temperatures was investigated by Cooke (1973). He developed the following equation:

$$
\beta=\frac{b}{K^{a}}
$$

Where $K$ is fracture permeability (md), $\beta$ is turbulence factor measured in $(1 / \mathrm{ft}), \mathrm{a}$ and $\mathrm{b}$ are based on proppant type. This correlation was only applied for used for single phase flow. Table 2.1, presents constant values of $\mathrm{a}$ and $\mathrm{b}$ for Cooke equation.

\section{Table 2.1: Constants a, $b$ for Cooke's Correlation}

\begin{tabular}{|c|c|c|}
\hline Sand size & $\mathrm{a}$ & $\mathrm{b}$ \\
\hline $8-12$ mesh & 1.24 & 2.32 \\
\hline $10-20$ mesh & 1.34 & 2.63 \\
\hline $20-40$ mesh & 1.54 & 2.65 \\
\hline $40-60$ mesh & 1.6 & 1.1 \\
\hline
\end{tabular}

A different correlation was developed by Geertsma (1974) by analyzing data obtained from consolidated sandstones, unconsolidated sandstones, limestone, and dolomites. He proposed the following equation:

$$
\beta=\frac{1.59 \times 10^{3}}{\phi^{5.5} K^{0.5}}
$$

There was another correlation for Geertsma (1974) when he developed a correlation for the turbulence factor for formation with residual water saturation. This correlation was defined by the following equation: 


$$
\beta=\frac{0.005}{K^{0.5} \phi^{0.5}}\left[\frac{1}{\left(1-s_{w}\right)^{5.5} K_{r e}^{0.5}}\right]
$$

Another correlation was introduced by Pascal et al. (1980). By using model and data from different rate tests in low permeability gas reservoir, he suggested a mathematical model to estimate the turbulence factor and fracture length. According to their analysis, the following correlation was developed:

$$
\beta=\frac{4.8 \times 10^{10}}{K^{1.176}}
$$

Jones (1987) executed a lab experiment on 355 sandstones and 29 limestone cores with various core sorts such as crystalline limestone, fine-grain sandstone, and vuggy limestone. Based on his final analysis, the following correlation for $\beta$ factor was obtained:

$$
\beta=\frac{2.018 \times 10^{9}}{K^{1.55}}
$$

Li et al. (1995) reviewed the non-Darcy effect using a reservoir simulator. They performed a number of experiments by injecting Nitrogen $\left(\mathrm{N}_{2}\right)$ at diverse rates, in many various directions into a wafer shaped Berea sandstone core. Subsequently, the pressure drop from experiments and simulations were compared and finally a correlation for the turbulence factor was obtained:

$$
\beta=\frac{11500}{k \phi}
$$

Coles and Hartman (1998) performed their experiment on sandstone and limestone samples (with no liquid present) and they developed a correlation for turbulence factor as follow: 


$$
\beta=\frac{3.51 \times 10^{10} \phi^{0.449}}{K^{1.88}}
$$

A detailed review of both empirical and theoretical correlations for $\beta$ has been presented by Li and Engler (2001). They have proposed the following correlation for the turbulence factor:

$$
\beta=\frac{1.15 \times 10^{7}}{K \phi}
$$

In recent investigations (Aminian et al, 2007), the values of $\beta$ from a number of these existing correlations were utilized in conjunction with equation (2) to determine the nonDarcy flow coefficient, D for a number of well test.

Table 2.2, presents some of the common correlations based on porosity and permeability. The units in this table are (md) for permeability and $(1 / \mathrm{cm})$ for $\beta$.

Table 2.2: $\beta$ Factor Correlation

\begin{tabular}{|c|c|}
\hline Source & Equation \\
\hline Janicek and Katz & $1.82 \times 10^{8} K^{-5 / 4} \phi^{-3 / 4}$ \\
\hline Pascal et al & $4.8 \times 10^{10} k^{-1.176}$ \\
\hline Coles and Hartman & $3.51 \times 10^{10} \phi^{0.449} k^{1.88}$ \\
\hline Coles and Hartman & $8.17 \times 10^{9} \phi^{0.537} k^{-1.79}$ \\
\hline Svec \& Engler & $1.15 \times 10^{7} \phi^{-1} k^{-1}$ \\
\hline Jones & $2.018 \times 10^{9} k^{-1.55}$ \\
\hline Jones & $1.88 \times 10^{10} \phi^{-0.53} k^{-1.47}$ \\
\hline Geertsma & $1.59 \times 10^{3} \phi^{-5.5} k^{-0.5}$ \\
\hline Tek et al. & $7.64 \times 10^{8} k^{-1.72}$ \\
\hline Ergun \& Orning & $1.429 \times 10^{3} \phi^{-1.5} k^{-0.5}$ \\
\hline Li et al & $2.92 \times 10^{7} \tau \phi^{-1} k^{-1}$ \\
\hline
\end{tabular}




\subsection{Flows around an Artificially Fractured Well}

The existence of an artificial fracture alters the flows near the wellbore significantly. The flows that can be developed around an artificially fractured well were presented by H.Cinco-Ley. Figure 2.1 shows the various flow conditions around the fracture:

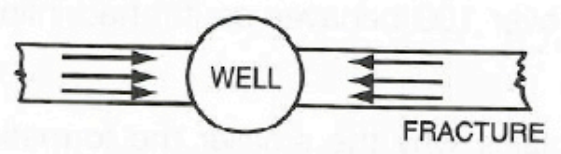

a. Linear flow in the fracture

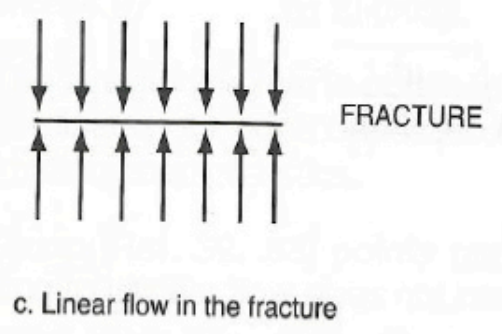

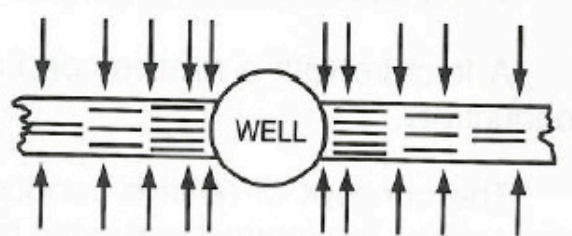

b. Bilinear flow

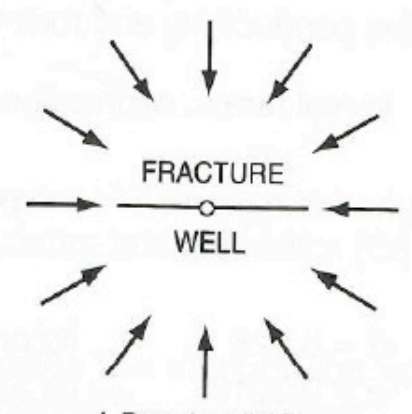

d. Pseudoradial flow

Figure 2.1: Various flow conditions near a hydraulic fracture, (Gilles Bourdarot, 1998)

Linear Flow in the Fracture: theoretically, this type of flow occurs at the beginning of the test and it is a linear flow. In this flow the majority of the fluids formed at the well come from expansion in the artificial fracture. Pressure differs linearly versus $\sqrt{t}$ same as any linear flow.

Bilinear Flow: Cinco was the first to describe this type of flow and since that this flow been observed many times in field cases. It is named bilinear as it corresponds to two concurrent linear flows: (a) a compressible linear flow in the formation and (b) an 
incompressible linear flow in the fracture. Bilinear flow remains only if the ends of the fracture do not disturb the flows. It is described by linear pressure difference versus the fourth root of time.

Linear Flow in the formation: This kind of flow is very often discernible during fractured wells testing. It is an essential element of the conventional analysis techniques of these tests. The ends of the fracture in this type of flow have been reached and the dimension of the fracture has an affect on flows. This flow corresponds to a linear variation of the pressure versus $\sqrt{t}$.

The existence of an artificial fracture alters the flows near the wellbore significantly.

Pseudoradial Flow: The existence of an artificial fracture alters the streamlines near the wellbore significantly. Equipotentials recover a radial equilibrium only at a specific distance from the well. Flow converts to radial when the compressible zone reaches this area. Pressure differs logarithmically versus time. Additionally, the existence of the fracture near the wellbore corresponds to a geometrical skin.

\subsection{Effect of non-Darcy on Fractured Wells}

In hydraulically fractured gas wells, Non-Darcy flow considered to be the most significant factor for pressure drop where high velocity happens in the fracture. Several studies were performed to investigate the effect of the non-Darcy flow on hydraulically fractured wells. The first who observed the effect of non-Darcy flow on vertically fractured well were Millheim and Cichowicz (1968). Holditch and Morse (1976) used 
some numerical methods and discussed the effect of non-Darcy flow in the fracture system and reservoir. Their results showed that the apparent fracture conductivity was reduced by the non-Darcy flow. Cinco-Ley and Sameniego (1978) were the first ones to develop the first solution for the finite conductivity vertical using the methods generated by Gringarten et al (1974). Their solutions were achieved numerically by using a discretized description of the fracture. A semi-analytical model for non-Darcy flow in wells with finite conductivity fracture was developed by Guppy et al. (1982). They discussed the alterations in flux distribution in the fracture system under the effect of non-Darcy flow. They have revealed a reduction in the apparent conductivity of the fracture.

\subsection{Gas Well Test Types and Purposes}

Gas well tests can be divided into two common groups based on their main function. The first group, pressure-transient tests, contains tests designed to measure important fluid and reservoir rock properties (e.g., porosity, permeability, and average reservoir pressure) and to define and locate reservoir heterogeneities (e.g., natural fractures, sealing faults, and layers). The second group, deliverability tests, contains tests designed to assess a well's production potential.

\subsubsection{Pressure-Transient Tests}

Pressure-transient tests describe well tests in which we can measure and generate pressure changes with time. From these measured pressures, we can assess near-wellbore conditions and also the in-situ reservoir properties further than the region affected by 
drilling operations. Furthermore, we can obtain significant formation properties of potential value in enhancing either a depletion plan or an individual completion for a reservoir. Pressure-transient tests can be divided into two wide categories- multi-well and single-well tests.

Single-well tests evaluate pressure drawdown, buildup, and fall-off, as well as injectivity. In these tests, we can use the calculated pressure response to find out the average properties in the drainage area of the tested well. Multiwell tests, which comprise pulse and interference tests, are used to calculate properties in an area centered along a line linking pairs of wells.

Drawdown Test: In a drawdown or flow test, a well that is shut-in, static, and stable is opened to flow at constant and identified rate while measuring bottomhole pressure (BHP) changes as a function of time. Figure 2.2 illustrates a drawdown test.
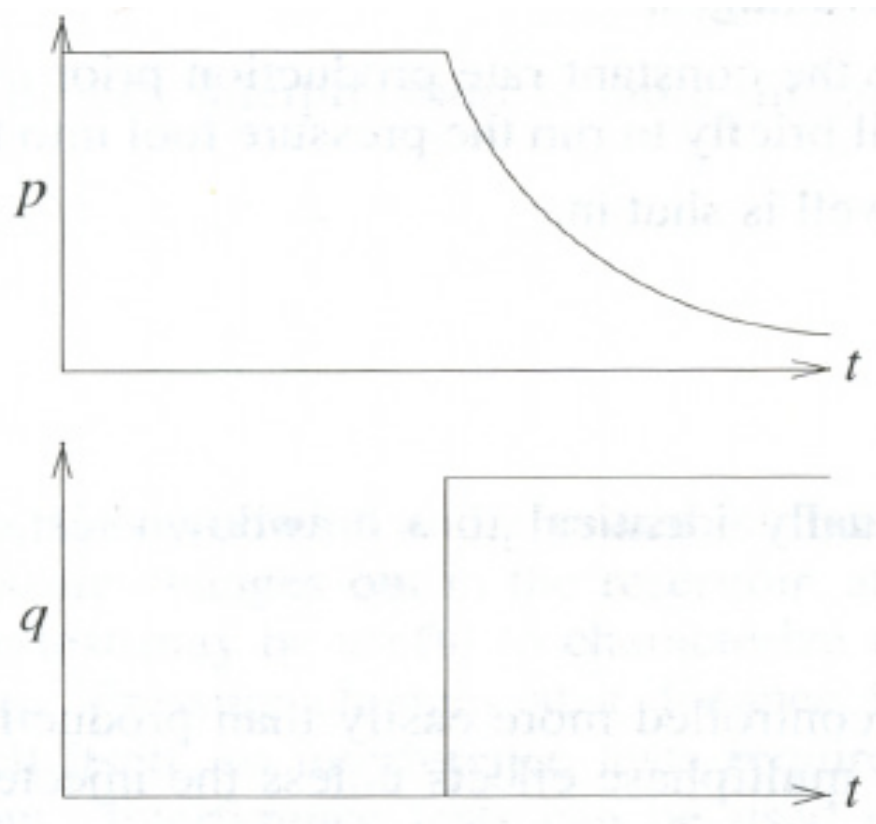

Figure 2.2: Pressure and flow rate of a typical drawdown test 
The drawdown test is used as a basis to derive several of the traditional analysis techniques. However, in actual fact, this test may be rather complicated to attain under the intended conditions. Especially: (a) it is not easy to make the well flow at constant rate, and (b) the well status may not originally be either stable or, static specially if it was newly drilled or had been flowed formerly. On the other hand, the drawdown test is good technique of reservoir limit testing, because the time needed to notice a boundary response is long, hence operating fluctuations in the flow rate become less important over such long times.

Buildup Test: In a buildup test, a well which is already producing at some fixed rate is shut-in, and the downhole pressure builds up as a function of time. Form this type of test; we can calculate average reservoir pressure, permeability, and skin factor in the well drainage area. Figure 2.3 illustrates a buildup test.
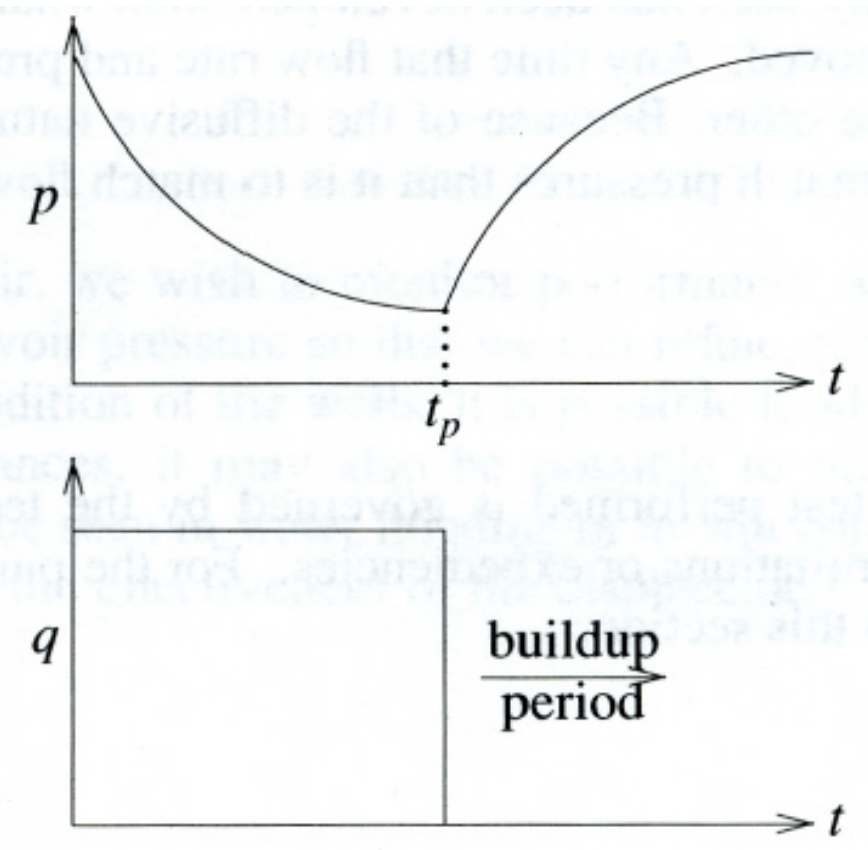

Figure 2.3: Pressure and flow rate of a typical buildup test 
Interpretation of a buildup test often needs only minor adjustment of the techniques used to describe constant rate drawdown test. The functional benefit of a buildup test is that the constant flow rate condition is more easily achieved as the flow rate is zero. Buildup tests also have some disadvantages: (a) it might be complicated to achieve the constant rate production before the shut-in, especially if it is essential to close the well for a short time to run the pressure tool into the hole. (b) Losing of production during the well is shut in time.

Injection Test: an injection test concept is almost identical to a drawdown test, except that flow is inside the well rather than out of it. Injection rates can frequently be controlled more easily than production rates; however interpretation of test results can be difficult by multiphase effects except if the injected fluid is identical to the original reservoir fluid.

Falloff Test: A pressure falloff test concept is almost identical to a pressure-buildup test, except that it is performed on an injection well. A falloff test gauges the pressure decline after the closure of an injection. Falloff test analysis is more complicated if the injected fluid is different from the original reservoir fluids.

Figure 2.4 illustrates a falloff test. 


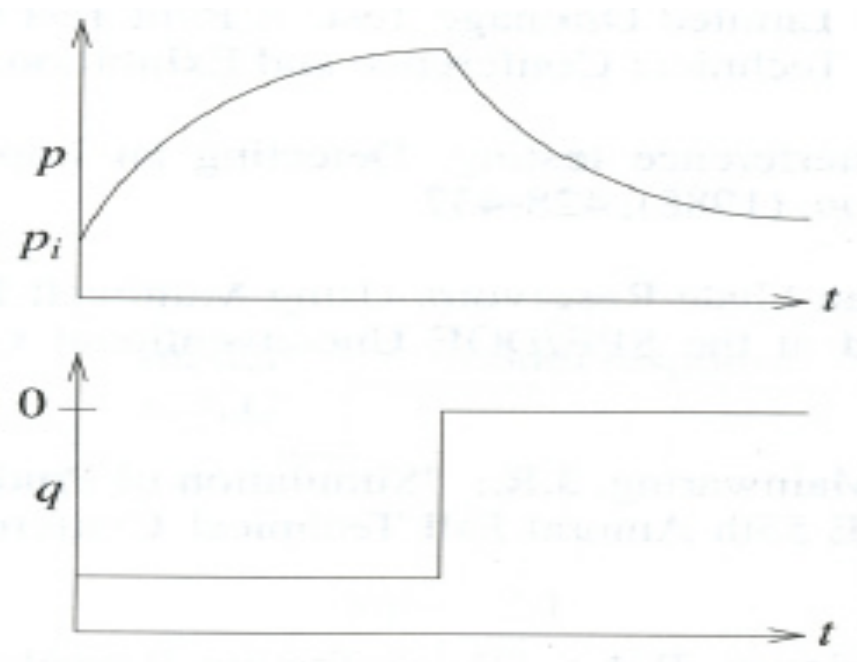

Figure 2.4: Pressure and flow rate of a typical falloff test

\subsubsection{Deliverability Tests}

Gas well deliverability tests are the testing of gas wells used to determine their production capabilities under specific bottomhole flowing pressures and reservoir conditions. They consist of a sequence of at least three or more flows with rates, pressures, and other data measured as a function of time. Gas well deliverability tests are generally performed on new wells and periodically on old wells. The full schedule of tests might take more than a few days. For the relatively short time of tests, the well behavior/reservoir is often transient, means, pressure or flow rate change with time. The characteristics which are desired for long-term forecasts should basically be nontransient (pseudo-steady state or steady state). Consequently, the basics of deliverability testing are to perform short-time tests that can be successfully used to forecast long-term behavior. The absolute open-flow (AOF) potential is the common productivity indicator achieved from deliverability tests. The AOF is the maximum flow rate at 14.7 psia sand face pressure. An additional, and perhaps more important, application of gas well 
deliverability testing is to create a reservoir inflow performance relationship (IPR). The IPR curve defines the relationship between bottomhole flowing pressure and surface production rate for a particular value of reservoir pressure. Several deliverability testing techniques have been developed for gas wells such as flow-after-flow, single-point, isochronal and modified isochronal tests.

Flow-after-flow Test: Flow-after-flow tests, sometimes called four-point or gas backpressure tests, are performed by producing the well at a sequence of different stabilized rates and gauging the stabilized bottomhole pressure $\left(\mathrm{p}_{\mathrm{wf}}\right)$. In many cases, stabilization is described in terms of percentage change per unit of time. Figure 2.5 shows the essential features of the flow-after-flow test.
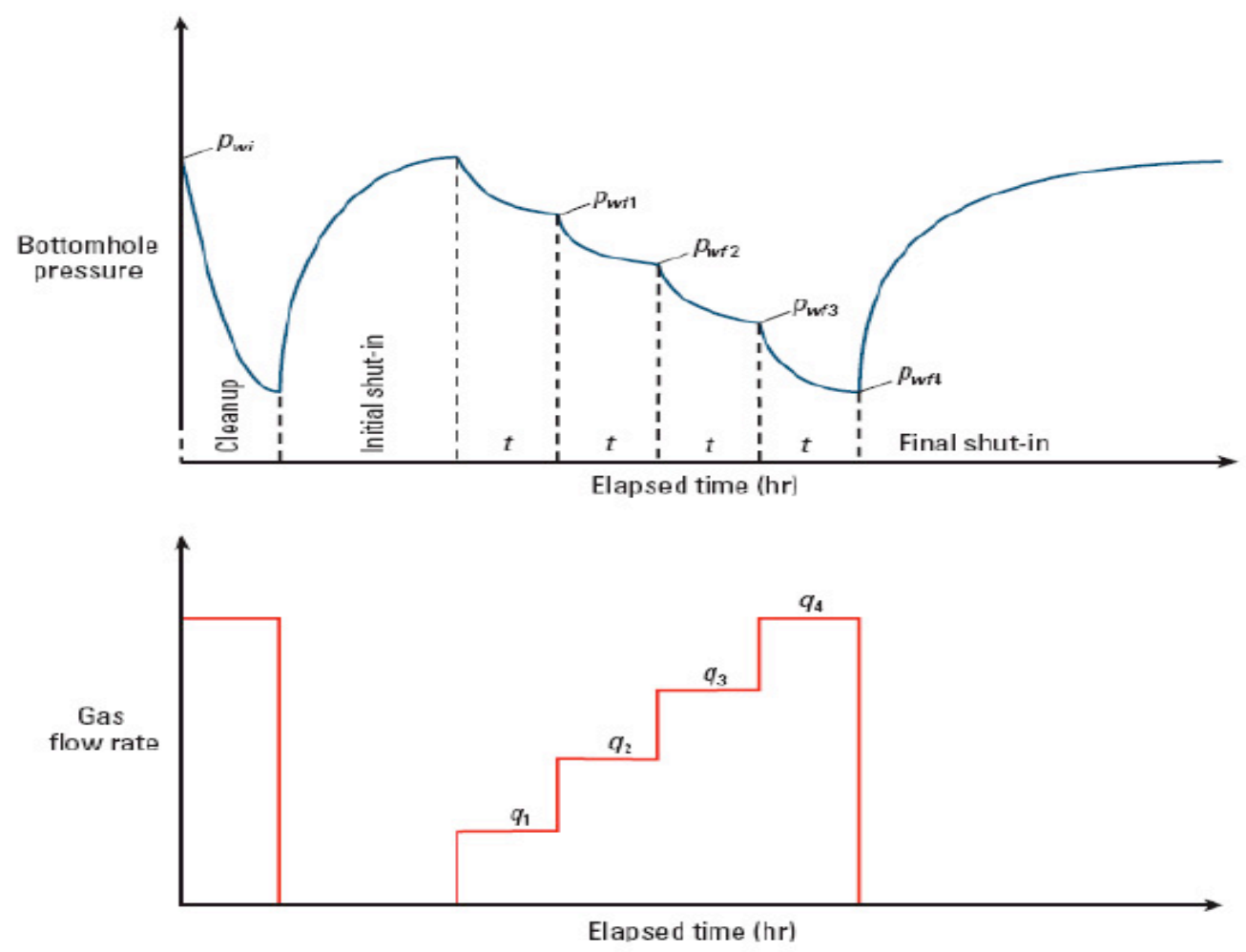

Figure 2.5: Flow-after-flow test, flow rate and pressure diagrams, (Aminian, 2008) 
The flow-after-flow test can be applied in high-permeability formations. Lowpermeability formations need undesirably long times for stabilization.

Single-Point Test: This type of test is performed by producing the well at single rate until bottomhole flowing pressure (BHFP) is stabilized. This test was created to overcome the restriction of long testing times needed to reach stabilization in the flowafter-flow test. If previous tests have provided values for the non-Darcy flow coefficient, $\mathrm{D}$ and $\mathrm{n}$, then a single-point test is enough to update values of $\mathrm{C}$ and $\mathrm{S}$. As part of a pressure survey, this kind of test is often conducted yearly. A single point on the deliverability curve can be obtained during this test.

Isochronal Test: Flow-after-flow gas well testing and the analysis of its data are quite simple. This type of test has been considered the basic standard for several years, however it has certain disadvantages. The complexity happens if the reservoir permeability is low, or flaring system needs to be optimized. In this type of reservoir a properly stabilized, Flow-after-flow deliverability test might not be performed in a logical period of time. In other words, the time needed to get stabilized flow conditions might be very long.

The isochronal gas well test was proposed by Cullender. In this type of test, a well is shut-in long enough before each test-flow time so that each flow will begin with the same pressure distribution in the reservoir. A typical isochronal test is illustrated in Figure 2.6. 


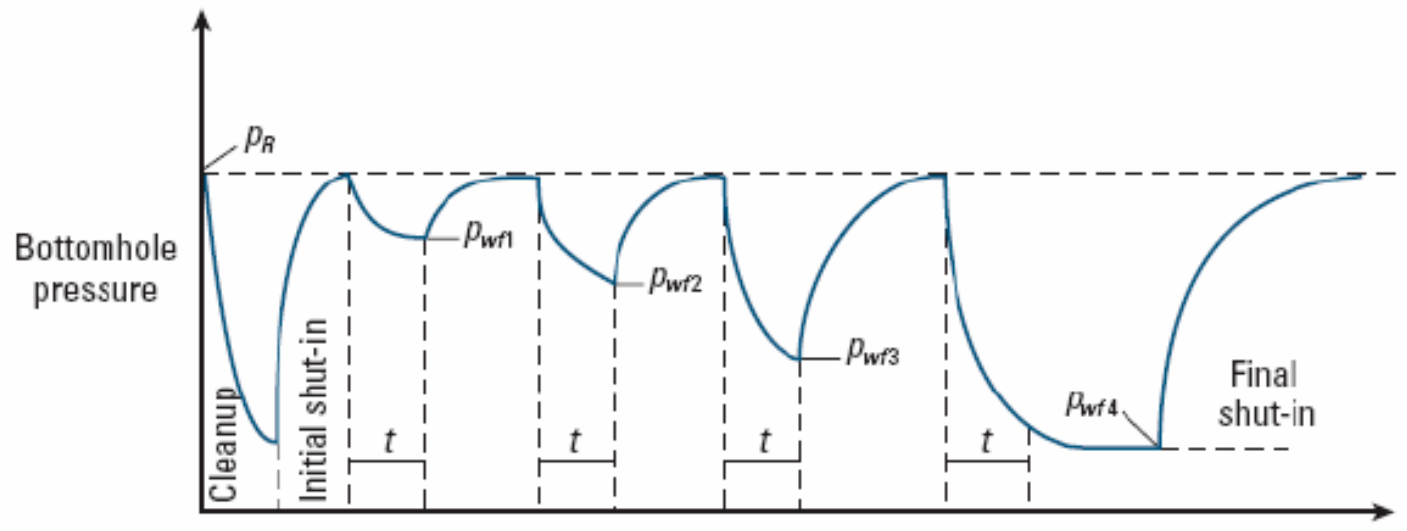

Elapsed time (hr)

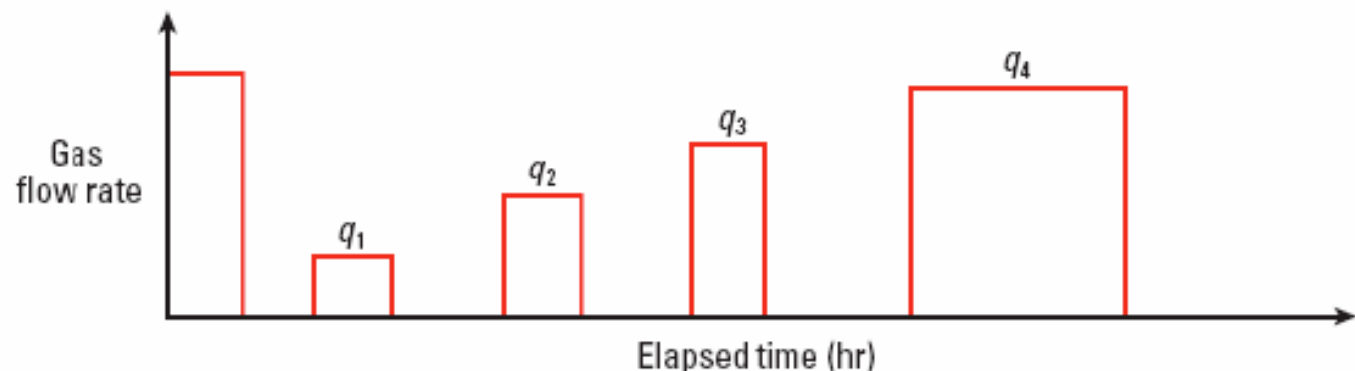

Figure 2.6: Isochronal test, flow rate and pressure diagrams, (Aminian, 2008)

Modified Isochronal Test: By comparing the flow-after-flow with the isochronal tests, a substantial volume of gas will be saved from being flared into the atmosphere by using the isochronal test. In addition, it might save time if the buildup time to static pressure subsequent to each flow period is short. This time saving during the flow periods might be substantial in the testing of wells producing from taut gas reservoirs, an isochronal test might not always be functional, since it is very complicated to achieve a totally stabilized static reservoir pressure prior to the first flow period and during each following shut-in time. 
A modification to the isochronal test was proposed by Katz et al. (1959). They proposed that both the flow period and the shut-in period for every test could be equal period as long as the unstabilized shut-in pressure, $P_{w R}$, at the end of every test can be used instead of the static reservoir pressure, $\overline{P_{R}}$, in determining the variation of pressure squared for the next flow rate. Figure 2.7 illustrates the flow rate and pressure series of typical modified isochronal test.

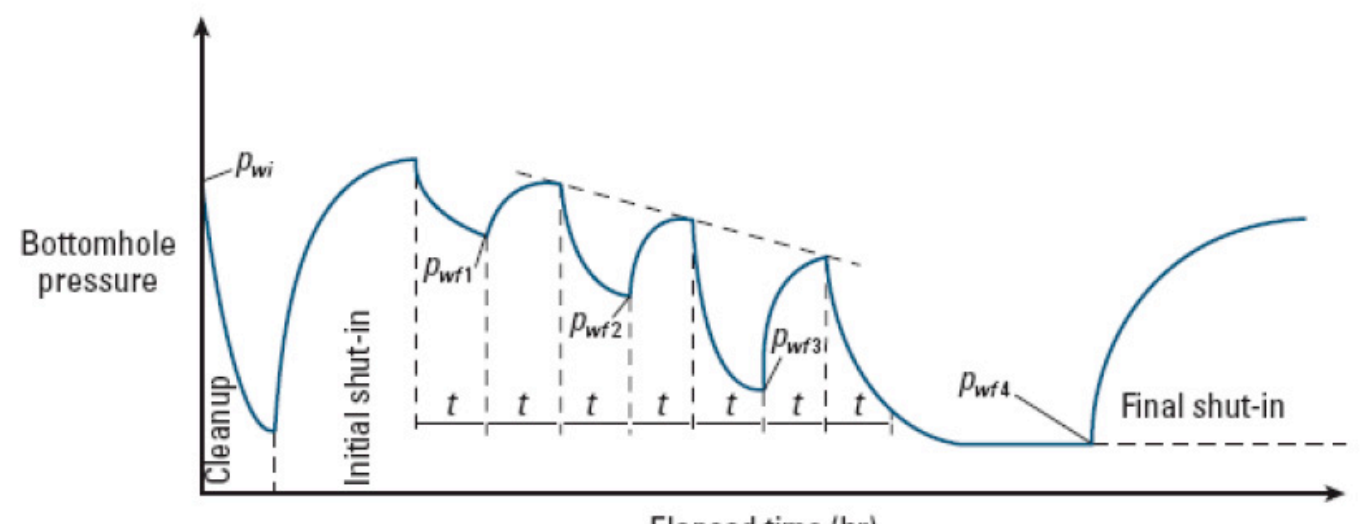

Elapsed time (hr)

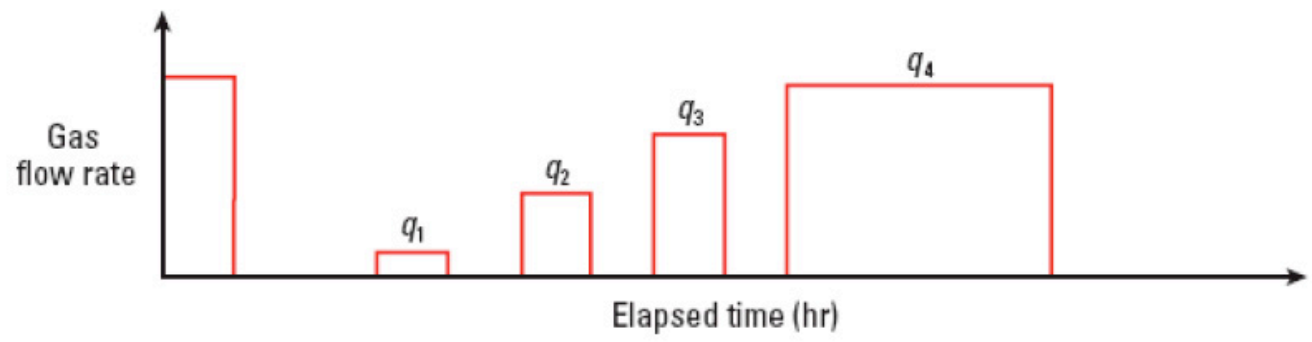

Figure 2.7: Modified Isochronal test, flow rate and pressure diagrams, (Aminian, 2008)

\subsection{Real Gas Pseudopressure and Pseudotime}

Since the viscosity and compressibility of real gases are very strong functions of pressure, it is incorrect to use the slightly compressible assumption when deriving the 
differential equations controlling the pressure transients. However, if the gas behavior can be described by the real gas law:

$$
P V=z n R T
$$

Then the controlling differential equations can be approximated by the description of a variable named the real gas pseudopressure by Al-Hussainy and Ramey (1966). They introduced the real gas pseudopressure as:

$$
m(p)=2 \int_{p_{0}}^{p} \frac{p d p}{\mu z}
$$

Pseudotime was presented by Agarwal (1979) as:

$$
t_{p}=\int_{0}^{t} \frac{1}{\mu c_{t}} d t
$$

\subsection{Pseudo-Steady State Solution}

Early time or transient solution can be described by the following equation:

$$
P_{p}\left(p_{s}\right)-P_{p}\left(p_{w f}\right)=\frac{1.422 \times 10^{6} q T}{K_{g} h} \times\left[1.151 \log \left(\frac{K_{g} t}{1688 \phi \overline{\mu_{g}} \bar{c}_{t} r_{w}^{2}}\right)+s+D q\right]
$$

Where:

$p_{s}$ is the stabilized shut-in bottomhole pressure (BHP) calculated before the deliverability test. In new reservoirs this shut-in pressure equals the initial reservoir pressure $\left(p_{s}=p_{i}\right)$ while in developed reservoirs, the shut-in pressure is less than the initial reservoir pressure $\left(p_{s}<p_{i}\right)$.

Pseudo-steady state solution or the late time of the controlling differential equation is: 


$$
P_{p}(\bar{p})-P_{p}\left(p_{w f}\right)=\frac{1.422 \times 10^{6} q T}{K_{g} h} \times\left[1.151 \log \left(\frac{10.06 A}{C_{A} r_{w}^{2}}\right)-\frac{3}{4}+s+D q\right]
$$

Where:

$\bar{p}$ is referring to the current drainage area pressure. Gas wells cannot arrive at pseudo steady state because of the changes in compressibility and viscosity as the average pressure decreases. It should be noticed that the stabilized shut-in bottomhole pressure $\left(p_{s}\right)$ remains constant while the current drainage area pressure $(\bar{p})$ decreases during a pseudo steady state flow test.

The transient and pseudosteady state equations were respectively expressed by Houpeurt as:

$$
\begin{gathered}
\Delta P_{p}=P_{p}\left(p_{s}\right)-P_{p}\left(p_{w f}\right)=a_{t} q+b q^{2} \\
\Delta P_{p}=P_{p}(\bar{p})-P_{p}\left(p_{w f}\right)=a q+b q^{2}
\end{gathered}
$$

Where:

$$
\begin{gathered}
a_{t}=\frac{1.422 \times 10^{6} T}{K_{g} h} \times\left[1.151 \log \left(\frac{K_{g} t}{1688 \phi \bar{\mu}_{g} \bar{c}_{t} r_{w}{ }^{2}}\right)+s\right] \\
a=\frac{1.422 \times 10^{6} T}{K_{g} h} \times\left[1.151 \log \left(\frac{10.06 A}{C_{A} r_{w}^{2}}\right)-\frac{3}{4}+s\right] \\
b=\frac{1.422 \times 10^{6} T D}{K_{g} h}
\end{gathered}
$$

In the above equations $q$ is in MMSCF/D and the coefficient of $q^{2}$ represents the nonDarcy flow coefficient. Houpeurt equations can be written in pressure-square formulation: 


$$
\begin{aligned}
& \Delta P^{2}=P_{s}^{2}-P_{w f}^{2}=a_{t} q+b q^{2} \\
& \Delta P^{2}=\bar{P}^{2}-P_{w f}{ }^{2}=a q+b q^{2}
\end{aligned}
$$

Where:

$$
\begin{gathered}
a_{t}=\frac{1.422 \times 10^{6} \bar{\mu}_{g} \overline{z T}}{K_{g} h} \times\left[1.151 \log \left(\frac{K_{g} t}{1688 \phi \bar{\mu}_{g} \bar{c}_{t} r_{w}^{2}}\right)+s\right] \\
a=\frac{1.422 \times 10^{6} \bar{\mu}_{g} \overline{z T}}{K_{g} h} \times\left[1.151 \log \left(\frac{10.06 A}{C_{A} r_{w}^{2}}\right)-\frac{3}{4}+s\right] \\
b=\frac{1.422 \times 10^{6} \bar{\mu}_{g} \overline{z T D}}{K_{g} h}
\end{gathered}
$$

\subsection{Recent Investigations}

Recent investigations were conducted by Aminian et al (2007) in order to develop a reliable method for gas well deliverability determination based on a single rate build-up or fall-off test. In these investigations, the values of $\beta$ from a number of the published correlations (Table 2.2) were utilized in conjunction with equation (2) to determine the non-Darcy flow coefficient, D for a number of well tests. The calculated value of D was then used to estimate the true skin factor, s, from the total skin factor, s', obtained from the same well tests using equation (1). The estimated true skin factors were then compared to the true skin factors determined from multi-rate tests on the same wells. The errors in skin factor varied from 5 to over 1000 percent.

It was concluded that the relation between the $\beta$ factor and the permeability, $K$, is restricted to each porous media and a general correlation cannot be developed that can 
provide accurate and consistent results in all cases. Furthermore, it was recommended to obtain and then analyze actual multi-rate test data from a number of wells in a certain reservoir. Accordingly, reservoir-specific $\beta$ correlations could be developed in order to accurately determine the skin factor from a single rate well test. 


\section{CHAPTER 3}

\section{METHODOLOGY}

The main objective of this study was to generate a reliable and simple technique for estimating the true skin factor from the single rate well tests, such as build-up or fall-off tests, on gas wells. More specifically, the objective is to develop a correlation for $\beta$ from field data. From previous investigations, it was concluded that the published correlations of turbulence factor, $\beta$ and permeability, $K$ are derived from limited set of laboratory measurements and they do not provide consistent results and cannot be applied universally to all reservoirs. Accordingly the reservoir-specific correlations will be further developed. To achieve this objective, the following 5 steps were used:

1. Well test data from 4 storage reservoirs in the Appalachian Basin, referred to in this study as reservoirs A, B, C and D, were obtained.

2. Multi-rate well test data were available from a number of wells in each reservoir. These tests were analyzed to obtain permeability, apparent skin factor, the nonDarcy coefficient, and the true skin factor.

3. $\beta$-Factor was determined for each well using equation (2).

4. The calculated $\beta$ and $K$ values were utilized to develop a $\beta$ correlation for each reservoir in the form of the following equation:

$$
\beta=\frac{a}{K^{b}}
$$

Equation (29) can be re-written as follows:

$$
\log \beta=\log a-b \log K
$$


Equation (30) indicates that a plot of $\beta$ against $K$ on a $\log -\log$ paper should follow a linear trend. The two constants ( $a$, and $b$ ) can then be determined from the intercept and slope of this line.

5. To evaluate the accuracy of the correlations, one well in each reservoir was set aside as a test well. The well test data from the test wells were treated as a single rate tests and the value of true skin factor was estimated using the reservoir correlation for $\beta$. This estimated skin factor was then compared to the skin factor determined from the analysis of the multi-rate tests.

\subsection{Well Test Data Collection}

In order to attain the primary objectives of this research, actual well test data were collected. This field well test data had to be prepared for well test analysis. One of the main required specifications is that data must have bottom hole pressures, but if the given data is only well head pressure which occurred in this case, then they have to be converted to Bottom Hole Pressures by using well flow and pressure loss calculation. A program was utilized to achieve this. In addition, the well test data reflected significant fluctuations that needed to be smoothed out before analysis.

In this study, the well test data from four storage reservoirs in the Appalachian Basin, referred to in this research as reservoirs A, B, C and D were available. Table 3.1, presents some of the parameters that were used throughout this study.

Table 3.1: Parameters used for each reservoir

\begin{tabular}{|c|c|c|c|c|}
\hline Parameter & Reservoir (A) & Reservoir (B) & Reservoir (C) & Reservoir (D) \\
\hline Average Formation Porosity, $\phi(\%)$ & 14 & 15 & 8.8 & 10 \\
\hline Gas Specific Gravity, $\gamma_{g}$ & 0.585 & 0.585 & 0.595 & 0.593 \\
\hline Average Pay Zone Thickness, $h(\mathrm{ft})$ & 10 & 45 & 24 & 97 \\
\hline Average Well-bore Radius, $r_{w}(\mathrm{ft})$ & 0.30 & 0.24 & 0.26 & 0.167 \\
\hline
\end{tabular}




\subsection{Analysis of Multi-rate Tests}

Multi-rate tests were available from different wells in four different reservoirs as reflected in the following table:

Table 3.2: Number of Wells Available for Each Reservoir

\begin{tabular}{|c|c|}
\hline Reservoir & Number of Wells Available \\
\hline A & 5 \\
\hline B & 4 \\
\hline C & 6 \\
\hline D & 3 \\
\hline
\end{tabular}

These tests were analyzed to determine permeability $(K)$, the non-Darcy coefficient $(D)$, and the true skin factor $(s)$. A sample evaluation for well D-2 (Reservoir-D) is presented in this section.

1. Adjusted bottom hole pressures $\left(P_{a}\right)$ were plotted in a semi-log paper against time $(t)$ and from the resulted straight line, the slope and intercept were determined for different flow rates.

2. From these slopes and intercepts, permeability and skin factor were obtained using the following equations:

$$
\begin{gathered}
K=\frac{162.6 q_{g} B_{g} \mu_{g}}{(m h)} \\
s^{\prime}=1.151\left[\frac{P_{1 h r}-\overline{P_{a}}}{m}-\log \left(\frac{K}{\phi \overline{\mu c_{t}} r_{w}^{2}}\right)+3.23\right]
\end{gathered}
$$

The above two equations might vary from one well to another depending on the bottom hole pressure values. Table 3.3, summarizes the permeability and apparent skin factor values at each flow rate for well D-2: 
Table 3.3: Permeability and apparent skin factor values for well D-2

\begin{tabular}{|c|c|c|}
\hline Q (MMcf/D) & K (md) & ' \\
\hline 2.10801 & 4.08 & -4.1706908 \\
\hline 3.20385 & 4.96 & -3.913617718 \\
\hline 4.68154 & 5.28 & -3.812443879 \\
\hline
\end{tabular}

3. The apparent skin factor values $\left(s^{\prime}\right)$ were plotted against flow rate values $(Q)$ and it was resulted in straight line. This straight line was used to determine true skin factor $(s)$ and non-Darcy flow coefficient $(D)$ from the intercept and slope respectively. Figure 3.1 illustrates the plot of apparent skin factor values $\left(s^{\prime}\right)$ vs. flow rates $(Q)$ :

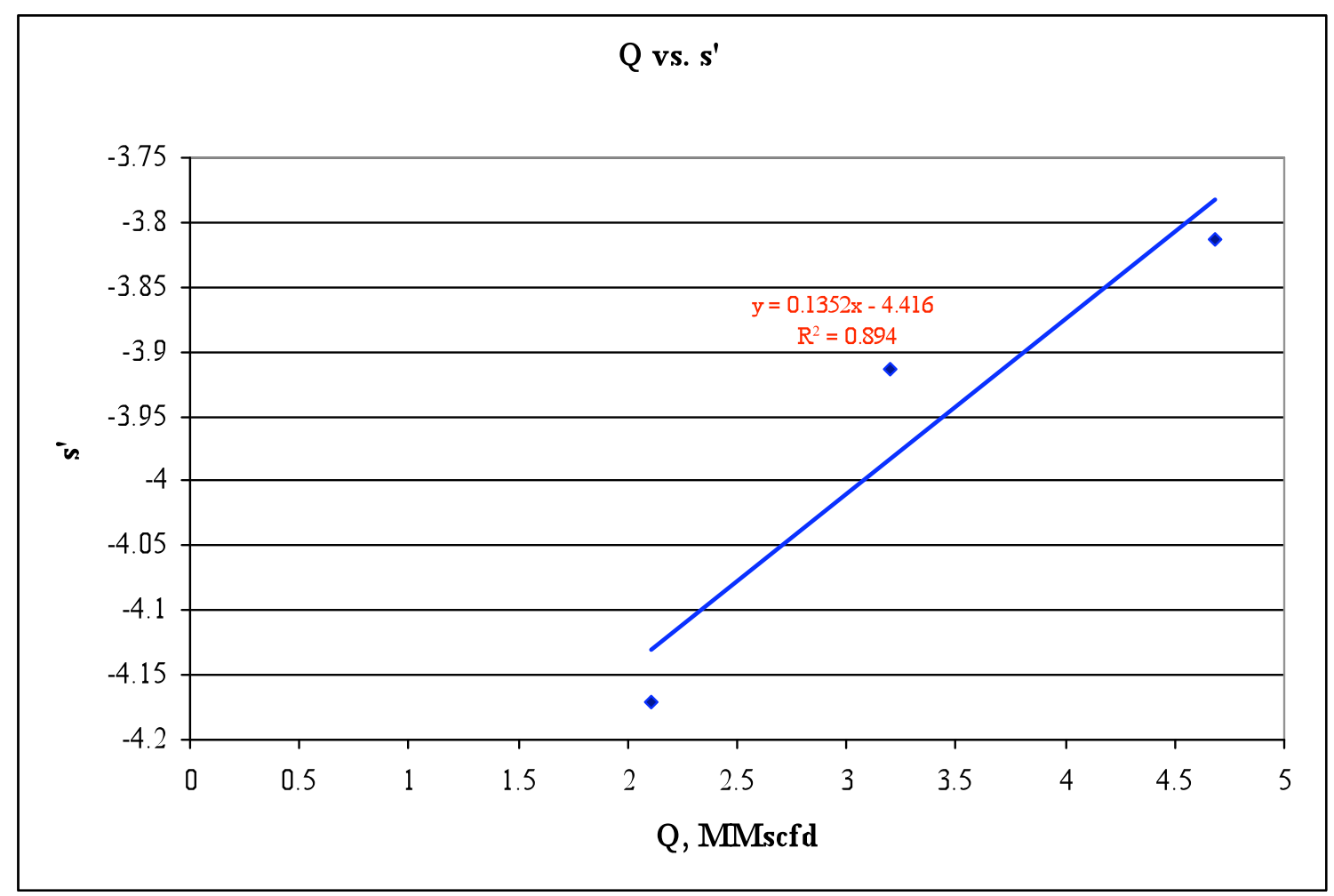

Figure 3.1: Apparent skin factors $\left(s^{\prime}\right)$ vs. Flow rates $(Q)$ for well D-2

From the above plot:

- $\quad$ The true skin factor $(s)=-4.416$

- $\quad$ The non-Darcy coefficient $(D)=0.1352 / 1000=0.0001352$ 


\subsection{Developing Reservoir specific $\beta$ Correlation}

Continuing the same well in the previous section (Well D-2), the turbulence factor $(\beta)$ can be determined by rearranging equation (2) as follow:

$$
\begin{gathered}
\beta=\frac{D \bar{\mu} h_{p} r_{w}}{2.223 \times 10^{-15} \gamma_{g} K} \\
\beta=6.68 \times 10^{9}
\end{gathered}
$$

Following the same procedures for the other two wells in Reservoir $D$, the permeability $(K)$ and $\beta$-factor values were obtained for each well. Table 3.4, presents the permeability and $\beta$-factor values for wells in Reservoir-D except for one well which was set aside as a test well:

Table 3.4: Permeability and $\beta$-factor values for each well in Reservoir-D

\begin{tabular}{|c|c|c|}
\hline Well & K (md) & $\boldsymbol{\beta}$ \\
\hline D-1 & 0.81 & $3.50 \mathrm{E}+10$ \\
\hline D-2 & 4.78 & $6.68 \mathrm{E}+09$ \\
\hline
\end{tabular}

The permeability $(K)$ and the turbulence factor $(\beta)$ values could be utilized to develop a relation between $K$ and $\beta$ for Reservoir D.

The permeability $(K)$ values were plotted in a log-log paper against turbulence factor $(\beta)$ values and then slope and intercept were determined. Figure 3.2 shows the plot of permeability $(K)$ vs. the coefficient of inertial resistance $(\beta)$ values for reservoir-D wells: 


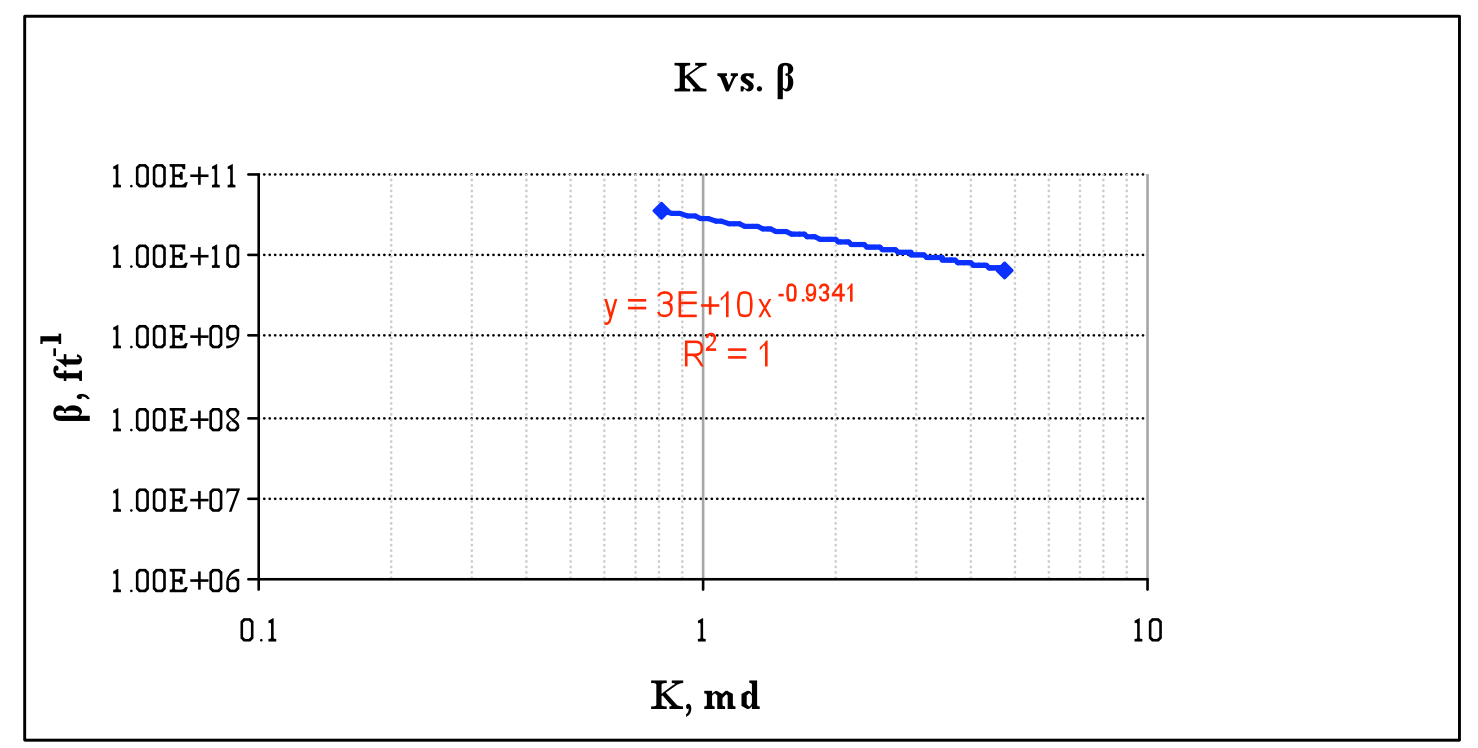

Figure 3.2: $\beta$ Factor vs. Permeability values $(K)$ for Reservoir-D wells

From the above plot:

- $\mathrm{a}=3 \mathrm{E}+10$

- $\quad b=-0.934$

Or

$$
\beta=\frac{3 \times 10^{10}}{K^{0.934}}
$$

\subsection{Verification of Reservoir-D $\beta$ Correlation}

One well in each reservoir was set aside as a test well in order to evaluate the accuracy of the reservoirs-specific $\beta$ correlation. Well D-3 was selected as a test well for reservoirD. This well test data were treated as a single rate test and the value of true skin factor $\left(\mathrm{s}_{\text {test }}\right)$ was estimated from the analysis of the multi-rate tests. This estimated skin factor was then compared to the skin factor determined from reservoir-D $\beta$ correlation ( $\mathrm{s}_{\mathrm{equ}}$.) to evaluate the error. 
A sample evaluation for well D-3 (Reservoir-D) is presented in this section. By using the same procedures in analyzing multi-rate test in section 3.2 for well D-2, the true skin factor ( $\left.\mathrm{s}_{\mathrm{test}}\right)$ of well D-3 was estimated to be:

$$
\mathrm{S}_{\text {test }}=-4.0
$$

In order to determine the true skin factor from reservoir-D $\beta$ correlation ( $\mathrm{s}_{\text {equ. }}$ ), we have to perform the following steps:

- Calculate $\beta$ using the permeability that was obtained from the well test analysis and use equation (34).

- Determine the non-Darcy coefficient $(D)$ by using equation (2).

- Calculate the true skin factor ( $\mathrm{s}_{\text {equ. }}$ ) using equation (1).

Table 3.5, summarizes the skin factor estimated from single rate tests using reservoir-D $\beta$-correlations, the calculated skin factors from multi-rate tests, and percent error in the estimated skin factor for well D-3.

Table 3.5: Estimated skin factor from single rate test (well D-3)

\begin{tabular}{|c|c|c|c|c|c|c|c|}
\hline $\begin{array}{c}\mathbf{Q} \\
\text { (Mcfd) }\end{array}$ & $\begin{array}{c}\mathbf{K} \\
(\mathbf{m d})\end{array}$ & $\mathbf{s}$ & $\boldsymbol{\beta}$ & $\mathbf{D}$ & $\mathrm{s}_{\text {equ }}$ & $\mathrm{s}_{\text {test }}$ & \% error \\
\hline 1900 & 11.34 & -3.7 & $2.98 \mathrm{E}+09$ & 0.000139 & -3.97 & -4.0 & 1 \\
\hline 3100 & 9.29 & -3.7 & $3.58 \mathrm{E}+09$ & 0.000137 & -4.10 & -4.0 & 4 \\
\hline 4450 & 7.47 & -3.4 & $4.39 \mathrm{E}+09$ & 0.000135 & -4.04 & -4.0 & 2 \\
\hline
\end{tabular}

\subsection{Evaluation of the Existing $\beta$ Correlation for reservoir-C wells}

Well C-6 was selected as a test well for reservoir-C. In this section, 3 existing $\beta$ correlations namely Ergun, Janicek \& Katz and Tek et al. were evaluated by determining the true skin factor by using these existing $\beta$ correlations ( $\mathrm{s}_{\text {equ. }}$ ) and then compared it with the value of true skin factor $\left(\mathrm{s}_{\text {test }}\right)$ that was estimated from the analysis of the multi- 
rate tests to evaluate the error. By using the same procedures in analyzing multi-rate test in section 3.2 for well D-2, the true skin factor $\left(\mathrm{s}_{\text {test }}\right)$ of well C-6 was estimated to be:

$$
\mathrm{S}_{\text {test }}=-5.4
$$

Now, in order to determine the true skin factor from these existing $\beta$ correlations ( $\mathrm{s}_{\text {equ. }}$ ), we have to perform the following steps:

- Calculate $\beta$ using the permeability that was obtained from the well test analysis and $\beta$ equations of Ergun, Janicek \& Katz and Tek et al.

- Determine the non-Darcy coefficient $(D)$ by using equation (2).

- Calculate the true skin factor ( $\left.\mathrm{s}_{\text {equ. }}\right)$ using equation (1).

Table 3.6, summarizes the skin factor estimated from single rate tests using Ergun, Janicek \& Katz and Tek et al. $\beta$-correlations, the calculated skin factors from multi-rate tests, and percent error in the estimated skin factor for well C-6.

Table 3.6: Evaluation of the Existing $\beta$ Correlation for wells in reservoir-C

\begin{tabular}{|c|c|c|c|c|c|c|c|c|c|}
\hline \multirow{2}{*}{$\begin{array}{c}\text { Reservoir } \\
\text { C }\end{array}$} & q & \multicolumn{2}{|c|}{ Well Test } & \multicolumn{2}{|c|}{ Ergun } & \multicolumn{2}{c|}{ Janicek \& Katz } & \multicolumn{2}{c|}{ Tek et al. } \\
\cline { 2 - 10 } & Mscfd & s & S $_{\text {test }}$ & S $_{\text {equ }}$ & $\begin{array}{c}\% \\
\text { ERROR }\end{array}$ & Sequ $_{\text {equ }}$ & $\begin{array}{c}\% \\
\text { ERROR }\end{array}$ & S $_{\text {equ }}$ & $\begin{array}{c}\% \\
\text { ERROR }\end{array}$ \\
\hline $\begin{array}{c}\text { Test Well } \\
\text { C-6 }\end{array}$ & 6700 & 1 & -5.4 & 1 & -119.2 & 0.2 & -103.6 & 0.2 & -102.8 \\
\cline { 2 - 10 } & 8150 & 2.4 & -5.4 & 2.4 & -145.1 & 1.4 & -126.3 & 1.4 & -125.3 \\
\hline
\end{tabular}

As mentioned earlier, these existing correlations are derived from limited set of laboratory measurements on various porous media and do not provide consistent results. Table 3.6 confirmed this theory and it can be seen from this table that the skin factors estimated from single rate tests using Ergun, Janicek \& Katz and Tek et al. $\beta$-correlations have a major percentage of error. 


\section{CHAPTER 4}

\section{RESULTS AND DISCUSSION}

The main objective of this study was to generate a reliable and simple method for estimating the true skin factor from the single rate well tests, such as build-up or fall-off tests, on gas wells. More specifically, the objective is to develop a correlation for $\beta$ from field data. Since, the correlation of turbulence factor, $\beta$ and permeability, $\mathrm{k}$ cannot be applied universally to all reservoirs, so the reservoir-specific correlations will be further developed. To achieve this objective, multi-rate well test data were analyzed to obtain permeability ( $K)$, apparent skin factor $\left(s^{\prime}\right)$, the non-Darcy coefficient $(D)$, the true skin factor $\left(s^{\prime}\right)$ and $(\beta)$ for every well in each reservoir. Table 4.1 summarizes multi-rate test analysis for wells in reservoir-C.

Table 4.1: Multi-rate test analysis for wells in reservoir-C

\begin{tabular}{|c|c|c|c|}
\hline Well & K, md & D & $\boldsymbol{\beta}$ \\
\hline C-1 & 130.00 & $5.12 \mathrm{E}-04$ & $2.18 \mathrm{E}+08$ \\
\hline C-2 & 71.00 & $9.68 \mathrm{E}-04$ & $1.15 \mathrm{E}+09$ \\
\hline C-3 & 193.00 & $3.66 \mathrm{E}-04$ & $1.21 \mathrm{E}+08$ \\
\hline C-4 & 203.00 & $7.00 \mathrm{E}-04$ & $1.64 \mathrm{E}+08$ \\
\hline C-5 & 102.00 & $7.64 \mathrm{E}-04$ & $5 . \mathrm{E}+08$ \\
\hline
\end{tabular}

Permeability $(K)$ and the coefficient of inertial resistance $(\beta)$ values were determined for each well of the other four reservoirs. Figure 4.1 shows the plot of permeability $(K)$ values vs. the coefficient of inertial resistance $(\beta)$ values for reservoirs $A, B, C$ and $D$. 


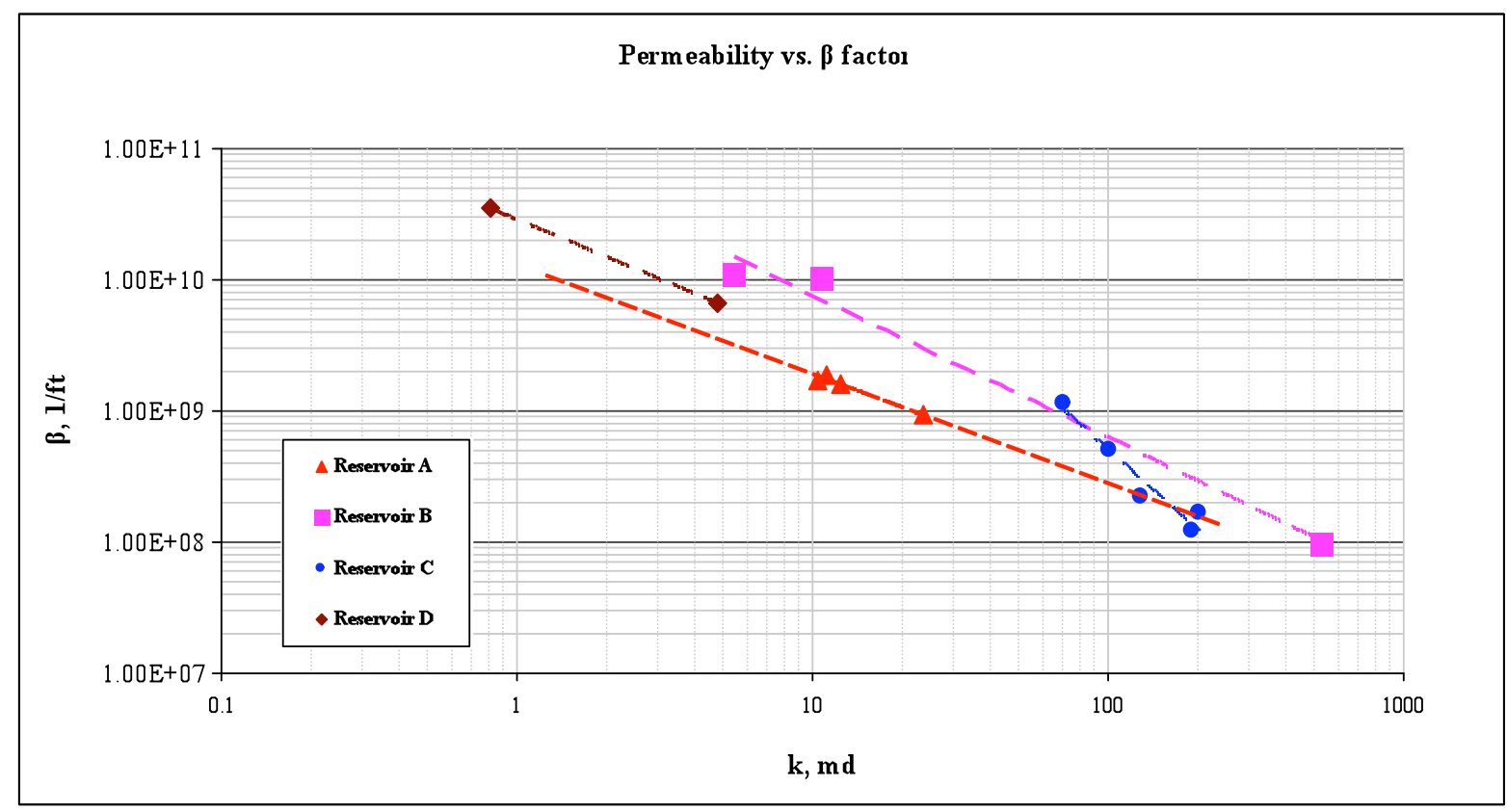

\section{Figure 4.1: $\beta$ Correlations for different reservoirs (A, B, C \& D)}

The straight line trends for each reservoir are shown on Figure 4.1. The trend lines for reservoir A, B, and D appear similar. However, reservoir $\mathrm{C}$ exhibit a different trend compare to the other reservoirs. Reservoir A appears to have the highest $\beta$ values while reservoir $\mathrm{B}$ appears to exhibit the lowest $\beta$ values. Several possible explanations for these differences can be stipulated. One possibility is the impact of stimulation treatments. The permeability near the wellbore in reservoir B could be higher than formation permeability due to more extensive fracturing. Presence of fractures could significantly impact the flow path and tortuosity near the wellbore and thereby reduce the value of $(\beta)$. Second possibility is presence of liquids which can significantly increase the value of $(\beta)$. The well tests in reservoir A were performed at the end of withdrawal cycle in the storage field. Invasion of the wells by water toward the end of withdrawal cycle in the storage field is a common phenomenon. However, the well tests in reservoir B were performed at the beginning of withdrawal cycle. Finally, the difference in the 
characteristics of reservoirs has led to different correlations. It is interesting to note that reservoir $\mathrm{C}$ exhibit a much steeper slope than the other reservoirs. The detail examination of Figure 4.1 reveals that several of data points for reservoir C are on the same trend as reservoir A and others are on the same trend as reservoir B. It is possible that reservoir C contains two different porous media causing a steep slope when treated as a single porous media. It should be also noted that the well tests from reservoir $\mathrm{C}$ were to some degree erratic and the results are not reliable.

Due to similarity of the linear trends, a general correlation based on the data from all the reservoirs was developed as illustrated in Figure 4.2. The constants (a, and b) as well as the correlation coefficient $\left(\mathrm{R}^{2}\right)$ for this line are also provided in Table 4.2. This correlation (all reservoirs) represents an average behavior for all the reservoirs and can be used in the absence of field data to develop a field specific correlation.

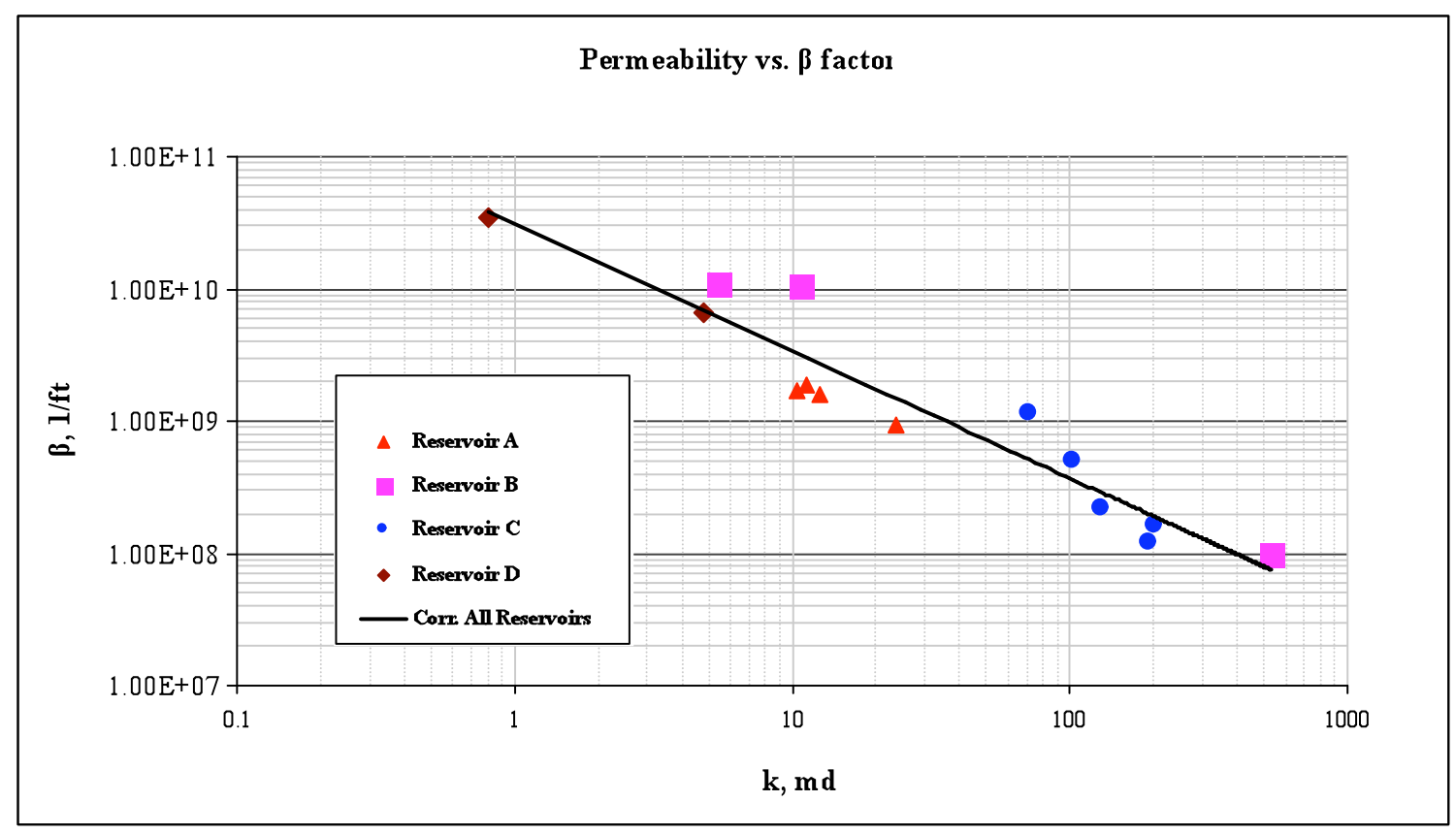

Figure 4.2: $\beta$ General Correlation based on the data from all reservoirs 
Table 4.2 Summarizes the values of constants (a, and b) as well as the correlation coefficient $\left(\mathrm{R}^{2}\right)$ for each line in Figures 4.1 and 4.2.

Table 4.2: $a, b \& R^{2}$ constant values for each line in Figures 4.1 and 4.2

\begin{tabular}{|c|c|c|c|}
\hline Reservoir & $\mathbf{a}$ & $\mathbf{b}$ & $\mathbf{R}^{2}$ \\
\hline A & $1.117 \times 10^{10}$ & 0.79 & 0.91 \\
\hline B & $9.412 \times 10^{10}$ & 1.09 & 0.98 \\
\hline C & $5.320 \times 10^{12}$ & 2.01 & 0.94 \\
\hline D & $2.876 \times 10^{10}$ & 0.93 & 1.00 \\
\hline All & $3.076 \times 10^{10}$ & 0.96 & 0.91 \\
\hline
\end{tabular}

Table 4.3 summarizes the skin factor estimated from single rate tests using reservoir specific $\beta$ correlations and percent error in the estimated skin factor for the 4 test wells.

Table 4.3: Skin Factors Estimated from Reservoir Specific $\beta$ Correlation

\begin{tabular}{|c|c|c|c|c|c|}
\hline \multirow{2}{*}{ Test Well } & \multirow{2}{*}{$\frac{q}{\text { Mscfd }}$} & \multicolumn{2}{|c|}{ Well Test } & \multicolumn{2}{|c|}{$\begin{array}{c}\text { Reservoir Specific } \\
\beta \text { Correlation }\end{array}$} \\
\hline & & $\mathbf{s}^{\prime}$ & $\mathbf{S}$ & $\mathbf{S}$ & $\begin{array}{c}\% \\
\text { ERROR }\end{array}$ \\
\hline \multirow{3}{*}{ Test Well A } & 820 & -2.5 & -3.0 & -3.1 & 3 \\
\hline & 1380 & -1.9 & -3.0 & -2.9 & 3 \\
\hline & 2080 & -1.6 & -3.0 & -3.0 & 1 \\
\hline \multirow{3}{*}{ Test Well B } & 1450 & -2.4 & -3.3 & -3.5 & 9 \\
\hline & 1750 & -2.4 & -3.3 & -3.8 & 15 \\
\hline & 2300 & -1.8 & -3.3 & -3.6 & 12 \\
\hline \multirow{2}{*}{ Test Well C } & 6700 & 1.0 & -5.4 & -5.0 & 8 \\
\hline & 8150 & 2.4 & -5.4 & -4.6 & 14 \\
\hline \multirow{3}{*}{ Test Well D } & 1900 & -3.7 & -4.0 & -4.0 & 1 \\
\hline & 3100 & -3.7 & -4.0 & -4.1 & 4 \\
\hline & 4450 & -3.4 & -4.0 & -4.0 & 2 \\
\hline
\end{tabular}

In addition, the general correlation (all reservoirs) was used for estimation of skin factor for all 4 test wells and the results are provided in Table 4.4. 
Table 4.4: Skin Factors Estimated from General $\beta$ Correlation (All Reservoirs)

\begin{tabular}{|c|c|c|c|c|c|}
\hline \multirow{2}{*}{ Test Well } & \multirow{2}{*}{$\frac{q}{\text { Mscfd }}$} & \multicolumn{2}{|c|}{ Well Test } & \multicolumn{2}{|c|}{$\begin{array}{c}\text { All Reservoirs } \beta \\
\text { Correlation }\end{array}$} \\
\hline & & s' & $\mathbf{S}$ & $\mathbf{S}$ & $\begin{array}{c}\% \\
\text { ERROR }\end{array}$ \\
\hline \multirow{3}{*}{ Test Well A } & 820 & -2.5 & -3.0 & -3.5 & 17 \\
\hline & 1380 & -1.9 & -3.0 & -3.6 & 22 \\
\hline & 2080 & -1.6 & -3.0 & -4.2 & 40 \\
\hline \multirow{3}{*}{ Test Well B } & 1450 & -2.4 & -3.3 & -3.0 & 8 \\
\hline & 1750 & -2.4 & -3.3 & -3.1 & 5 \\
\hline & 2300 & -1.8 & -3.3 & -2.8 & 15 \\
\hline \multirow{2}{*}{ Test Well C } & 6700 & 1.0 & -5.4 & -2.2 & 59 \\
\hline & 8150 & 2.4 & -5.4 & -1.5 & 71 \\
\hline \multirow{3}{*}{ Test Well D } & 1900 & -3.7 & -4.0 & -4.0 & 1 \\
\hline & 3100 & -3.7 & -4.0 & -4.1 & 4 \\
\hline & 4450 & -3.4 & -4.0 & -4.0 & 3 \\
\hline
\end{tabular}

For comparison purposes, the correlations developed for $\beta$ in reservoir $\mathrm{A}$ and $\mathrm{B}$ were also used to estimate skin factors in all the test wells and the results are provided in Table 4.5.

Table 4.5: Skin Factors Estimated from Reservoirs A \& B $\beta$ Correlations

\begin{tabular}{|c|c|c|c|c|c|c|c|}
\hline \multirow{4}{*}{ Test Well } & $\mathbf{q}$ & \multicolumn{2}{|c|}{ Well Test } & \multicolumn{2}{c|}{$\begin{array}{c}\text { Reservoir A } \\
\beta\end{array}$} & \multicolumn{2}{c|}{$\begin{array}{c}\text { Reservoir B } \\
\beta \text { Correlation }\end{array}$} \\
\cline { 2 - 8 } & Mscfd & $\mathbf{s}$ & $\mathbf{s}$ & $\mathbf{s}$ & \% ERROR & $\mathbf{s}$ & $\begin{array}{c}\text { \% } \\
\text { ERROR }\end{array}$ \\
\hline \multirow{3}{*}{ Test Well A } & 820 & -2.5 & -3.0 & -3.1 & 3 & -4.7 & 57 \\
\cline { 2 - 8 } & 1380 & -1.9 & -3.0 & -2.9 & -3 & -5.7 & 91 \\
\cline { 2 - 8 } & 2080 & -1.6 & -3.0 & -3.0 & 1 & -7.3 & 145 \\
\hline \multirow{3}{*}{ Test Well B } & 1450 & -2.4 & -3.3 & -2.8 & 15 & -3.5 & 9 \\
\cline { 2 - 8 } & 1750 & -2.4 & -3.3 & -2.8 & 13 & -3.8 & 15 \\
\cline { 2 - 8 } & 2300 & -1.8 & -3.3 & -2.4 & 25 & -3.6 & 12 \\
\hline \multirow{3}{*}{ Test Well C } & 6700 & 1.0 & -5.4 & -1.4 & 74 & -4.7 & 13 \\
\cline { 2 - 8 } & 8150 & 2.4 & -5.4 & -0.6 & 90 & -4.5 & 16 \\
\hline \multirow{3}{*}{ Test Well D } & 1900 & -3.7 & -4.0 & -3.9 & -2 & -4.3 & 9 \\
\cline { 2 - 8 } & 3100 & -3.7 & -4.0 & -3.9 & -1 & -4.7 & 18 \\
\cline { 2 - 8 } & 4450 & -3.4 & -4.0 & -3.8 & -5 & -4.9 & 24 \\
\hline
\end{tabular}

These two correlations appear to be the upper and lower limits of $\beta$. As it can be seen from Table 4.3, the reservoir specific correlations provide accurate results in all cases. The general correlation (all reservoirs) also provides reasonable results in all test wells 
with exception of test well $\mathrm{C}$. This is probably due to the unusual nature of reservoir $\mathrm{C}$. Data from more reservoirs in the Appalachian Basin is required to confirm if this correlation can provide reasonable results for the Appalachian Basin reservoirs. The reservoir A and B correlations also provided reasonable results in 3 out of 4 test wells. It is interesting to note that the correlation for reservoir B provides good results for test well C. This may be attributed to the similarity between reservoir B and some of the wells in reservoir $\mathrm{C}$ as discussed earlier. 


\section{CHAPTER 5}

\section{CONCLUSIONS AND RECOMMENDATIONS}

In this study, a simple and reliable method for estimating the true skin factor from the single rate well tests was generated. The following conclusions have been obtained based on the work done during this study:

1. Four reservoir-specific $\beta$ correlations were developed based on the actual field well tests data.

2. The reservoir-specific $\beta$-correlations provided accurate estimate of skin factors in test wells.

3. Single-rate test can be analyzed to determine the true skin factor upon availability of reservoir-specific $\beta$-correlation. Accordingly, there would be no need for additional multi-rate tests.

4. It can be concluded that each reservoir has its own specific characteristics.

5. It is possible for one reservoir to contain two different porous media and as a result two $\beta$-correlations are required to analyze well test data.

6. A general correlation has been developed that can be used to estimate skin factor when reservoir-specific $\beta$-correlation cannot be developed.

\section{RECOMMENDATION}

Additional well test data from gas wells in the Appalachian Basin are needed to confirm the applicability of the general correlation developed in this study. 


\section{REFERENCES}

A.W. Brannon, CNG Transmission Crop., K. Aminian, S. Ameri, and H.I. Bilgesu, West Virginia University, “A New Approach for Testing Gas Storage Wells” SPE 39223, presented at the 1997 SPE Eastern Regional Meeting held in Lexington, KY, 22- 24 October 1997.

Alvarez, C., Holditch, S., and McVay, D., "Effects of Non-Darcy Flow on Pressure Transient Analysis of Hydraulically Fractured Gas Wells" SPE 77468-MS, presented at 2000 Annual Technical Conference and Exhibition, San Antonio, Texas, USA, 29 September 29 - October 2, 2000.

Aminian, K., Ameri, S. and Yussefabad, A.G.: "A Simple and reliable Method for Gas Well Deliverability Determination," SPE 111195, presented at SPE Eastern Regional Conference, October 2007.

Barak, A.Z.: "Comments on High-Velocity Flow in Porous Media" by Hassanizadeh and Gary," Transport in Porous Media (1987) 1, 63-97.

Barree, R.D. and Conway, M. W.: "Beyond Beta Factors: A Complete Model for Darcy, Forchheimer, and Trans-Forchheimer Flow in Porous Media” SPE 89325, presented at the SPE annual Technical Conference and Exhibition, Houston, TX, Sept. 26-59, 2004. 
Belhaj, H.A., Agha, K.R, Nouri, A.M., Butt, S.D., Isalm, M.R. and Vaziri, H.F.: “Numerical Modeling of Forchheimer's Equation to Describe Darcy and Non-Darcy Flow in Porous Medium System" SPE 80440 proc., the SPE Asia Pacific Oil and Gas Conference and Exhibition, Jakarta, Indonesia, April 15-17, 2003.

Cornell, D. and Katz, D.L.: "Flow of Gases through Consolidated Porous Media," Industrial and Engineering Chemistry (Oct. 1953) 45, 2145.

Chi U. Ikoku: "Natural Gas Reservoir Engineering ", 1992.

Coles, M.E. and Hartman, K.J.: "Non-Darcy Measurement in Dry Core and the Effect of Immobile Liquid” SPE 39977, presented at the 1998 SPE Gas Technology Symposium, Calgary, Alberta, Canada, March 15-18.

Civan, F., and Evans, R.D.: "Determination of Non-Darcy Flow Parameters Using a Differential Formulation of the Forchheimer Equation," SPE 35621 presented at the 1996 SPE Gas Technology Conference, Calgary, Alberta, Canada, April 28 - May 1.

Chase, R.W., Alkandari, H., "Prediction of Gas Well Deliverability from a Pressure Buildup or Drawdown Test” SPE 26915, presented at 1993 SPE regional conference, PA, WV, USA, 2-4 November 1993. 
Dacun, L., "Analytical Study of the Wafer Non-Darcy Flow Experiments," SPE 76778, presented at 2000 Western Regional/AAPG Pacific Section Joint Meeting, Anchorage, Alaska, May, 20-22, 2000.

Forchheimer, P.: "Wasserbewewegung durch Boden," ZVDI (1901) 45, 1781.

Firoozabadi, A. and Katz, D.L.: “An Analysis of High-Velocity Gas Flow through Porous Media" JPT (Feb. 1979), 211-216.

Gilles Bourdarot: "Well Testing: Interpretation Methods ", October 1999, Edition Technip.

Guppy, K. H., Cinco-Ley, H., Ramey, Jr. H. J., and Sameniego V., F.: "Non-Darcy Flow in Wells with Finite-Conductivity Vertical Fractures" SPEJ (Oct. 1982) 681.

Geertsma, J.: "Estimating the Coefficient of Inertial Resistance in Fluid Flow through Porous Media," SPE 4706, SPE J. (Oct. 1974) 445-450.

Gewers, C.W.W. and Nichol, L.R.: "Gas Turbulence Factor in Microvugular Carbonate," j.Cdan. Pet Tech.(April-June 1969) 31. 
H.A. Belhaj, K.R. Agha, A.M. Nouri, S.D. Butt, H.F. Vaziri, M.R. Islam, Dalhousie University, "Numerical Simulation of Non-Darcy Flow Utilizing the New Forchheimer's Diffusivity Equation” SPE 81499-MS, Middle East Oil Show, 9-12 June 2003, Bahrain.

J.P. S;pivey, SPE, K.G. Brown, SPE, W.K. Sawyer, SPE, and J.H. Frantz, SPE, Schlumberger, "Estimating Non-Darcy coefficient from Buildup Test with Wellbore Storage" SPE 77484, presented at the SPE Annual Technical Conference and Exhibition held in San Antonio, Texas, 29 September - 2 October 2002.

Jones, L.G., Blount, E.M., and Glaze, O.H.: "Use of Short term Multiple Rate Flow Tests to Predict Performance of Well Having Turbulence," SPE 6133, presented at SPE Annual Technical Conference and Exhibition, New Orleans LA, USA, 3-6 October 1975.

Kutasov, I.M.: "Equation Predicts Non-Darcy Flow Coefficient," Oil \& Gas Journal (March 15, 1993) 66-67.

Katz, D. L., Cornell, D., Kobayashi, R., Poettmann, F. H., Vary, J. A., Elenbaas, J. R. and Weinaug, C. F.: Handbook of Natural Gas Engineering, McGraw-Hill Book Co. Inc., New York, 1959. 
Li, D., and Engler, T.W.: "Literature Review on Correlations of Non-Darcy Coefficient," SPE 70015, presented at SPE Permian Basin Oil and Gas Recovery conference, Midland, Texas, USA, 15-16 May 2001.

Liu, X., Civan, F., and Evans, R.D.: "Correlation of the Non-Darcy Flow Coefficient,” J. Cdn. Pet. Tech. (Dec. 1995) 34, No. 10, 50-54.

Lee, W.J.: Well Testing, SPE Textbook Series, Richardson, TX (1982).

Milton-Tayler, D.: "Non-Darcy Gas Flow: From Laboratory Data to Field Prediction" SPE 26146, presented at the Gas Technology Symposium, Calgary, Alberta, Canada, June 28-30, 1993.

Ma, H., and Ruth, D.W.: "Physical Explanations of Non-Darcy Effects for Fluid Flow in Porous Media," SPE 26150 presented at the 1993 SPE Gas Technology, Calgary, Canada, June 28-30.

Narayanaswamy, G., Sharma, M.M., and Pope, G.A.: "Effect of Heterogeneity on the Non-Darcy Flow Coefficient,” SPE Reservoir Eval. \& Eng. (June 1999) 296-302.

Pascal, H., Quillian, R.G. and Kingston, J.: "Analysis of Vertical Fracture Length and Non-Darcy Flow Coefficient Using Variable Rate Test" SPE 9438, presented at the 1980 SPE Annual Technical Conference and Exhibition, Dallas, September 21-24. 
R. Norman and J.S. Archer, Imperial college:" The effect of pore structure on non- Darcy gas flow in some low permeability reservoir rocks" SPE/DOE 16400, presented at the SPE/DOE low permeability reservoirs symposium held in Denver, Colorado May 18-19 1987.

Ramey, H. J. Jr.: "Non-Darcy Flow and Wellbore Storage Effects in Pressure Build-Up and Drawdown of Gas Wells," JPT, October 1985, 1751.

S.C. Jones, Core Research. Div. of Western Atlas, "Using the inertial Coefficient, $\beta$, To Characterize Heterogeneity in Reservoir Rock" SPE 16949, presented at the $62^{\text {nd }}$ Annual

SLB, I. Schlumberger Oilfield Glossary, Available: http://www.slb.com

Thauvin, F., and Mohanty, K.K.: "Network Modeling of Non-Darcy Flow through Porous Media," Transport in Porous Media (1998) 31, 19-37.

Tek, M.R., Coats, K.H., and Katz, D.L.: "The Effect of Turbulence on Flow of Natural Gas through Porous Media," SPE 147, JPT, July 1962.

Umnuayponwiwat, S., Ozkan, E., Pearson, C. and Vincent, M., "Effect of non-Darcy Flow on the Interpretation of Transient Pressure Responses of Hydraulically Fractured Wells," SPE 63176, presented at the 2000 SPE Annual Technical Conference and Exhibition, Dallas, Texas, U.S.A, October 1-4, 2000. 


\section{APPENDIX A \\ Reservoirs A and B Wells Data}

\section{Reservoir A Parameters:}

Table A.1 summarizes reservoir-A parameters and the calculated values of permeability $(K)$ and $(\beta)$ factor for each well.

Table A.1: Reservoir A Parameters Obtained from Multi-rate Tests

\begin{tabular}{|c|c|c|c|c|c|c|c|c|c|}
\hline \multicolumn{10}{|c|}{ Reservoir A Parameters Obtained from Multi-rate Tests } \\
\hline Well & $\mathrm{h}$ & $\mathrm{r}_{\mathrm{w}}$ & $\mu$ & $\gamma$ & $\mathrm{D}$ & $\mathrm{k}$ & $\beta$ & $\varphi$ & $\mathrm{Kh}$ \\
\hline A-1 & 10 & 0.3 & 0.0122 & 0.585 & $7.82 \mathrm{E}-04$ & 23.62 & $9.28 \mathrm{E}+08$ & 0.14 & 236.15 \\
\hline A-2 & 10 & 0.3 & 0.012 & 0.585 & $7.51 \mathrm{E}-04$ & 11.19 & $1.87 \mathrm{E}+09$ & 0.14 & 111.9 \\
\hline A-3 & 10 & 0.3 & 0.0126 & 0.585 & $6.80 \mathrm{E}-04$ & 12.52 & $1.61 \mathrm{E}+09$ & 0.14 & 125.2 \\
\hline A-4 & 10 & 0.3 & 0.0126 & 0.585 & $6.17 \mathrm{E}-04$ & 10.47 & $1.71 \mathrm{E}+09$ & 0.14 & 104.7 \\
\hline A-5 & 10 & 0.3 & 0.012 & 0.585 & $6.80 \mathrm{E}-04$ & 13.00 & $1.45 \mathrm{E}+09$ & 0.14 & 130 \\
\hline
\end{tabular}

Figure A.1 shows the plot of permeability $(K)$ values vs. the coefficient of inertial resistance $(\beta)$ values for reservoirs A.

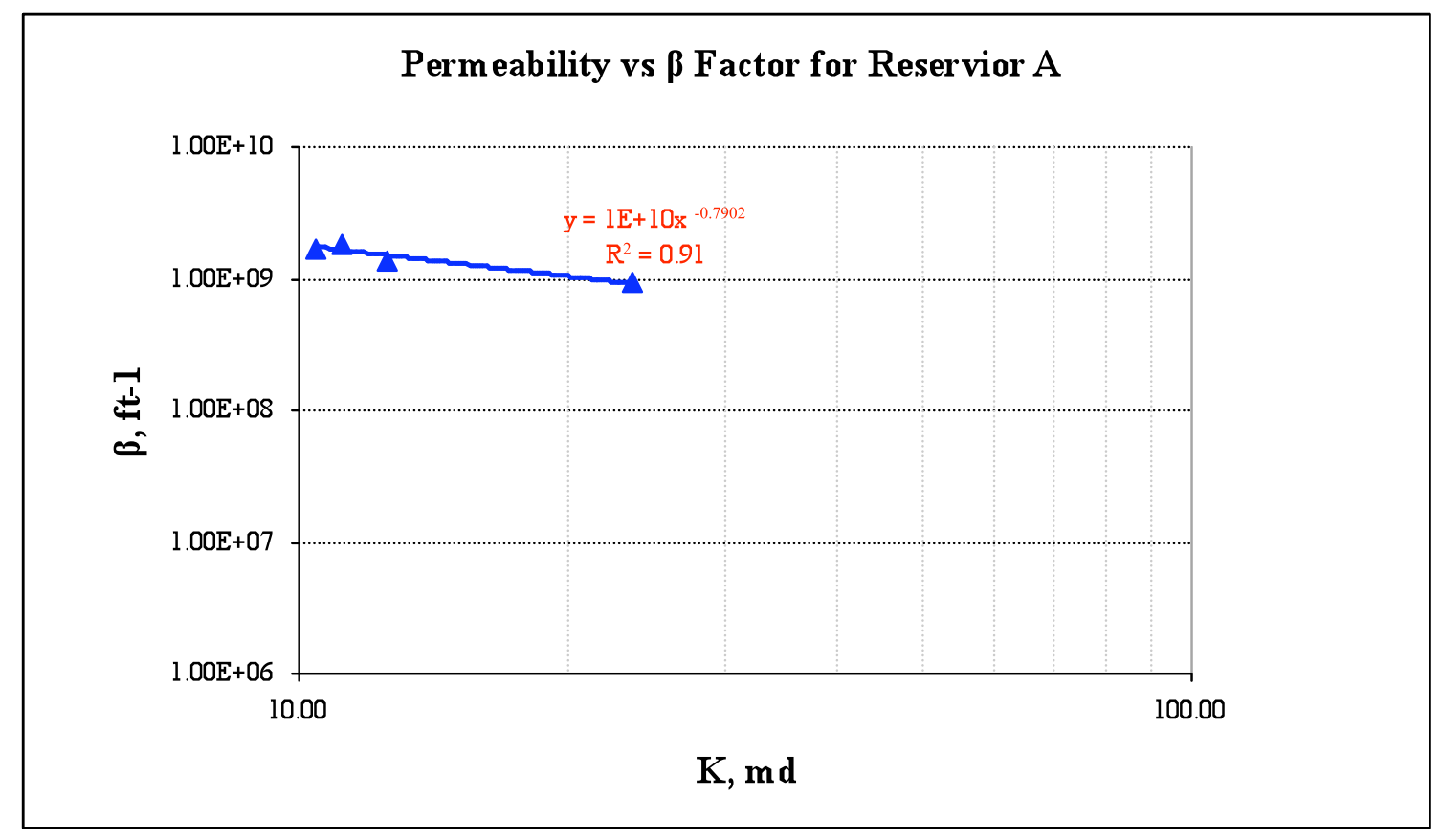

Figure A.1: $(\beta)$ Correlation for reservoir A 


\section{Reservoir B Parameters:}

Table A.2 summarizes reservoir-A parameters and the calculated values of permeability $(K)$ and $(\beta)$ factor for each well.

Table A.2: Reservoir B Parameters Obtained from Multi-rate Tests

\begin{tabular}{|c|c|c|c|c|c|c|c|c|c|}
\hline \multicolumn{10}{|c|}{ Reservoir B Parameters Obtained from Multi-rate Tests } \\
\hline Well & $\mathrm{h}$ & $\mathrm{r}_{\mathrm{w}}$ & $\mu$ & $\gamma$ & $\mathrm{D}$ & $\mathrm{k}$ & $\beta$ & $\varphi$ & $\mathrm{Kh}$ \\
\hline $\mathrm{B}-1$ & 45 & 0.269 & 0.01125 & 0.58 & $1.05 \mathrm{E}-03$ & 10.71 & $1.04 \mathrm{E}+10$ & 0.15 & 482 \\
\hline $\mathrm{B}-2$ & 40 & 0.204 & 0.01121 & 0.58 & $7.20 \mathrm{E}-04$ & 527.43 & $9.68 \mathrm{E}+07$ & 0.15 & 21097.067 \\
\hline B-3 & 50 & 0.269 & 0.01127 & 0.58 & $5.00 \mathrm{E}-04$ & 5.41 & $1.09 \mathrm{E}+10$ & 0.12 & 270.25 \\
\hline B-4 & 50 & 0.204 & 0.01123 & 0.58 & $5.82 \mathrm{E}-04$ & 38.84 & $4.71 \mathrm{E}+08$ & 0.15 & 1553.5 \\
\hline
\end{tabular}

Figure A.2 shows the plot of permeability $(K)$ values vs. the coefficient of inertial resistance $(\beta)$ values for reservoirs A.

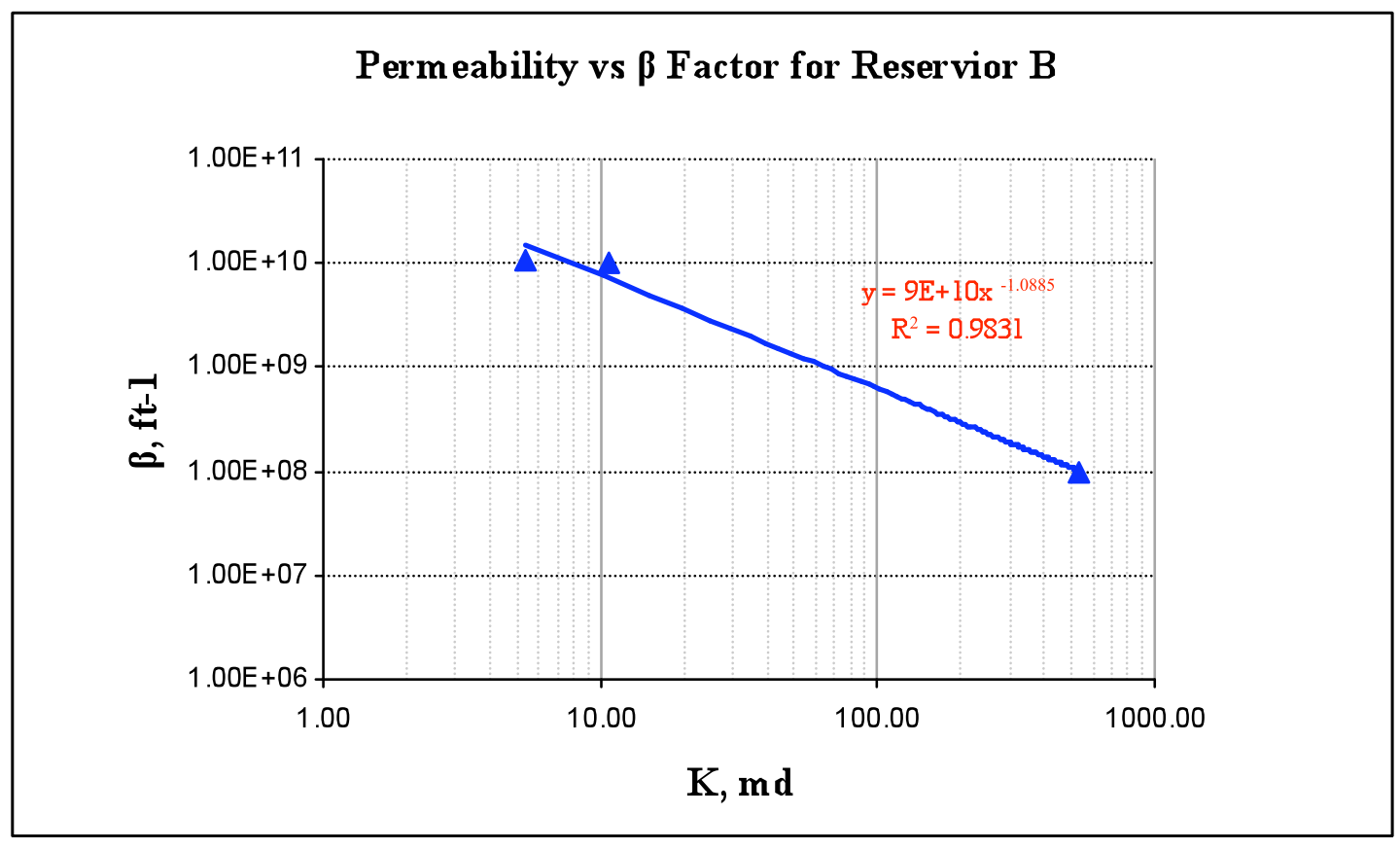

Figure A.2: $(\beta)$ Correlation for reservoir B 


\section{APPENDIX B}

\section{Reservoirs C Wells Data}

\section{Reservoir C Parameters:}

Table B.1 summarizes reservoir-C parameters and the calculated values of permeability $(K)$ and $(\beta)$ factor for each well.

Table B.1: Reservoir C Parameters Obtained from Multi-rate Tests

\begin{tabular}{|c|c|c|c|c|c|c|c|c|c|}
\hline \multicolumn{9}{|c|}{ Reservoir C Parameters Obtained from Multi-rate Tests } \\
\hline Well & $\mathrm{h}$ & rw & $\mu$ & $\gamma$ & $\mathrm{D}$ & $\mathrm{k}$ & $\beta$ & $\varphi$ & $\mathrm{Kh}$ \\
\hline C-1 & 19 & 0.262 & 0.014703359 & 0.595 & $5.12 \mathrm{E}-04$ & 130.00 & $2.18 \mathrm{E}+08$ & 0.0878 & 2470 \\
\hline C-2 & 29 & 0.262 & 0.014693368 & 0.595 & $9.68 \mathrm{E}-04$ & 71.00 & $1.15 \mathrm{E}+09$ & 0.0877 & 2059 \\
\hline C-3 & 22 & 0.262 & 0.014613441 & 0.595 & $3.66 \mathrm{E}-04$ & 193.00 & $1.21 \mathrm{E}+08$ & 0.09 & 4246 \\
\hline C-4 & 26 & 0.167 & 0.014456084 & 0.595 & $7.00 \mathrm{E}-04$ & 203.00 & $1.64 \mathrm{E}+08$ & 0.103 & 5278 \\
\hline C-5 & 23 & 0.262 & 0.014665893 & 0.595 & $7.64 \mathrm{E}-04$ & 102.00 & $5.00 \mathrm{E}+08$ & 0.0888 & 2346 \\
\hline
\end{tabular}

Figure B.1 shows the plot of permeability $(K)$ values vs. the coefficient of inertial resistance $(\beta)$ values for reservoirs $\mathrm{C}$.

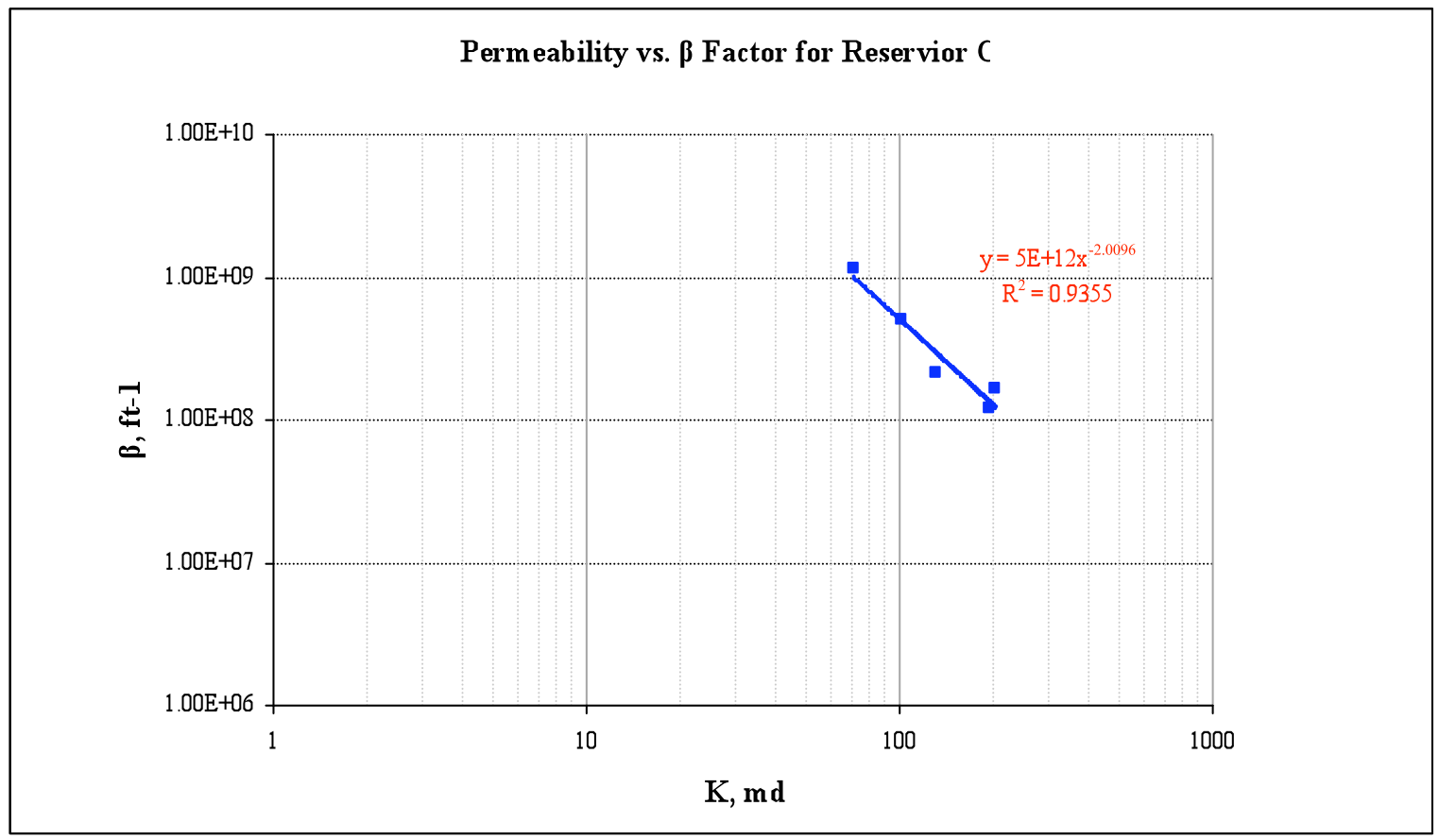

Figure B.1: $(\beta)$ Correlation for reservoir $\mathbf{C}$ 


\section{Reservoir-C Well Tests Data}

Multi-rate test data for wells C-1, C-2, C-3, C-4, C-5 and C-6 were available:

\section{Well C-1:}

Table B.2: Multi-rate test analysis for well C-1 (Rate-1)

\begin{tabular}{|c|c|c|c|c|c|c|c|c|c|c|c|}
\hline \multicolumn{11}{|c|}{ Well C-1 (Rate-1) } & \\
\hline Time (hrs) & Time (hrs) & $\Delta \mathrm{t}$, hrs & Log Time & $\begin{array}{c}\text { BHT } \\
\text { Temp (F) }\end{array}$ & $\begin{array}{c}\text { WH } \\
\text { Pressure } \\
\text { (Psig) }\end{array}$ & $\begin{array}{l}\text { BHP Pressure } \\
\text { (Psig) Using } \\
\text { program }\end{array}$ & $\begin{array}{l}\text { BHP } \\
\text { Pressure } \\
\text { (Psia) }\end{array}$ & $\begin{array}{l}\text { BHP Adjusted } \\
\text { Pressure (Psia) }\end{array}$ & $\Delta \mathrm{P}$ & $\mathrm{Q}$ (MMscfd) & \\
\hline 11:33:04 & 0.083333 & & & 123 & 1450.53 & 1717.22 & 1731.92 & 876.128006 & & 8709.34 & \\
\hline $11: 34: 04$ & 0.100000 & 0.016667 & -1.77815125 & 123 & 1455.21 & 1722.96 & 1737.66 & 881.945028 & 5.817022 & 6508.62 & \\
\hline $11: 35: 04$ & 0.116667 & 0.033333 & -1.477121255 & 123 & 1454.43 & 1722 & 1736.7 & 880.9708059 & 4.8428 & 6075.86 & \\
\hline $11: 36: 04$ & 0.133333 & 0.050000 & -1.301029996 & 123 & 1454.43 & 1722 & 1736.7 & 880.9708059 & 4.8428 & 5811.51 & 1 \\
\hline $11: 37: 04$ & 0.150000 & 0.066667 & -1.176091259 & 123 & 1454.43 & 1722 & 1736.7 & 880.9708059 & 4.8428 & 5829.51 & 2 \\
\hline $11: 38: 04$ & 0.166667 & 0.083333 & -1.079181246 & 123 & 1453.65 & 1721.05 & 1735.75 & 880.007262 & 3.879256 & 5856.4 & 3 \\
\hline 11:39:04 & 0.183333 & 0.100000 & -1 & 123 & 1453.65 & 1721.05 & 1735.75 & 880.007262 & 3.879256 & 5865.34 & 4 \\
\hline 11:40:04 & 0.200000 & 0.116667 & -0.93305321 & 123 & 1452.09 & 1719.13 & 1733.83 & 878.0614986 & 1.933493 & 5865.34 & 5 \\
\hline 11:41:04 & 0.216667 & 0.133333 & -0.875061263 & 123 & 1451.31 & 1718.18 & 1732.88 & 877.0995474 & 0.971541 & 5883.17 & \\
\hline 11:42:04 & 0.233333 & 0.150000 & -0.823908741 & 123 & 1451.31 & 1718.18 & 1732.88 & 877.0995474 & 0.971541 & 5900.95 & 7 \\
\hline 11:43:04 & 0.250000 & 0.166667 & -0.77815125 & 123 & 1451.31 & 1718.18 & 1732.88 & 877.0995474 & 0.971541 & 5918.67 & 8 \\
\hline 11:44:04 & 0.266667 & 0.183333 & -0.736758565 & 123 & 1451.31 & 1718.18 & 1732.88 & 877.0995474 & 0.971541 & 5927.51 & \\
\hline 11:45:04 & 0.283333 & 0.200000 & -0.698970004 & 123 & 1452.09 & 1719.13 & 1733.83 & 878.0614986 & 1.933493 & 5945.16 & 10 \\
\hline 11:46:04 & 0.300000 & 0.216667 & -0.664207898 & 123 & 1452.09 & 1719.13 & 1733.83 & 878.0614986 & 1.933493 & 5936.34 & 11 \\
\hline $11: 47: 04$ & 0.316667 & 0.233333 & -0.632023215 & 123 & 1452.87 & 1720.09 & 1734.79 & 879.0341111 & 2.906105 & 5829.51 & 12 \\
\hline 11:48:04 & 0.333333 & 0.250000 & -0.602059991 & 123 & 1453.65 & 1721.05 & 1735.75 & 880.007262 & 3.879256 & 5847.45 & 13 \\
\hline 11:49:04 & 0.350000 & 0.266667 & -0.574031268 & 123 & 1453.65 & 1721.05 & 1735.75 & 880.007262 & \begin{tabular}{|l|l|}
3.879256 \\
\end{tabular} & 5847.45 & 14 \\
\hline 11:50:04 & 0.366667 & 0.283333 & -0.547702329 & 123 & 1453.65 & 1721.05 & 1735.75 & 880.007262 & \begin{tabular}{|l|}
3.879256 \\
\end{tabular} & 5856.4 & 15 \\
\hline 11:51:04 & 0.383333 & 0.300000 & -0.522878745 & 123 & 1453.65 & 1721.05 & 1735.75 & 880.007262 & \begin{tabular}{|l|}
3.879256 \\
\end{tabular} & 5865.34 & 16 \\
\hline 11:52:04 & 0.400000 & 0.316667 & -0.499397649 & 123 & 1454.43 & 1722 & 1736.7 & 880.9708059 & 4.8428 & 5865.34 & 17 \\
\hline 11:53:04 & 0.416667 & 0.333333 & -0.477121255 & 123 & 1455.21 & 1722.96 & 1737.66 & 881.945028 & \begin{tabular}{|l|}
5.817022 \\
\end{tabular} & 5883.17 & 18 \\
\hline 11:54:04 & 0.433333 & 0.350000 & -0.455931956 & 123 & 1454.43 & 1722 & 1736.7 & 880.9708059 & 4.8428 & 5874.26 & 19 \\
\hline 11:55:04 & 0.450000 & 0.366667 & -0.43572857 & 123 & 1453.65 & 1721.05 & 1735.75 & 880.007262 & 3.879256 & 5883.17 & 20 \\
\hline 11:56:04 & 0.466667 & 0.383333 & -0.416423414 & 123 & 1453.65 & 1721.05 & 1735.75 & 880.007262 & \begin{tabular}{|l|}
3.879256 \\
\end{tabular} & 5883.17 & 21 \\
\hline 11:57:04 & 0.483333 & 0.400000 & -0.397940009 & 123 & 1453.65 & 1721.05 & 1735.75 & 880.007262 & \begin{tabular}{|l|}
3.879256 \\
\end{tabular} & 5883.17 & 22 \\
\hline $11: 58: 04$ & 0.500000 & 0.416667 & -0.380211242 & 123 & 1455.21 & 1722.96 & 1737.66 & 881.945028 & \begin{tabular}{|l|}
5.817022 \\
\end{tabular} & 5874.26 & 23 \\
\hline 11:59:04 & 0.516667 & 0.433333 & -0.363177902 & 123 & 1454.43 & 1722 & 1736.7 & 880.9708059 & 4.8428 & 5883.17 & 24 \\
\hline 12:00:04 & 0.533333 & 0.450000 & -0.346787486 & 123 & 1453.65 & 1721.05 & 1735.75 & 880.007262 & \begin{tabular}{|l|}
3.879256 \\
\end{tabular} & 5892.07 & 25 \\
\hline 12:01:04 & 0.550000 & 0.466667 & -0.330993219 & 123 & 1452.87 & 1720.09 & 1734.79 & 879.0341111 & 2.906105 & 5909.82 & 26 \\
\hline & verage Reser & ir Pressure $\mathbb{C}$ & & 123 & 1434.14 & 1697.12 & 1711.82 & 855.91 & & $\begin{array}{l}5877.601923 \\
5.877601923\end{array}$ & $\begin{array}{l}\text { Avg q (Mscfd) } \\
\text { Avg q (MMscfd) }\end{array}$ \\
\hline
\end{tabular}

Since the calculated BHP is between $1500 \& 3000$ psi, the adjusted pressure Method has

been used.

$$
\mathrm{P}_{\mathrm{a}}=\mathrm{P}^{2} /\left(2^{*} \mathrm{P}^{-}\right)
$$

- By plotting the adjusted pressure against time in a semi-log paper as follow: 


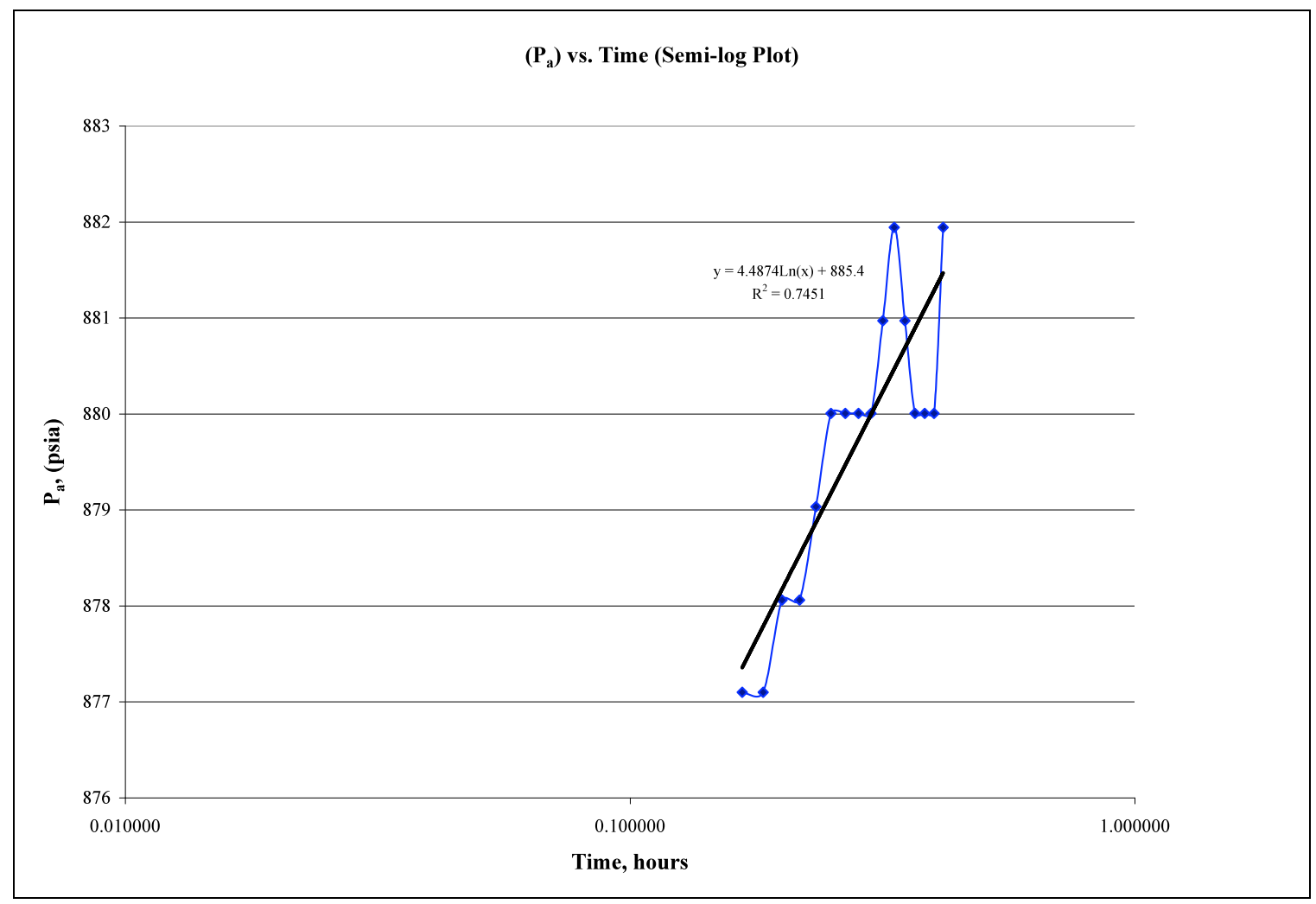

Figure B.2: Semi-log plot for well C-1 (Rate-1)

- Now, permeability (K) and apparent skin factor (s') can be calculated as follow:

From Regression

$$
\begin{aligned}
& m= \\
& \left(P_{a}\right)_{1 h r}= \\
& 13.596822 \\
& 885.4 \quad \text { psia } \\
& K=\frac{162.6 q_{g} B{ }_{g} \mu_{g}}{(m h)} \\
& K=\quad 80.10 \quad \text { md } \\
& s^{\prime}=1.151\left[\frac{P_{1 h r}-\overline{P_{a}}}{m}-\log \left(\frac{k}{\phi \overline{\mu c_{t} r_{w}^{2}}}\right)+3.23\right] \\
& s^{\prime}=\quad-4.322601309
\end{aligned}
$$

- By following the same procedures with the other two rates, the values of the permeability (K) and apparent skin factor (s') were obtained. Table B.3 summarizes the results of the multi-rate test analysis for well $\mathrm{C}-1$ at each flow rate. 
Table B.3: $\mathrm{K}$ and $\mathrm{S}$ ' values for well $\mathrm{C}-1$ at different rates

\begin{tabular}{|c|c|c|}
\hline \multicolumn{3}{|c|}{ Multi-Rate test Analysis for well C-1 } \\
\hline $\mathrm{q}(\mathrm{MMcf} / \mathrm{D})$ & $\mathrm{K} \mathrm{md}$ & $\mathrm{S}^{\prime}$ \\
\hline 5.877601923 & $\mathbf{8 0 . 1 0}$ & -4.322601309 \\
\hline 10.41539538 & 144.86 & -2.047374814 \\
\hline 14.07750358 & 164.88 & -0.125359816 \\
\hline & 389.84 & \\
Average $\mathrm{K}=$ & 129.9452568
\end{tabular}

- By plotting the flow rate (Q) against the apparent skin factor (s') values, we had the following result:

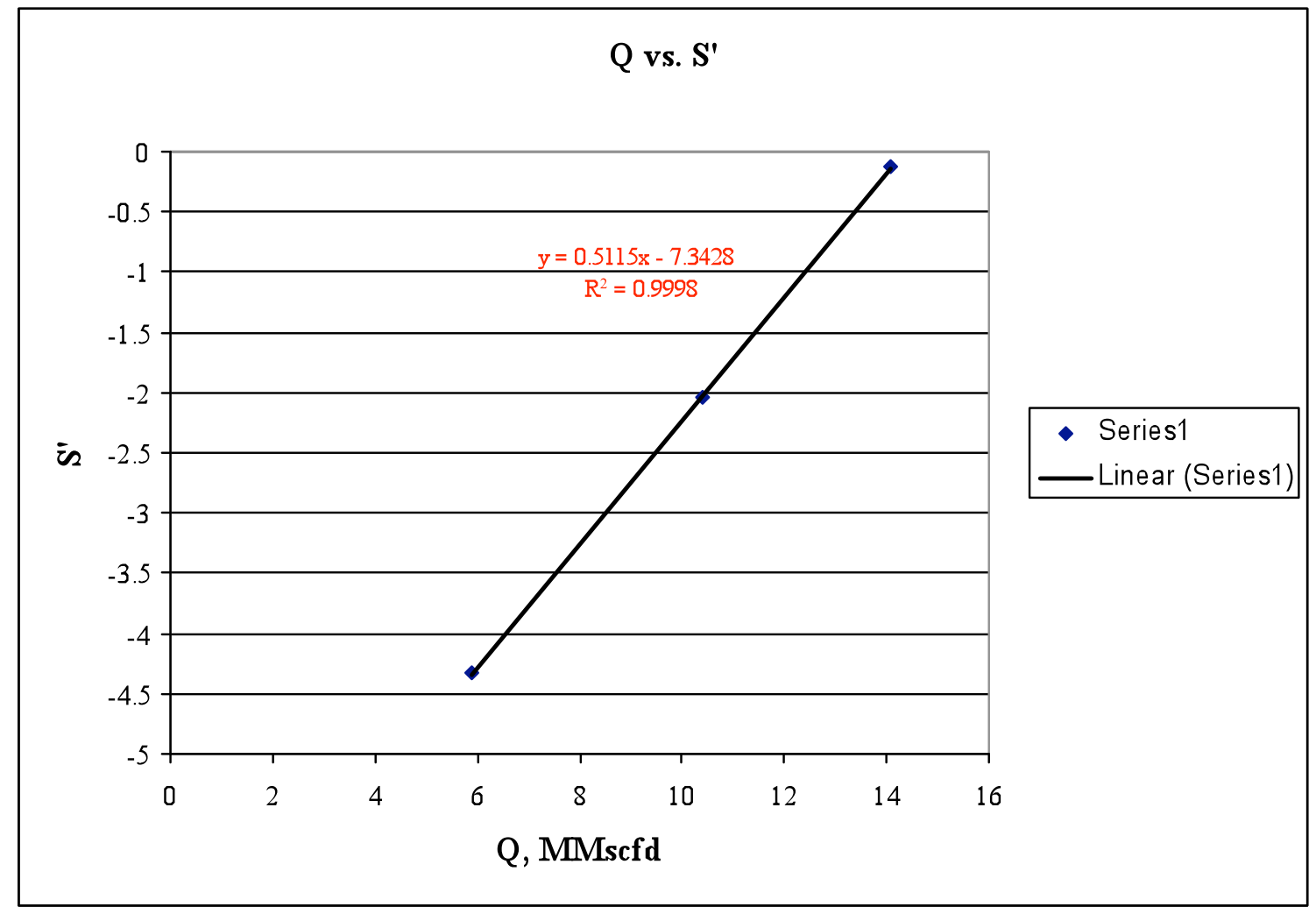

Figure B.3: Flow rates against skin factor (s') for well C-1

From Trendline equ.

Slope $=$ Non-Darcy flow coefficient $D$
$D=$
0.5115
0.0005115
$\beta=$
$\left(D^{*} \mu^{*} \mathrm{~h} * \mathrm{rw}\right) /(2.223 \times 10-15 \mathrm{~g} \mathrm{~K})$
$\beta=$
$2.18 \mathrm{E}+08$ 


\section{Well C-2:}

Table B.4: Multi-rate test analysis for well C-2 (Rate-1)

\begin{tabular}{|c|c|c|c|c|c|c|c|c|c|c|c|}
\hline \multicolumn{11}{|c|}{ Well C-2 (Rate-1) } & \\
\hline Time (hrs) & Time (hrs) & $\Delta \mathrm{t}, \mathrm{hrs}$ & Log Time & $\begin{array}{c}\text { BHT } \\
\text { Temp (F) }\end{array}$ & $\begin{array}{c}\text { WH Pressure } \\
\text { (Psig) }\end{array}$ & $\begin{array}{c}\text { BHP Pressure } \\
\text { (Psig) Using } \\
\text { program }\end{array}$ & $\begin{array}{c}\text { BHP Pressure } \\
\text { (Psia) }\end{array}$ & $\begin{array}{l}\text { BHP Adjusted } \\
\text { Pressure (Psia) }\end{array}$ & $\Delta \mathrm{P}$ & $Q$ (MMscfd) & \\
\hline $11: 12: 22$ & 0.083333 & & & 123 & 1475.5 & 1749.25 & 1763.95 & 913.7177499 & & 2830.46 & \\
\hline $11: 13: 22$ & 0.100000 & 0.016667 & -1.7781513 & 123 & 1477.06 & 1751.16 & 1765.86 & 915.6975631 & 1.9798132 & 2776.25 & \\
\hline $11: 14: 22$ & 0.116667 & 0.033333 & -1.4771213 & 123 & 1477.84 & 1752.12 & 1766.82 & 916.6934616 & 2.9757116 & 2613.3 & \\
\hline $11: 15: 22$ & 0.133333 & 0.050000 & -1.30103 & 123 & 1477.06 & 1751.16 & 1765.86 & 915.6975631 & 1.9798132 & 2567.66 & 4 \\
\hline $11: 16: 22$ & 0.150000 & 0.066667 & -1.1760913 & 123 & 1476.28 & 1750.2 & 1764.9 & 914.7022059 & 0.984456 & 2507.75 & \\
\hline $11: 17: 22$ & 0.166667 & 0.083333 & -1.0791812 & 123 & 1475.5 & 1749.25 & 1763.95 & 913.7177499 & 0 & 2473.85 & \\
\hline 11:18:22 & 0.183333 & 0.100000 & -1 & 123 & 1477.06 & 1751.16 & 1765.86 & 915.6975631 & 1.9798132 & 2677.15 & 7 \\
\hline $11: 19: 22$ & 0.200000 & 0.116667 & -0.9330532 & 123 & 1476.28 & 1750.2 & 1764.9 & 914.7022059 & 0.984456 & 2580.78 & $l_{8}$ \\
\hline $11: 20: 22$ & 0.216667 & 0.133333 & -0.8750613 & 123 & 1475.5 & 1749.25 & 1763.95 & 913.7177499 & 0 & 2514.48 & 9 \\
\hline $11: 21: 22$ & 0.233333 & 0.150000 & -0.8239087 & 123 & 1475.5 & 1749.25 & 1763.95 & 913.7177499 & 0 & 2480.66 & 10 \\
\hline $11: 22: 22$ & 0.250000 & 0.166667 & -0.7781513 & 123 & 1473.94 & 1747.33 & 1762.03 & 911.7297306 & -1.988019 & 2362.07 & 11 \\
\hline $11: 23: 22$ & 0.266667 & 0.183333 & -0.7367586 & 123 & 1473.94 & 1747.33 & 1762.03 & 911.7297306 & \begin{tabular}{|l}
-1.988019 \\
\end{tabular} & 2547.85 & 12 \\
\hline $11: 24: 22$ & 0.283333 & 0.200000 & -0.69897 & 123 & 1474.72 & 1748.29 & 1762.99 & 912.7234696 & -0.99428 & 2567.66 & 13 \\
\hline $11: 25: 22$ & 0.300000 & 0.216667 & -0.6642079 & 123 & 1474.72 & 1748.29 & 1762.99 & 912.7234696 & -0.99428 & 2480.66 & 14 \\
\hline $11: 26: 22$ & 0.316667 & 0.233333 & -0.6320232 & 123 & 1473.94 & 1747.33 & 1762.03 & 911.7297306 & -1.988019 & 2658.15 & 15 \\
\hline $11: 27: 22$ & 0.333333 & 0.250000 & -0.60206 & 123 & 1473.94 & 1747.33 & 1762.03 & 911.7297306 & -1.988019 & 2521.19 & 16 \\
\hline 11:28:22 & 0.350000 & 0.266667 & -0.5740313 & 123 & 1473.16 & 1746.38 & 1761.08 & 910.7468759 & -2.970874 & 2613.3 & 17 \\
\hline $11: 29: 22$ & 0.366667 & 0.283333 & -0.5477023 & 123 & 1472.38 & 1745.42 & 1760.12 & 909.7542138 & -3.963536 & 2439.47 & 18 \\
\hline 11:30:22 & 0.383333 & 0.300000 & -0.5228787 & 123 & 1473.94 & 1747.33 & 1762.03 & 911.7297306 & -1.988019 & 2600.34 & 19 \\
\hline $11: 31: 22$ & 0.400000 & 0.316667 & -0.4993976 & 123 & 1474.72 & 1748.29 & 1762.99 & 912.7234696 & -0.99428 & 2574.23 & 20 \\
\hline $11: 32: 22$ & 0.416667 & 0.333333 & -0.4771213 & 123 & 1474.72 & 1748.29 & 1762.99 & 912.7234696 & -0.99428 & 2534.55 & 21 \\
\hline 11:33:22 & 0.433333 & 0.350000 & -0.455932 & 123 & 1475.5 & 1749.25 & 1763.95 & 913.7177499 & 0 & 2574.23 & 22 \\
\hline $11: 34: 22$ & 0.450000 & 0.366667 & -0.4357286 & 123 & 1476.28 & 1750.2 & 1764.9 & 914.7022059 & 0.984456 & 2658.15 & 23 \\
\hline $11: 35: 22$ & 0.466667 & 0.383333 & -0.4164234 & 123 & 1476.28 & 1750.2 & 1764.9 & 914.7022059 & 0.984456 & 2613.3 & 24 \\
\hline $11: 36: 22$ & 0.483333 & 0.400000 & $\begin{array}{r}-0.39794 \\
\end{array}$ & 123 & 1477.06 & 1751.16 & 1765.86 & 915.6975631 & 1.9798132 & 2501.01 & 25 \\
\hline \multicolumn{4}{|c|}{ Average Resevoir Pressure @ $\mathrm{t}=0$} & 123 & 1425.56 & 1687.97 & 1702.67 & 851.335 & & 2570.74 & scfd) \\
\hline
\end{tabular}

Since the calculated BHP is between $1500 \& 3000$ psi, the adjusted pressure Method has

been used.

$$
\mathrm{P}_{\mathrm{a}}=\mathrm{P}^{2} /\left(2 * \mathrm{P}^{-}\right)
$$

- By plotting the adjusted pressure against time in a semi-log paper as follow: 


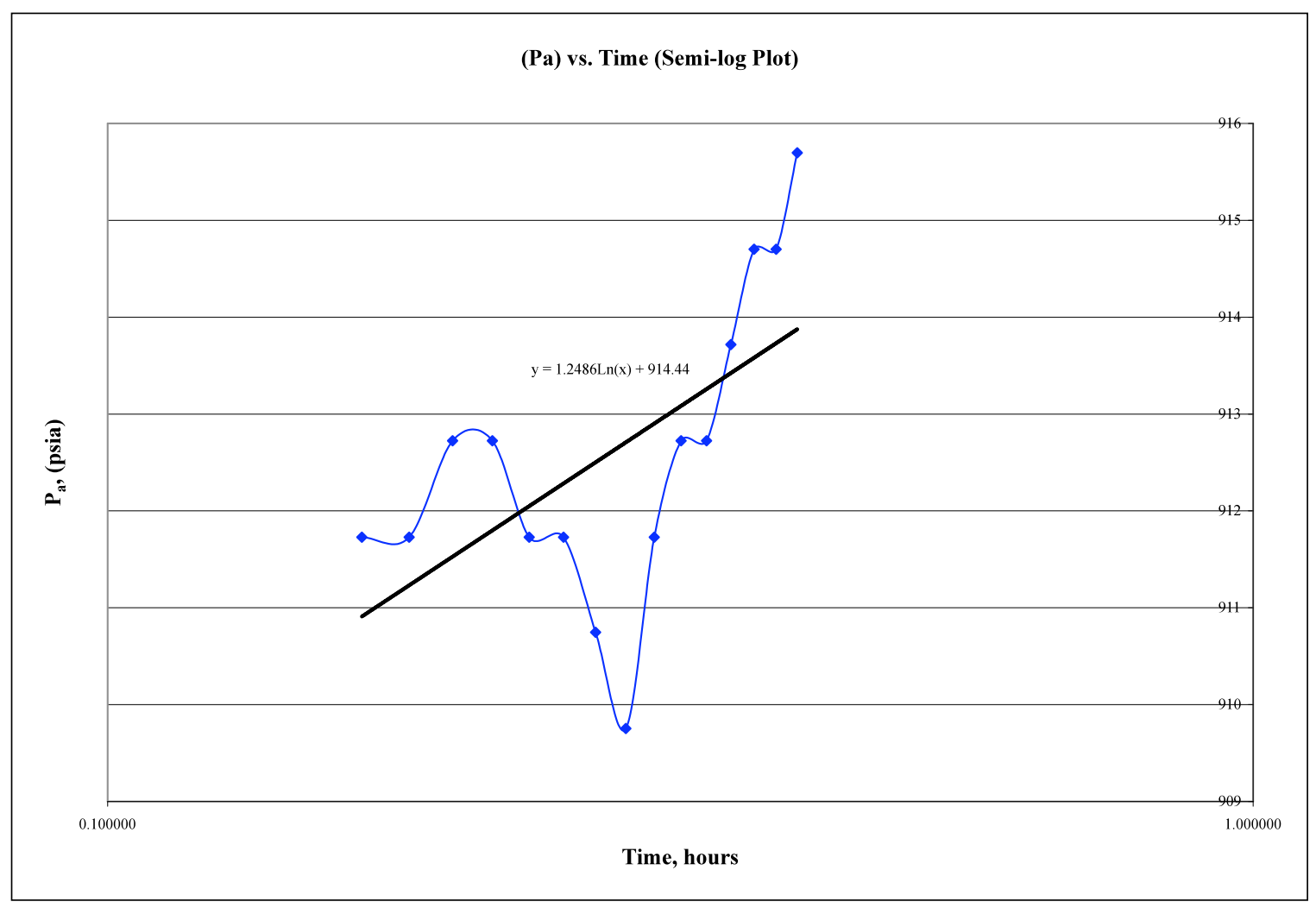

Figure B.4: Semi-log plot for well C-2 (Rate-1)

- Now, permeability (K) and apparent skin factor ( $\left.\mathrm{s}^{\prime}\right)$ can be calculated as follow:

From Regression

$$
\begin{aligned}
& m=\quad 3.783258 \\
& \left(P_{a}\right)_{1 h r},=\quad 914.44 \quad \text { psia } \\
& K=\frac{162.6 q_{g} B_{g} \mu_{g}}{(m h)} \\
& K=\quad 82.84 \quad m d \\
& s^{\prime}=1.151\left[\frac{P_{1 h r}-\overline{P_{a}}}{m}-\log \left(\frac{k}{\phi \overline{\mu c_{t} r_{w}^{2}}}\right)+3.23\right] \\
& s^{\prime}=\quad 12.36457223
\end{aligned}
$$

- By following the same procedures with the other two rates, the values of the permeability (K) and apparent skin factor (s') were obtained. Table B.5 
summarizes the results of the multi-rate test analysis for well $\mathrm{C}-2$ at each flow rate.

Table B.5: $\mathrm{K}$ and $\mathrm{S}^{\prime}$ values for well $\mathrm{C}-2$ at different rates

\begin{tabular}{|c|c|c|}
\hline \multicolumn{3}{|c|}{ Multi-Rate test Analysis for well C-2 } \\
\hline $\mathrm{q}(\mathrm{MMcf} / \mathrm{D})$ & $\mathrm{K} \mathrm{md}$ & $\mathrm{S}^{\prime}$ \\
\hline 3.910362963 & 76.48 & 18.53061177 \\
\hline 4.930597089 & 65.25 & 19.51818925 \\
\hline & 141.73 \\
Average $\mathrm{K}=$ & 70.86662584
\end{tabular}

- By plotting the flow rate (Q) against the apparent skin factor (s') values, we had the following result:

Q vs. $S^{\prime}$

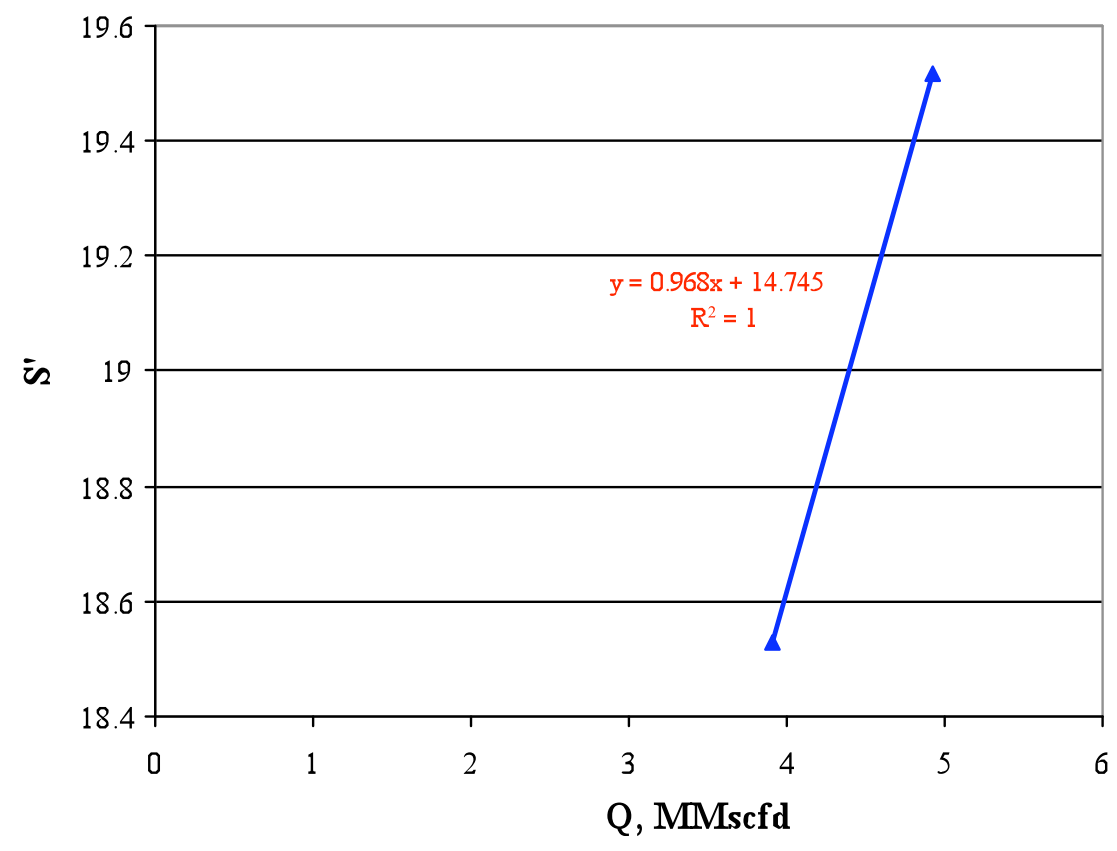

Figure B.5: Flow rates against skin factor (s') for well C-2 
From Trendline equ.

Slope $=$ Non-Darcy flow coefficient $D$
$D=$
0.968
0.000968
$\beta=$
$\left(D^{*} \mu * \mathrm{~h} * \mathrm{rw}\right) /(2.223 \times 10-15 \mathrm{~g} \mathrm{~K})$
$\beta=$
$1.15 \mathrm{E}+09$

Well C-3:

Table B.6: Multi-rate test analysis for well C-3 (Rate-1)

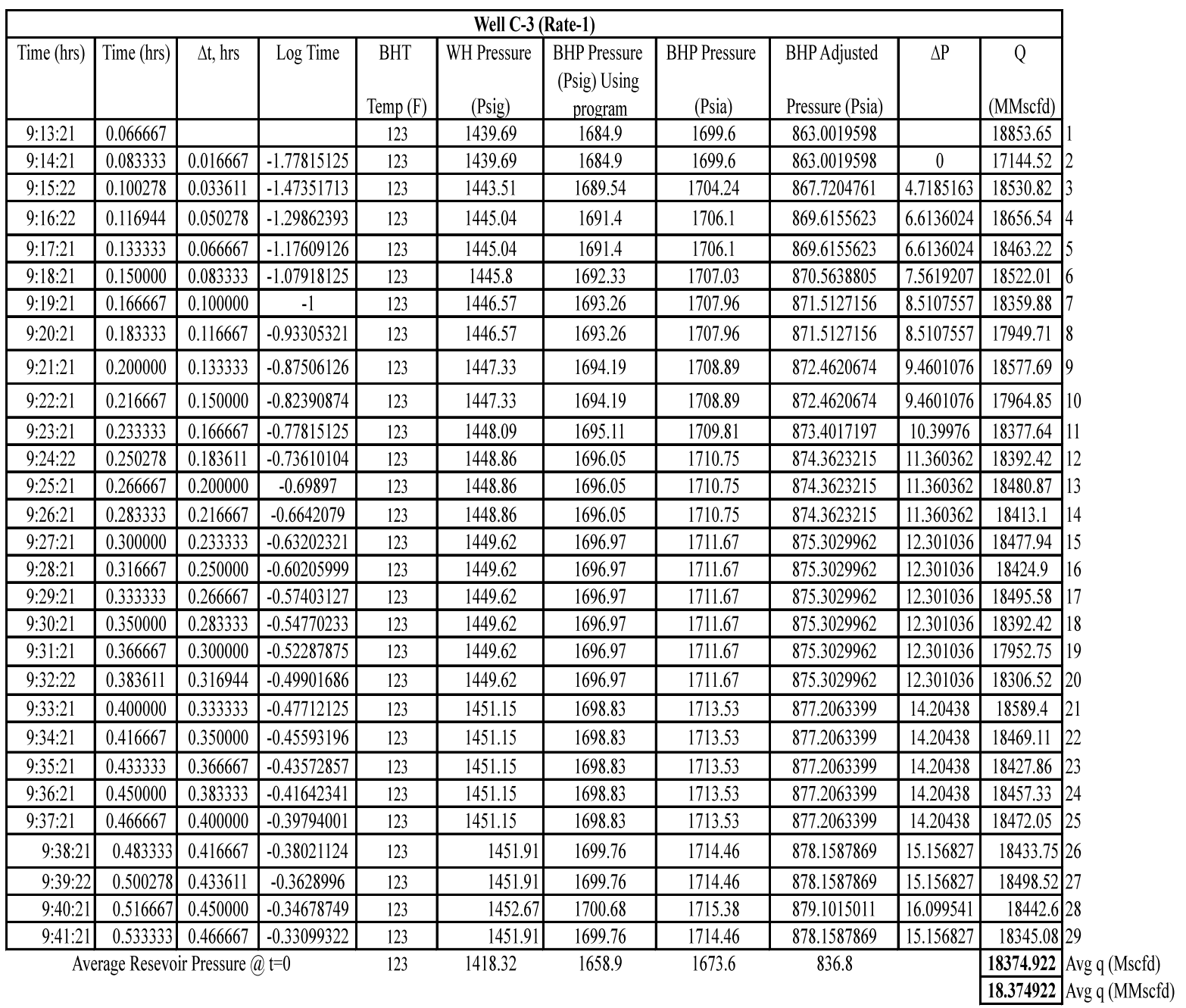

Since the calculated BHP is between $1500 \& 3000$ psi, the adjusted pressure Method has

been used.

$$
\mathrm{P}_{\mathrm{a}}=\mathrm{P}^{2} /\left(2 * \mathrm{P}^{-}\right)
$$


- By plotting the adjusted pressure against time in a semi-log paper as follow:

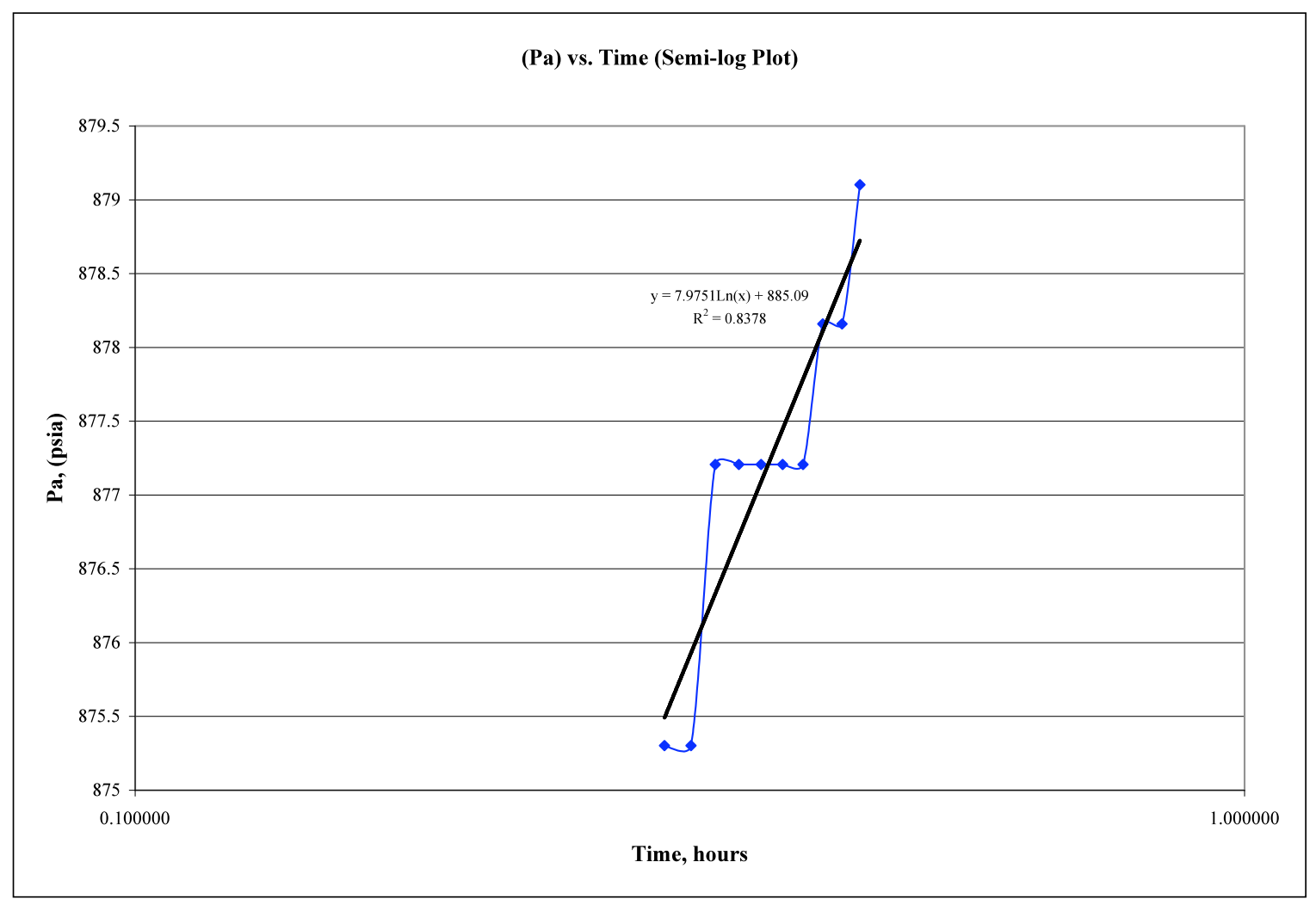

Figure B.6: Semi-log plot for well C-3 (Rate-1)

- Now, permeability (K) and apparent skin factor (s') can be calculated as follow:

From Regression

$$
\begin{aligned}
& \begin{array}{l}
m= \\
\left(P_{a}\right)_{1 h r},= \\
K=
\end{array} \\
& K=\frac{162.6 q_{g} B_{g} \mu_{g}}{(m h)} \\
& s^{\prime}=1.151\left[\frac{P_{1 h r}-\overline{P_{a}}}{m}-\log \left(\frac{k}{\phi \overline{\mu c_{t}} r_{w}^{2}}\right)+3.23\right] \\
& s^{\prime}=
\end{aligned}
$$


- By following the same procedures with the other two rates, the values of the permeability (K) and apparent skin factor (s') were obtained. Table B.7 summarizes the results of the multi-rate test analysis for well C-3 at each flow rate.

Table B.7: $\mathrm{K}$ and $\mathrm{S}$ ' values for well $\mathrm{C}-3$ at different rates

\begin{tabular}{|c|c|c|}
\hline \multicolumn{3}{|c|}{ Multi-Rate test Analysis for well C-3 } \\
\hline $\mathrm{q}(\mathrm{MM} \mathrm{Mcf} / \mathrm{D})$ & $\mathrm{K}$ md & $\mathrm{S}^{\prime}$ \\
\hline 28.60971214 & 140.32 & -3.827433742 \\
\hline 36.62508281 & 246.00 & -0.890760696 \\
\hline & 386.32 \\
Average $\mathrm{K}=$ & 193.1585555 \\
\hline
\end{tabular}

- By plotting the flow rate $(\mathrm{Q})$ against the apparent skin factor (s') values, we had the following result:

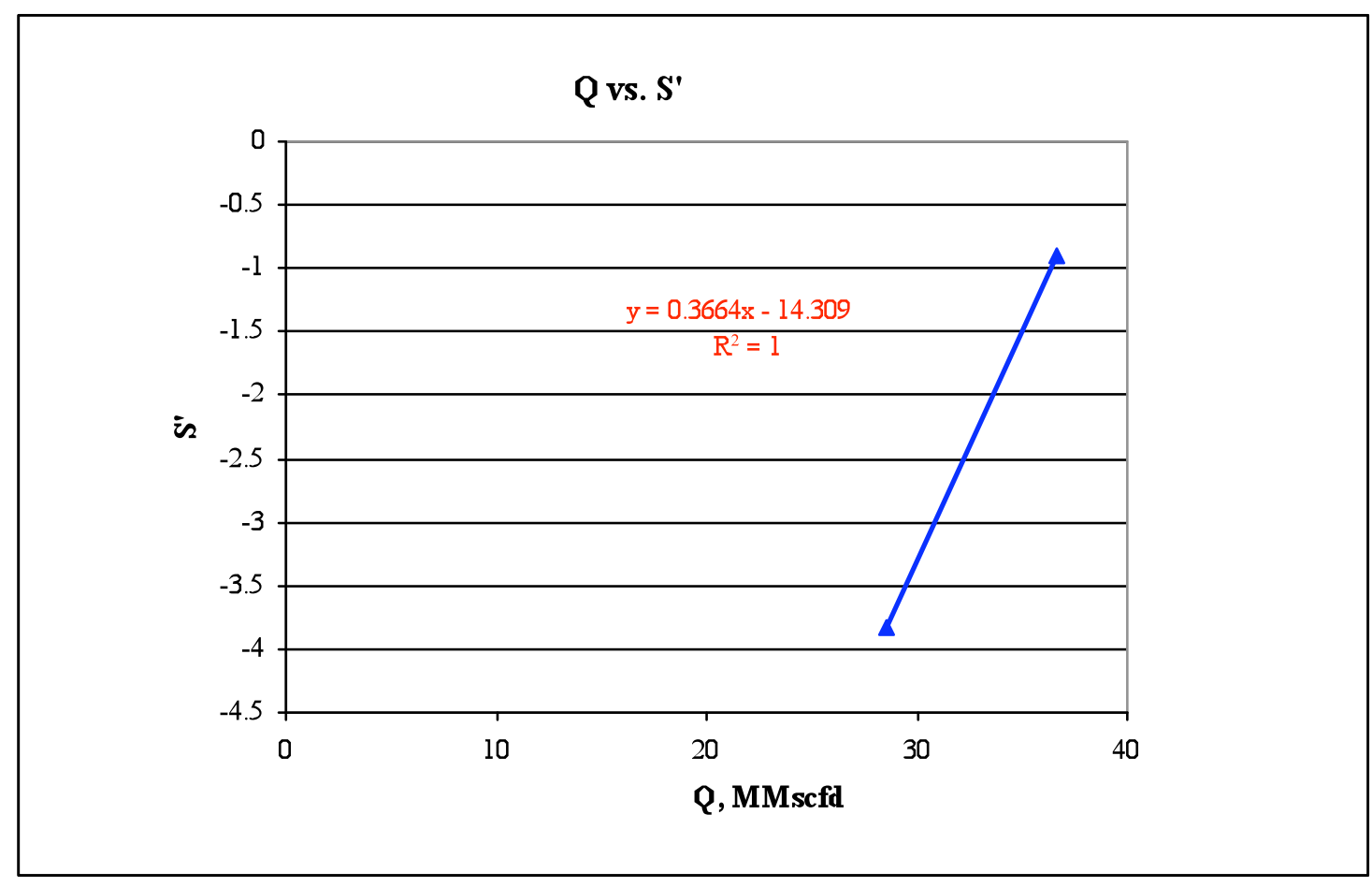

Figure B.7: Flow rates against skin factor (s') for well C-3 
From Trendline equ.
Slope $=$ Non-Darcy flow coefficient D
$\mathbf{D}=$
$0.3664 \quad 0.0003664$
$\beta=$
$(\mathrm{D} * \mu * \mathrm{~h} * \mathrm{rw}) /(2.223 \times 10-15 \mathrm{~g} \mathrm{~K})$
$\beta=$
$1.21 \mathrm{E}+08$

\section{Well C-4:}

Table B.8: Multi-rate test analysis for well C-4 (Rate-1)

\begin{tabular}{|c|c|c|c|c|c|c|c|c|c|c|c|}
\hline \multicolumn{11}{|c|}{ Well C-4 (Rate-1) } & \\
\hline Time (hrs) & Time (hrs) & $\Delta t$, hrs & Log Time & $\begin{array}{c}\text { BHT Temp } \\
\text { (F) }\end{array}$ & $\begin{array}{c}\text { WH Pressure } \\
\text { (Psig) } \\
\end{array}$ & $\begin{array}{c}\text { BHP Pressure } \\
\text { (Psig) Using } \\
\text { program }\end{array}$ & \begin{tabular}{|c} 
BHP Pressure \\
(Psia)
\end{tabular} & $\begin{array}{l}\text { BHP Adjusted } \\
\text { Pressure (Psia) }\end{array}$ & $\Delta \mathrm{P}$ & $\begin{array}{c}\text { Q } \\
\text { (MMscfd) }\end{array}$ & \\
\hline 12:02:56 & 1.009444 & & & 123 & 1405.34 & 1649.12 & 1663.82 & 847.2269126 & & 8645.53 & \\
\hline 12:03:56 & 1.026111 & 0.016667 & -1.778151 & 123 & 1406.11 & 1650.07 & 1664.77 & 848.19468 & 0.9677674 & 8764.25 & \\
\hline 12:04:56 & 1.042778 & 0.033333 & -1.477121 & 123 & 1406.11 & 1650.07 & 1664.77 & 848.19468 & 0.9677674 & 8535.26 & \\
\hline $12: 05: 56$ & 1.059444 & 0.050000 & -1.30103 & 123 & 1406.11 & 1650.07 & 1664.77 & 848.19468 & 0.9677674 & 8675.36 & \\
\hline 12:06:56 & 1.076111 & 0.066667 & -1.176091 & 123 & 1406.11 & 1650.07 & 1664.77 & 848.19468 & 0.9677674 & 8595.58 & \\
\hline $12: 07: 56$ & 1.092778 & 0.083333 & -1.079181 & 123 & 1406.87 & 1651.01 & 1665.71 & 849.152804 & 1.9258914 & 8585.56 & \\
\hline 12:08:56 & 1.109444 & 0.100000 & -1 & 123 & 1406.87 & 1651.01 & 1665.71 & 849.152804 & 1.9258914 & 8565.47 & \\
\hline $12: 09: 56$ & 1.126111 & 0.116667 & -0.933053 & 123 & 1406.87 & 1651.01 & 1665.71 & 849.152804 & 1.9258914 & 8724.85 & 8 \\
\hline $12: 10: 56$ & 1.142778 & 0.133333 & -0.875061 & 123 & 1406.87 & 1651.01 & 1665.71 & 849.152804 & 1.9258914 & 8595.58 & \\
\hline $12: 11: 56$ & 1.159444 & 0.150000 & -0.823909 & 123 & 1406.11 & 1650.07 & 1664.77 & 848.19468 & 0.9677674 & 8484.66 & 10 \\
\hline $12: 12: 56$ & 1.176111 & 0.166667 & -0.778151 & 123 & 1406.87 & 1651.01 & 1665.71 & 849.152804 & 1.9258914 & 8545.34 & 11 \\
\hline $12: 13: 57$ & 1.193056 & 0.183611 & -0.736101 & 123 & 1406.87 & 1651.01 & 1665.71 & 849.152804 & 1.9258914 & 8645.53 & 12 \\
\hline $12: 14: 56$ & 1.209444 & 0.200000 & -0.69897 & 123 & 1406.87 & 1651.01 & 1665.71 & 849.152804 & 1.9258914 & 8615.6 & 13 \\
\hline 12:15:56 & 1.226111 & 0.216667 & -0.664208 & 123 & 1406.87 & 1651.01 & 1665.71 & 849.152804 & 1.9258914 & 8535.26 & 14 \\
\hline $12: 16: 56$ & 1.242778 & 0.233333 & -0.632023 & 123 & 1407.63 & 1651.94 & 1666.64 & 850.1012675 & 2.8743549 & 8675.36 & 15 \\
\hline $12: 17: 56$ & 1.259444 & 0.250000 & -0.60206 & 123 & 1407.63 & 1651.94 & 1666.64 & 850.1012675 & 2.8743549 & 8595.58 & 16 \\
\hline $12: 18: 56$ & 1.276111 & 0.266667 & -0.574031 & 123 & 1407.63 & 1651.94 & 1666.64 & 850.1012675 & 2.8743549 & 8595.58 & 17 \\
\hline 12:19:56 & 1.292778 & 0.283333 & -0.547702 & 123 & 1407.63 & 1651.94 & 1666.64 & 850.1012675 & 2.8743549 & 8575.52 & 18 \\
\hline $12: 20: 56$ & 1.309444 & 0.300000 & -0.522879 & 123 & 1407.63 & 1651.94 & 1666.64 & 850.1012675 & 2.8743549 & 8595.58 & 19 \\
\hline $12: 21: 56$ & 1.326111 & 0.316667 & -0.499398 & 123 & 1407.63 & 1651.94 & 1666.64 & 850.1012675 & 2.8743549 & 8504.94 & 20 \\
\hline $12: 22: 56$ & 1.342778 & 0.333333 & -0.477121 & 123 & 1407.63 & 1651.94 & 1666.64 & 850.1012675 & 2.8743549 & 8585.56 & 21 \\
\hline $12: 23: 56$ & 1.359444 & 0.350000 & -0.455932 & 123 & 1407.63 & 1651.94 & 1666.64 & 850.1012675 & 2.8743549 & 8525.17 & 22 \\
\hline $12: 24: 57$ & 1.376389 & 0.366944 & -0.4354 & 123 & 1407.63 & 1651.94 & 1666.64 & 850.1012675 & 2.8743549 & 8625.59 & 23 \\
\hline $12: 25: 56$ & 1.392778 & 0.383333 & -0.416423 & 123 & 1407.63 & 1651.94 & 1666.64 & 850.1012675 & 2.8743549 & 8575.52 & 24 \\
\hline $12: 26: 56$ & 1.409444 & 0.400000 & -0.39794 & 123 & 1407.63 & 1651.94 & 1666.64 & 850.1012675 & 2.8743549 & 8595.58 & 25 \\
\hline $12: 27: 56$ & 1.426111 & 0.416667 & -0.380211 & 123 & 1407.63 & 1651.94 & 1666.64 & 850.1012675 & 2.8743549 & 8605.6 & 26 \\
\hline $12: 28: 56$ & 1.442778 & 0.433333 & -0.363178 & 123 & 1407.63 & 1651.94 & 1666.64 & 850.1012675 & 2.8743549 & 8575.52 & 77 \\
\hline \multicolumn{10}{|c|}{ Average Resevoir Pressure @ $\mathrm{t}=0$} & \begin{tabular}{|l|}
8597.9604 \\
8.5979604 \\
\end{tabular} & $\begin{array}{l}\text { Iscfd) } \\
\text { (Mscfd) }\end{array}$ \\
\hline
\end{tabular}

Since the calculated BHP is between $1500 \& 3000$ psi, the adjusted pressure Method has

been used.

$$
\mathrm{P}_{\mathrm{a}}=\mathrm{P}^{2} /\left(2 * \mathrm{P}^{-}\right)
$$

- $\quad$ lotting the adjusted pressure against time in a semi-log paper as follow: 


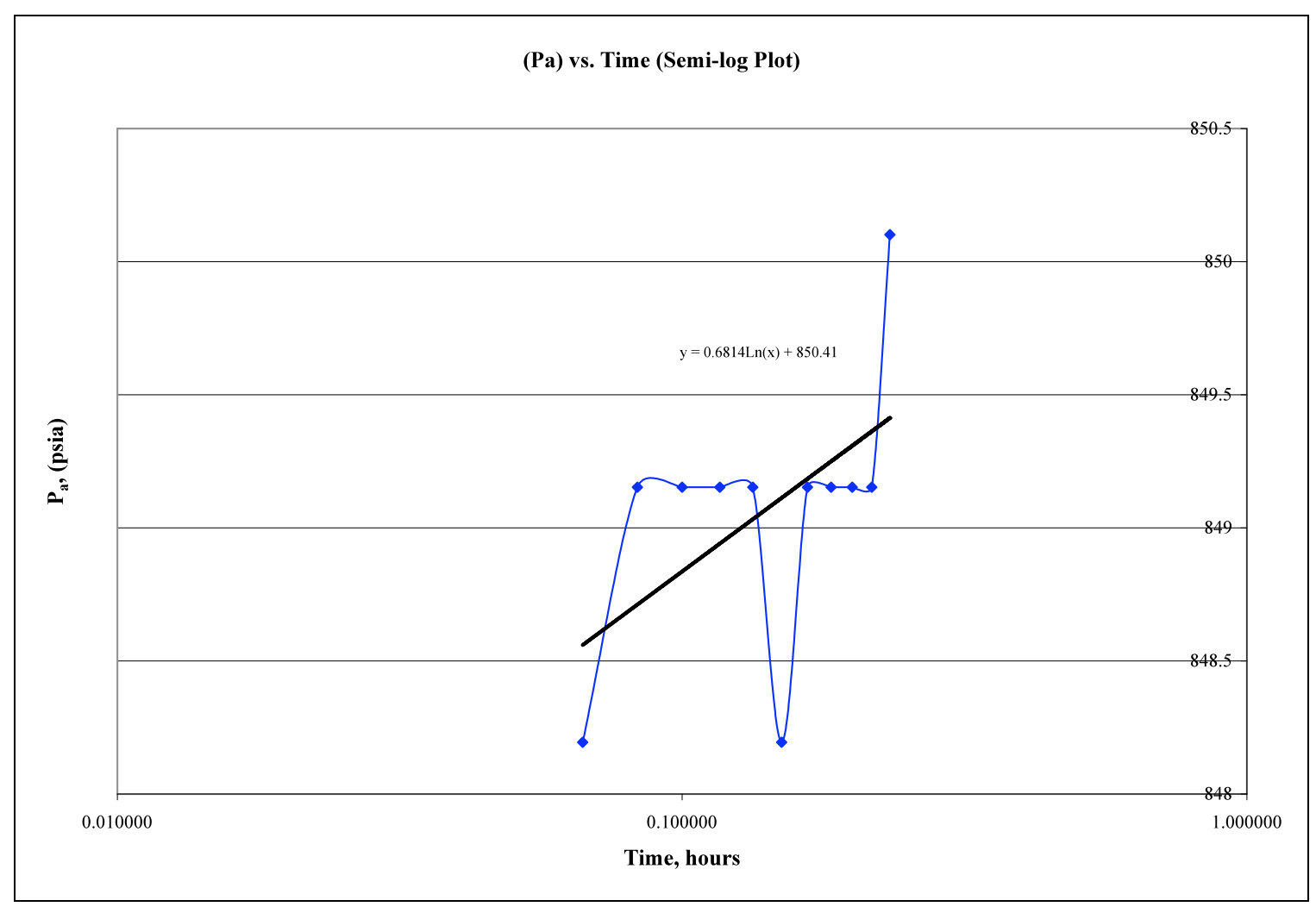

Figure B.8: Semi-log plot for well C-4 (Rate-1)

- Now, permeability (K) and apparent skin factor (s') can be calculated as follow:

From Regression

$$
\begin{aligned}
& m= \\
& \left(P_{a}\right)_{1 h r}= \\
& 2.064642 \\
& 850.41 \quad \text { psia } \\
& K=\frac{162.6 q_{g} B{ }_{g} \mu_{g}}{(m h)} \\
& K=\quad 585.37 \quad \text { md } \\
& s^{\prime}=1.151\left[\frac{P_{1 h r}-\overline{P_{a}}}{m}-\log \left(\frac{k}{\phi \overline{\mu c_{t}} r_{w}^{2}}\right)+3.23\right] \\
& s^{\prime}=\quad 10.533401
\end{aligned}
$$

- By following the same procedures with the other two rates, the values of the permeability (K) and apparent skin factor (s') were obtained. Table B.9 
summarizes the results of the multi-rate test analysis for well C-4 at each flow rate.

Table B.9: $K$ and S' values for well $C-4$ at different rates

\begin{tabular}{|c|c|c|}
\hline \multicolumn{3}{|c|}{ Multi-Rate test Analysis for well C-4 } \\
\hline $\mathrm{q}(\mathrm{MMcf} / \mathrm{D})$ & $\mathrm{K} \mathrm{md}$ & $\mathrm{S}^{\prime}$ \\
\hline 13.82850214 & 196.91 & 1.608730279 \\
\hline 17.20929027 & 208.62 & 3.975599497 \\
\hline \multirow{3}{*}{ Average $\mathrm{K}=$} & 405.53 \\
\end{tabular}

- By plotting the flow rate (Q) against the apparent skin factor (s') values, we had the following result:

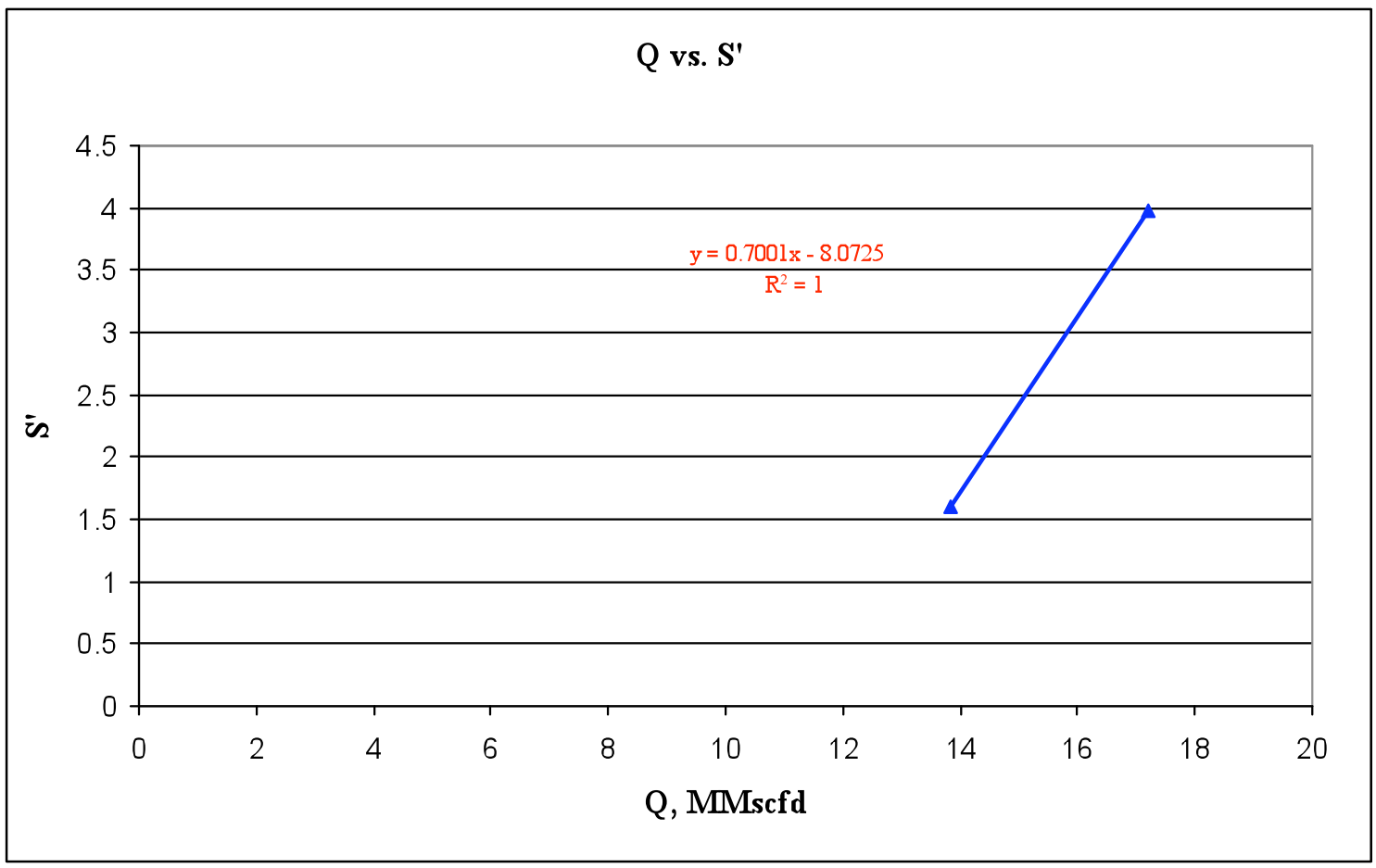

Figure B.9: Flow rates against skin factor (s') for well C-4

From Trendline equ.

Slope $=$ Non-Darcy flow coefficient $D$
$D=$
0.7
0.0007
$\beta=$
$\left(D^{*} \mu^{*} \mathrm{~h}^{*} \mathrm{rw}\right) /(2.223 \times 10-15 \mathrm{~g} \mathrm{~K})$
$\beta=$
$1.64 \mathrm{E}+08$ 


\section{Well C-5:}

Table B.10: Multi-rate test analysis for well C-5 (Rate-1)

\begin{tabular}{|c|c|c|c|c|c|c|c|c|c|c|c|}
\hline \multicolumn{11}{|c|}{ Well C-5 (Rate-1) } & \\
\hline Time (hrs) & Time (hrs) & $\Delta \mathrm{t}, \mathrm{hrs}$ & Log Time & $\begin{array}{c}\text { BHT Temp } \\
\text { (F) }\end{array}$ & $\begin{array}{c}\text { WH } \\
\text { Pressure } \\
\text { (Psig) }\end{array}$ & $\begin{array}{c}\text { BHP Pressure } \\
\text { (Psig) Using } \\
\text { program }\end{array}$ & $\begin{array}{c}\text { BHP Pressure } \\
\text { (Psia) }\end{array}$ & $\begin{array}{l}\text { BHP Adjusted } \\
\text { Pressure (Psia) }\end{array}$ & $\Delta \mathrm{P}$ & Q (MMscfd) & \\
\hline 10:51:02 & 0.483333 & & & 123 & 1446.63 & 1713.44 & 1728.14 & 882.5572596 & & 3961.52 & 1 \\
\hline $10: 52: 02$ & 0.500000 & 0.016667 & -1.778151 & 123 & 1445.85 & 1712.48 & 1727.18 & 881.5769922 & -0.980267 & 3949.46 & 2 \\
\hline 10:53:02 & 0.516667 & 0.033333 & -1.477121 & 123 & 1446.63 & 1713.44 & 1728.14 & 882.5572596 & 0 & 3953.49 & 3 \\
\hline $10: 54: 02$ & 0.533333 & 0.050000 & -1.30103 & 123 & 1446.63 & 1713.44 & 1728.14 & 882.5572596 & 0 & 3961.52 & 4 \\
\hline $10: 55: 02$ & 0.550000 & 0.066667 & -1.176091 & 123 & 1447.41 & 1714.4 & 1729.1 & 883.5380717 & 0.9808121 & 3965.53 & 5 \\
\hline $10: 56: 02$ & 0.566667 & 0.083333 & -1.079181 & 123 & 1448.19 & 1715.35 & 1730.05 & 884.5092032 & 1.9519436 & 3965.53 & 6 \\
\hline $10: 57: 02$ & 0.583333 & 0.100000 & -1 & 123 & 1448.19 & 1715.35 & 1730.05 & 884.5092032 & 1.9519436 & 3965.53 & 7 \\
\hline 10:58:02 & 0.600000 & 0.116667 & -0.933053 & 123 & 1448.97 & 1716.31 & 1731.01 & 885.491099 & 2.9338394 & 3957.51 & 8 \\
\hline 10:59:02 & 0.616667 & 0.133333 & -0.875061 & 123 & 1449.75 & 1717.27 & 1731.97 & 886.4735395 & 3.9162799 & 3953.49 & 9 \\
\hline 11:00:02 & 0.633333 & 0.150000 & -0.823909 & 123 & 1448.97 & 1716.31 & 1731.01 & 885.491099 & 2.9338394 & 3949.46 & 10 \\
\hline 11:01:02 & 0.650000 & 0.166667 & -0.778151 & 123 & 1448.97 & 1716.31 & 1731.01 & 885.491099 & 2.9338394 & 3945.44 & 11 \\
\hline 11:02:02 & 0.666667 & 0.183333 & -0.736759 & 123 & 1448.97 & 1716.31 & 1731.01 & 885.491099 & 2.9338394 & 3945.44 & 12 \\
\hline 11:03:02 & 0.683333 & 0.200000 & -0.69897 & 123 & 1448.19 & 1715.35 & 1730.05 & 884.5092032 & 1.9519436 & 3949.46 & 13 \\
\hline 11:04:02 & 0.700000 & 0.216667 & -0.664208 & 123 & 1448.19 & 1715.35 & 1730.05 & 884.5092032 & 1.9519436 & 3953.49 & 14 \\
\hline 11:05:02 & 0.716667 & 0.233333 & -0.632023 & 123 & 1448.97 & 1716.31 & 1731.01 & 885.491099 & \begin{tabular}{|l|}
2.9338394 \\
\end{tabular} & 3953.49 & 15 \\
\hline 11:06:02 & 0.733333 & 0.250000 & -0.60206 & 123 & 1448.97 & 1716.31 & 1731.01 & 885.491099 & 2.9338394 & 3945.44 & 16 \\
\hline 11:07:02 & 0.750000 & 0.266667 & -0.574031 & 123 & 1448.19 & 1715.35 & 1730.05 & 884.5092032 & 1.9519436 & 3937.37 & 17 \\
\hline 11:08:02 & 0.766667 & 0.283333 & -0.547702 & 123 & 1448.19 & 1715.35 & 1730.05 & 884.5092032 & 1.9519436 & 3925.24 & 18 \\
\hline 11:09:02 & 0.783333 & 0.300000 & -0.522879 & 123 & 1448.97 & 1716.31 & 1731.01 & 885.491099 & 2.9338394 & 3957.51 & 19 \\
\hline 11:10:02 & 0.800000 & 0.316667 & -0.499398 & 123 & 1448.97 & 1716.31 & 1731.01 & 885.491099 & \begin{tabular}{|l|}
2.9338394 \\
\end{tabular} & 3941.41 & 20 \\
\hline 11:11:02 & 0.816667 & 0.333333 & -0.477121 & 123 & 1449.75 & 1717.27 & 1731.97 & 886.4735395 & 3.9162799 & 3933.33 & 21 \\
\hline 11:12:02 & 0.833333 & 0.350000 & -0.455932 & 123 & 1448.97 & 1716.31 & 1731.01 & 885.491099 & 2.9338394 & 3937.37 & 22 \\
\hline 11:13:02 & 0.850000 & 0.366667 & -0.435729 & 123 & 1448.19 & 1715.35 & 1730.05 & 884.5092032 & 1.9519436 & 3933.33 & 23 \\
\hline 11:14:02 & 0.866667 & 0.383333 & -0.416423 & 123 & 1448.19 & 1715.35 & 1730.05 & 884.5092032 & 1.9519436 & 3925.24 & 24 \\
\hline 11:15:02 & 0.883333 & 0.400000 & -0.39794 & 123 & 1448.19 & 1715.35 & 1730.05 & 884.5092032 & 1.9519436 & 3937.37 & 25 \\
\hline 11:16:02 & 0.900000 & 0.416667 & -0.380211 & 123 & 1448.19 & 1715.35 & 1730.05 & 884.5092032 & 1.9519436 & 3945.44 & 26 \\
\hline & rage Resev & - Pressure @ & & 123 & 1416.98 & 1677.24 & 1691.94 & 845.97 & & \begin{tabular}{|l|}
3948.054231 \\
3.948054231
\end{tabular} & $\begin{array}{l}\text { Avg q (Mscfd) } \\
\text { Avg q (MMscfd) }\end{array}$ \\
\hline
\end{tabular}

Since the calculated BHP is between $1500 \& 3000 \mathrm{psi}$, the adjusted pressure Method has

been used.

$$
\mathrm{P}_{\mathrm{a}}=\mathrm{P}^{2} /\left(2 * \mathrm{P}^{-}\right)
$$

- plotting the adjusted pressure against time in a semi-log paper as follow: 


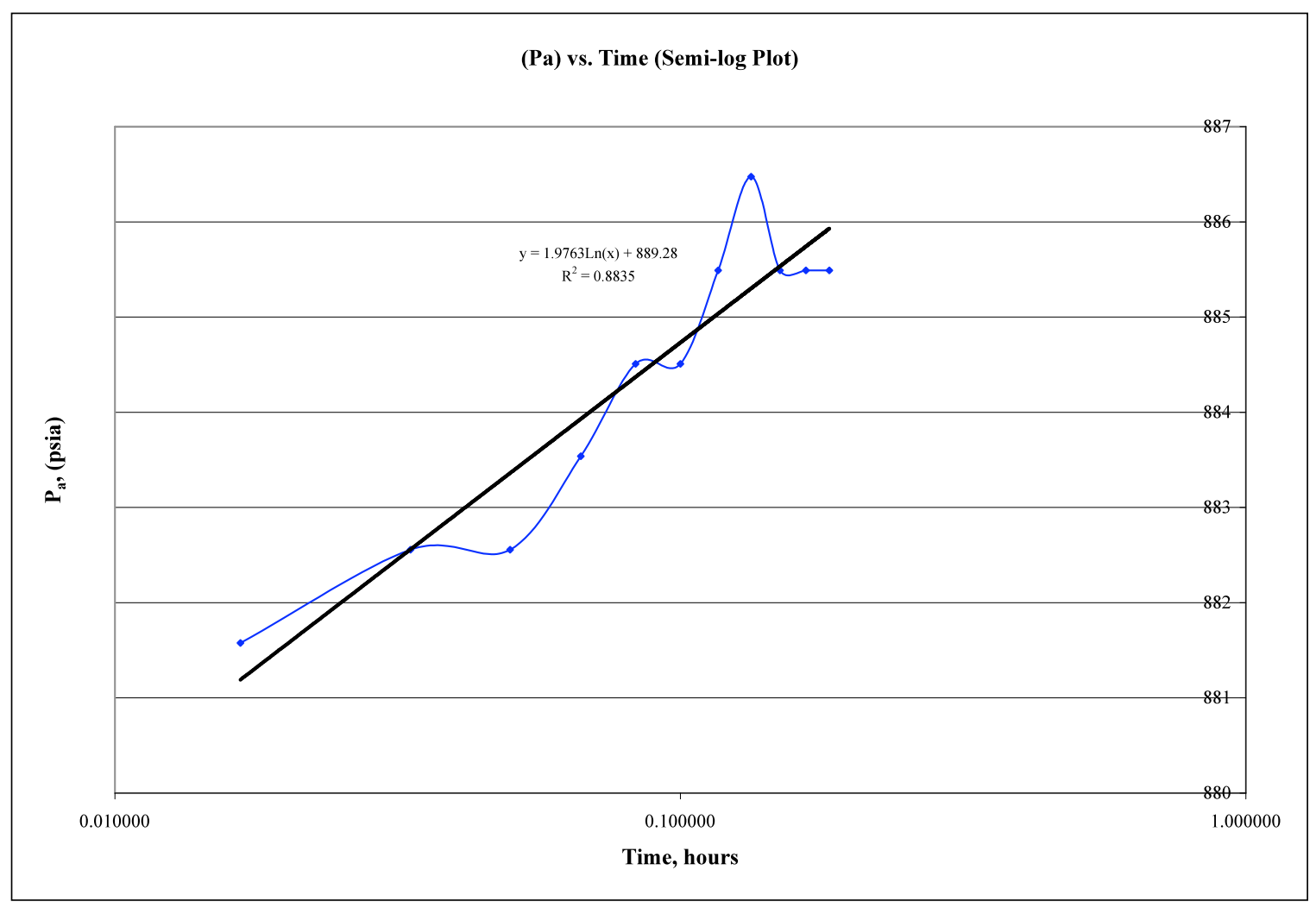

Figure B.10: Semi-log plot for well C-5 (Rate-1)

- Now, permeability (K) and apparent skin factor (s') can be calculated as follow:

From Regression

$$
\begin{aligned}
& m= \\
& \left(P_{a}\right)_{1 h r}= \\
& 5.988189 \\
& \text { 889.28 psia } \\
& K=\frac{162.6 q_{g} B_{g} \mu_{g}}{(m h)} \\
& K=\quad 101.86 \quad \text { md } \\
& s^{\prime}=1.151\left[\frac{P_{1 h r}-\overline{P_{a}}}{m}-\log \left(\frac{k}{\phi \overline{\mu c_{t}} r_{w}^{2}}\right)+3.23\right] \\
& s^{\prime}=\quad 1.396109975
\end{aligned}
$$

- In this well, the type of test id Flow after flow test. Therefore, different procedures to obtain $\beta$ value were performed. 
1. Flow after flow test analysis were conducted as shown in the following table:

Table B.11: Flow after flow test analysis for well C-5

\begin{tabular}{|c|c|c|c|c|c|r|}
\hline \multicolumn{9}{|c|}{ Well C-5 } \\
\hline \multicolumn{7}{|c|}{ Flow after flow test } \\
\hline $\begin{array}{c}\text { Flow Rate } \\
\text { (Mscfd) }\end{array}$ & WHP (Psig) & BHT (F) & $\begin{array}{c}\text { BHP Pressure (Psig) Using } \\
\text { Program }\end{array}$ & BHP Pressure (Psia) & $\Delta \mathrm{P}^{2}$ & $\Delta \mathrm{P}^{2} / \mathrm{q}$ \\
\hline 3945.44 & 1448.19 & 123 & 1715.36 & 1730.06 & 130446.64 & 33.06263433 \\
\hline 6605.83 & 1485.64 & 123 & 1760.97 & 1775.67 & 290342.99 & 43.95253667 \\
\hline 9103.14 & 1529.34 & 123 & 1814.10 & 1828.80 & 481848.48 & 52.93211753 \\
\hline
\end{tabular}

2. Plot $\Delta \mathrm{P}^{2} / \mathrm{q}$ vs. $\mathrm{q}$

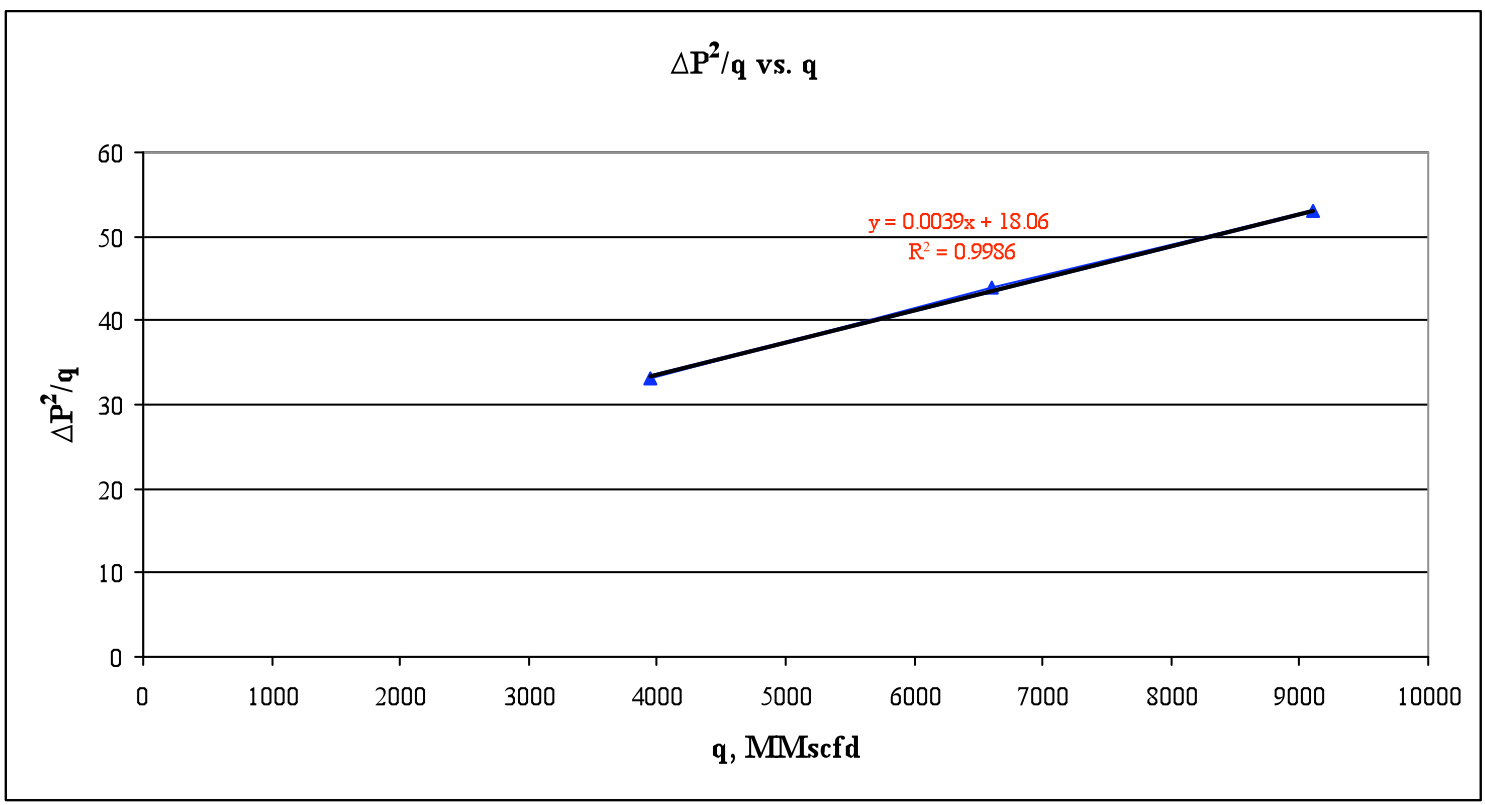

Figure B.11: Flow-after flow analysis for well C-5 (Rate-1)

3. Plot $\Delta \mathrm{P}^{2} / \mathrm{q}$ vs. $\mathrm{q}$

$$
\begin{array}{lc}
B= & 0.0039 \\
\beta= & \left(\mathrm{r}_{\mathrm{w}} \mathrm{h}^{2} \mathrm{~B}\right) /\left(3.161 \times 10^{-12} \gamma_{\mathrm{g}} Z T\right) \\
\beta= & 5.75 \mathrm{E}+08
\end{array}
$$




\section{Well C-6: (It was selected to be Reservoir C test well)}

Table B.12: Multi-rate test analysis for well C-6 (Rate-1)

\begin{tabular}{|c|c|c|c|c|c|c|c|c|c|c|c|}
\hline \multicolumn{11}{|c|}{ Well C-6 (Rate-1) } & \\
\hline Time (hrs) & Time (hrs) & $\Delta t$, hrs & Log Time & $\begin{array}{c}\text { BHT Temp } \\
\text { (F) }\end{array}$ & $\begin{array}{c}\text { WH Pressure } \\
\text { (Psig) }\end{array}$ & $\begin{array}{l}\text { BHP Pressure } \\
\text { (Psig) Using } \\
\text { program }\end{array}$ & $\begin{array}{c}\text { BHP } \\
\text { Pressure } \\
\text { (Psia) }\end{array}$ & $\begin{array}{l}\text { BHP Adjusted } \\
\text { Pressure (Psia) }\end{array}$ & $\Delta \mathrm{P}$ & $\begin{array}{c}\text { Q } \\
\text { (MMscfd) }\end{array}$ & \\
\hline $9: 54: 41$ & 0.000000 & & & 123 & 1403.71 & 1645.07 & 1659.77 & 829.8950001 & & 3266.97 & 1 \\
\hline $9: 55: 41$ & 0.016667 & 0.016667 & -1.778151 & 123 & 1404.49 & 1646.02 & 1660.72 & 830.8452834 & 0.9502833 & 3266.97 & \\
\hline $9: 56: 41$ & 0.033333 & 0.033333 & -1.477121 & 123 & 1405.27 & 1646.96 & 1661.66 & 831.786099 & 1.8910989 & 3266.97 & 3 \\
\hline $9: 57: 41$ & 0.050000 & 0.050000 & -1.30103 & 123 & 1405.27 & 1646.96 & 1661.66 & 831.786099 & 1.8910989 & 3266.97 & 4 \\
\hline 9:58:41 & 0.066667 & 0.066667 & -1.176091 & 123 & 1405.27 & 1646.96 & 1661.66 & 831.786099 & \begin{tabular}{|l|}
1.8910989 \\
\end{tabular} & 3266.97 & \\
\hline 9:59:41 & 0.083333 & 0.083333 & -1.079181 & 123 & 1405.27 & 1646.96 & 1661.66 & 831.786099 & 1.8910989 & 3266.97 & \\
\hline $10: 00: 41$ & 0.100000 & 0.100000 & -1 & 123 & 1405.27 & 1646.96 & 1661.66 & 831.786099 & \begin{tabular}{|l|}
1.8910989 \\
\end{tabular} & 3184.37 & \\
\hline 10:01:41 & 0.116667 & 0.116667 & -0.933053 & 123 & 1406.84 & 1648.87 & 1663.57 & 833.699396 & 3.8043958 & 3184.37 & \\
\hline 10:02:41 & 0.133333 & 0.133333 & -0.875061 & 123 & 1407.62 & 1649.81 & 1664.51 & 834.6418256 & 4.7468255 & 3184.37 & 9 \\
\hline $10: 03: 41$ & 0.150000 & 0.150000 & -0.823909 & 123 & 1406.84 & 1648.87 & 1663.57 & 833.699396 & 3.8043958 & 3184.37 & 10 \\
\hline 10:04:41 & 0.166667 & 0.166667 & -0.778151 & 123 & 1406.84 & 1648.87 & 1663.57 & 833.699396 & \begin{tabular}{|l|}
3.8043958 \\
\end{tabular} & 3184.37 & 11 \\
\hline 10:05:41 & 0.183333 & 0.183333 & -0.736759 & 123 & 1406.05 & 1647.91 & 1662.61 & 832.7374641 & 2.842464 & 3184.37 & 12 \\
\hline $10: 06: 41$ & 0.200000 & 0.200000 & -0.69897 & 123 & 1407.62 & 1649.81 & 1664.51 & 834.6418256 & 4.7468255 & 3184.37 & 13 \\
\hline 10:07:41 & 0.216667 & 0.216667 & -0.664208 & 123 & 1406.84 & 1648.87 & 1663.57 & 833.699396 & 3.8043958 & 3184.37 & 14 \\
\hline 10:08:41 & 0.233333 & 0.233333 & -0.632023 & 123 & 1406.84 & 1648.87 & 1663.57 & 833.699396 & 3.8043958 & 3184.37 & 15 \\
\hline 10:09:41 & 0.250000 & 0.250000 & -0.60206 & 123 & 1406.05 & 1647.91 & 1662.61 & 832.7374641 & \begin{tabular}{|l|}
2.842464 \\
\end{tabular} & 3099.56 & 16 \\
\hline $10: 10: 41$ & 0.266667 & 0.266667 & -0.574031 & 123 & 1406.05 & 1647.91 & 1662.61 & 832.7374641 & 2.842464 & 3099.56 & 17 \\
\hline 10:11:41 & 0.283333 & 0.283333 & -0.547702 & 123 & 1406.05 & 1647.91 & 1662.61 & 832.7374641 & 2.842464 & 3099.56 & 18 \\
\hline 10:12:41 & 0.300000 & 0.300000 & -0.522879 & 123 & 1406.05 & 1647.91 & 1662.61 & 832.7374641 & 2.842464 & 3099.56 & 19 \\
\hline 10:13:41 & 0.316667 & 0.316667 & -0.499398 & 123 & 1404.49 & 1646.02 & 1660.72 & 830.8452834 & 0.9502833 & 3099.56 & 20 \\
\hline $10: 14: 41$ & 0.333333 & 0.333333 & -0.477121 & 123 & 1404.49 & 1646.02 & 1660.72 & 830.8452834 & 0.9502833 & 3099.56 & 21 \\
\hline $10: 15: 41$ & 0.350000 & 0.350000 & -0.455932 & 123 & 1404.49 & 1646.02 & 1660.72 & 830.8452834 & 0.9502833 & 3012.36 & 22 \\
\hline $10: 16: 41$ & 0.366667 & 0.366667 & -0.435729 & 123 & 1404.49 & 1646.02 & 1660.72 & 830.8452834 & 0.9502833 & 3012.36 & 23 \\
\hline $10: 17: 41$ & 0.383333 & 0.383333 & -0.416423 & 123 & 1404.49 & 1646.02 & 1660.72 & 830.8452834 & 0.9502833 & 3012.36 & 24 \\
\hline 10:18:41 & 0.400000 & 0.400000 & -0.39794 & 123 & 1404.49 & 1646.02 & 1660.72 & 830.8452834 & \begin{tabular}{|l|}
0.9502833 \\
\end{tabular} & 3012.36 & 25 \\
\hline $10: 19: 41$ & 0.416667 & 0.416667 & -0.380211 & 123 & 1405.27 & 1646.96 & 1661.66 & 831.786099 & 1.8910989 & 3012.36 & 26 \\
\hline $10: 20: 41$ & 0.433333 & 0.433333 & -0.363178 & 123 & 1405.27 & 1646.96 & 1661.66 & 831.786099 & 1.8910989 & 3012.36 & 27 \\
\hline $10: 21: 41$ & 0.450000 & 0.450000 & -0.346787 & 123 & 1405.27 & 1646.96 & 1661.66 & 831.786099 & \begin{tabular}{|l|}
1.8910989 \\
\end{tabular} & 3012.36 & 28 \\
\hline $10: 22: 41$ & 0.466667 & 0.466667 & -0.330993 & 123 & 1405.27 & 1646.96 & 1661.66 & 831.786099 & \begin{tabular}{|l|l|}
1.8910989 \\
\end{tabular} & 2922.55 & 29 \\
\hline 10:23:41 & 0.483333 & 0.483333 & -0.315753 & 123 & 1405.27 & 1646.96 & 1661.66 & 831.786099 & 1.8910989 & 2922.55 & 30 \\
\hline 10:24:41 & 0.500000 & 0.500000 & -0.30103 & 123 & 1406.84 & 1648.87 & 1663.57 & 833.699396 & 3.8043958 & 2922.55 & 31 \\
\hline 10:25:41 & 0.516667 & 0.516667 & -0.28679 & 123 & 1406.84 & 1648.87 & 1663.57 & 833.699396 & \begin{tabular}{|l|}
3.8043958 \\
\end{tabular} & 2922.55 & 32 \\
\hline $10: 26: 41$ & 0.533333 & 0.533333 & -0.273001 & 123 & 1406.05 & 1647.91 & 1662.61 & 832.7374641 & \begin{tabular}{|l|}
2.842464 \\
\end{tabular} & 2922.55 & 33 \\
\hline $10: 27: 41$ & 0.550000 & 0.550000 & -0.259637 & 123 & 1406.84 & 1648.87 & 1663.57 & 833.699396 & 3.8043958 & 2922.55 & 34 \\
\hline $10: 28: 41$ & 0.566667 & 0.566667 & -0.246672 & 123 & 1407.62 & 1649.81 & 1664.51 & 834.6418256 & 4.7468255 & 2922.55 & 35 \\
\hline 10:29:41 & 0.583333 & 0.583333 & -0.234083 & 123 & 1408.4 & 1650.76 & 1665.46 & 835.594822 & \begin{tabular}{|l|}
5.6998219 \\
\end{tabular} & 2922.55 & 36 \\
\hline $10: 30: 41$ & 0.600000 & 0.600000 & -0.221849 & 123 & 1407.62 & 1649.81 & 1664.51 & 834.6418256 & 4.7468255 & 2829.88 & 37 \\
\hline 10:31:41 & 0.616667 & 0.616667 & -0.20995 & 123 & 1408.4 & 1650.76 & 1665.46 & 835.594822 & \begin{tabular}{|l|}
5.6998219 \\
\end{tabular} & 2829.88 & 38 \\
\hline 10:32:41 & 0.633333 & 0.633333 & -0.198368 & 123 & 1408.4 & 1650.76 & 1665.46 & 835.594822 & \begin{tabular}{|l|}
5.6998219 \\
\end{tabular} & 2829.88 & 39 \\
\hline $10: 33: 41$ & 0.650000 & 0.650000 & -0.187087 & 123 & 1408.4 & 1650.76 & 1665.46 & 835.594822 & 5.6998219 & 2829.88 & 40 \\
\hline $10: 34: 41$ & 0.666667 & 0.666667 & -0.176091 & 123 & 1409.18 & 1651.71 & 1666.41 & 836.5483621 & \begin{tabular}{|l|}
6.653362 \\
\end{tabular} & 2829.88 & 41 \\
\hline 10:35:41 & 0.683333 & 0.683333 & -0.165367 & 123 & 1409.18 & 1651.71 & 1666.41 & 836.5483621 & \begin{tabular}{|l|}
6.653362 \\
\end{tabular} & 2829.88 & 42 \\
\hline 10:36:41 & 0.700000 & 0.700000 & -0.154902 & 123 & 1408.4 & 1650.76 & 1665.46 & 835.594822 & 5.6998219 & 2829.88 & 43 \\
\hline 10:37:41 & 0.716667 & 0.716667 & -0.144683 & 123 & 1407.62 & 1649.81 & 1664.51 & 834.6418256 & 4.7468255 & 2829.88 & 44 \\
\hline $10: 38: 41$ & 0.733333 & 0.733333 & -0.134699 & 123 & 1407.62 & 1649.81 & 1664.51 & 834.6418256 & 4.7468255 & 2829.88 & 45 \\
\hline $10: 39: 41$ & 0.750000 & 0.750000 & -0.124939 & 123 & 1406.84 & 1648.87 & 1663.57 & 833.699396 & \begin{tabular}{|l|}
3.8043958 \\
\end{tabular} & 2829.88 & 46 \\
\hline $10: 40: 41$ & 0.766667 & 0.766667 & -0.115393 & 123 & 1406.84 & 1648.87 & 1663.57 & 833.699396 & \begin{tabular}{|l|}
3.8043958 \\
\end{tabular} & 2829.88 & 47 \\
\hline $10: 41: 41$ & 0.783333 & 0.783333 & -0.106053 & 123 & 1406.84 & 1648.87 & 1663.57 & 833.699396 & 3.8043958 & 2829.88 & 48 \\
\hline $10: 42: 41$ & 0.800000 & 0.800000 & -0.09691 & 123 & 1407.62 & 1649.81 & 1664.51 & 834.6418256 & 4.7468255 & 2829.88 & 49 \\
\hline $10: 43: 41$ & 0.816667 & 0.816667 & -0.087955 & 123 & 1409.18 & 1651.71 & 1666.41 & 836.5483621 & 6.653362 & 2829.88 & 50 \\
\hline $10: 44: 41$ & 0.833333 & 0.833333 & -0.079181 & 123 & 1409.18 & 1651.71 & 1666.41 & 836.5483621 & 6.653362 & 2634.77 & 51 \\
\hline \multicolumn{10}{|c|}{ Average Resevoir Pressure @ $\mathrm{t}=0$} & \begin{tabular}{|l|}
3011.3435 \\
3.0113435 \\
\end{tabular} & $\begin{array}{l}\text { Avg q (Mscfd) } \\
\text { Avg q (MMscfd) }\end{array}$ \\
\hline
\end{tabular}


Since the calculated BHP is between $1500 \& 3000$ psi, the adjusted pressure Method has been used.

$$
\mathrm{P}_{\mathrm{a}}=\mathrm{P}^{2} /\left(2 * \mathrm{P}^{-}\right)
$$

- plotting the adjusted pressure against time in a semi-log paper as follow:

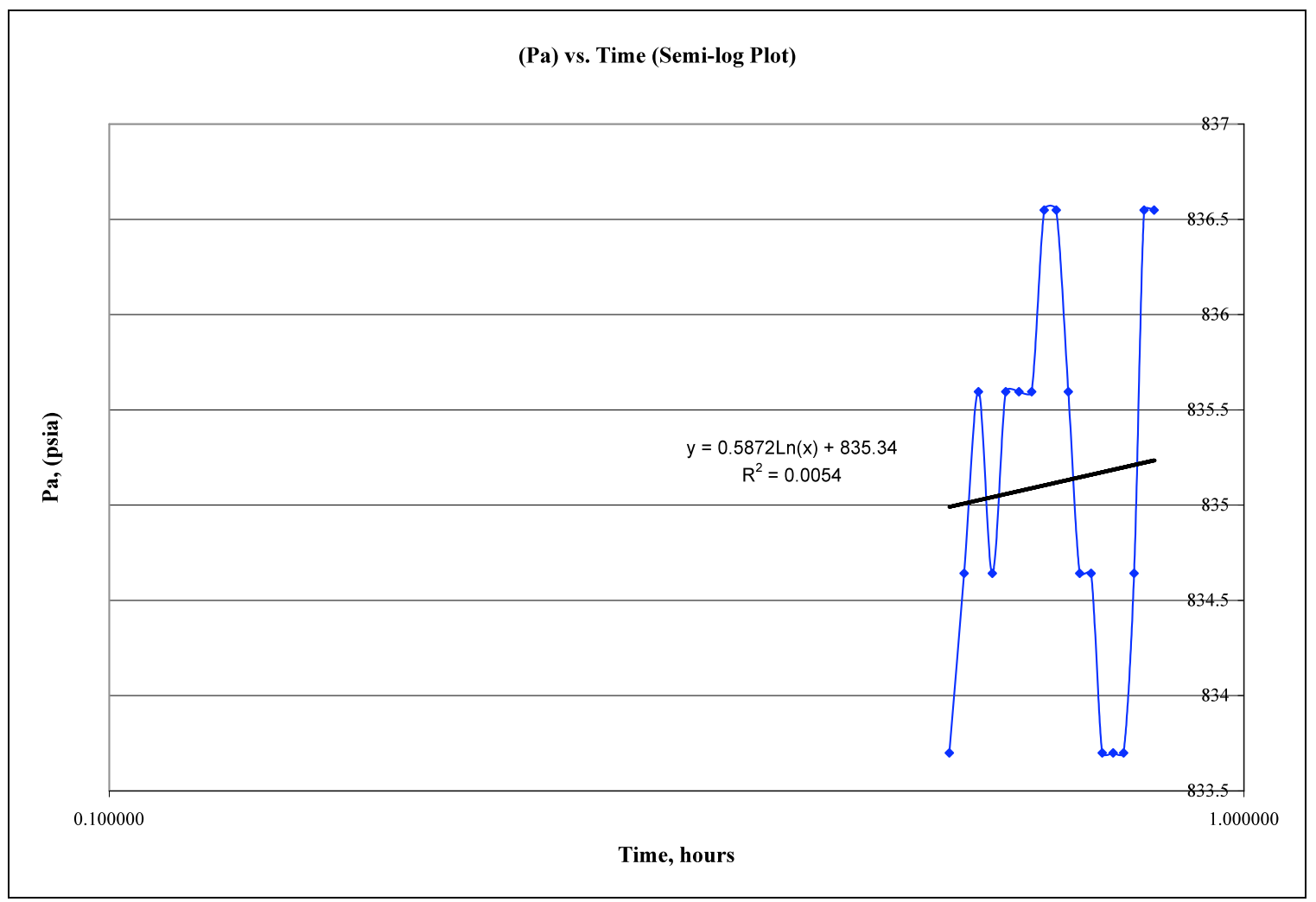

Figure B.12: Semi-log plot for well C-6 (Rate-1)

- Now, permeability (K) and apparent skin factor (s') can be calculated as follow:

From Regression

$$
\begin{aligned}
& m= \\
& 1.779216 \\
& \text { (Pa) } 1 \mathrm{hr} \text {, } \\
& 835.34 \quad \text { psia } \\
& K=\frac{162.6 q_{g} B{ }_{g} \mu_{g}}{(m h)} \\
& K=\quad 234.90 \quad m d \\
& s^{\prime}=1.151\left[\frac{P_{1 h r}-\overline{P_{a}}}{m}-\log \left(\frac{k}{\phi \overline{\mu c_{t}} r_{w}^{2}}\right)+3.23\right] \\
& s^{\prime}=\quad-3.660575467
\end{aligned}
$$


- By following the same procedures with the other two rates, the values of the permeability (K) and apparent skin factor (s') were obtained. Table B.13 summarizes the results of the multi-rate test analysis for well C-6 at each flow rate.

Table B.13: $K$ and S' values for well C-6 at different rates

\begin{tabular}{|c|c|c|}
\hline \multicolumn{3}{|c|}{ Multi-Rate test Analysis for well C-6 } \\
\hline $\mathrm{q}(\mathrm{MM}$ cf/D) & $\mathrm{K} \mathrm{md}$ & $\mathrm{S}^{\prime}$ \\
\hline 6.700277 & 71.77 & 1.036791096 \\
\hline 8.154709468 & 73.83 & 2.438002342 \\
\hline \multicolumn{3}{|c|}{145.60} \\
Average $\mathrm{K}=$ & 72.79950729 \\
\hline
\end{tabular}

- By plotting the flow rate (Q) against the apparent skin factor (s') values, we had the following result:

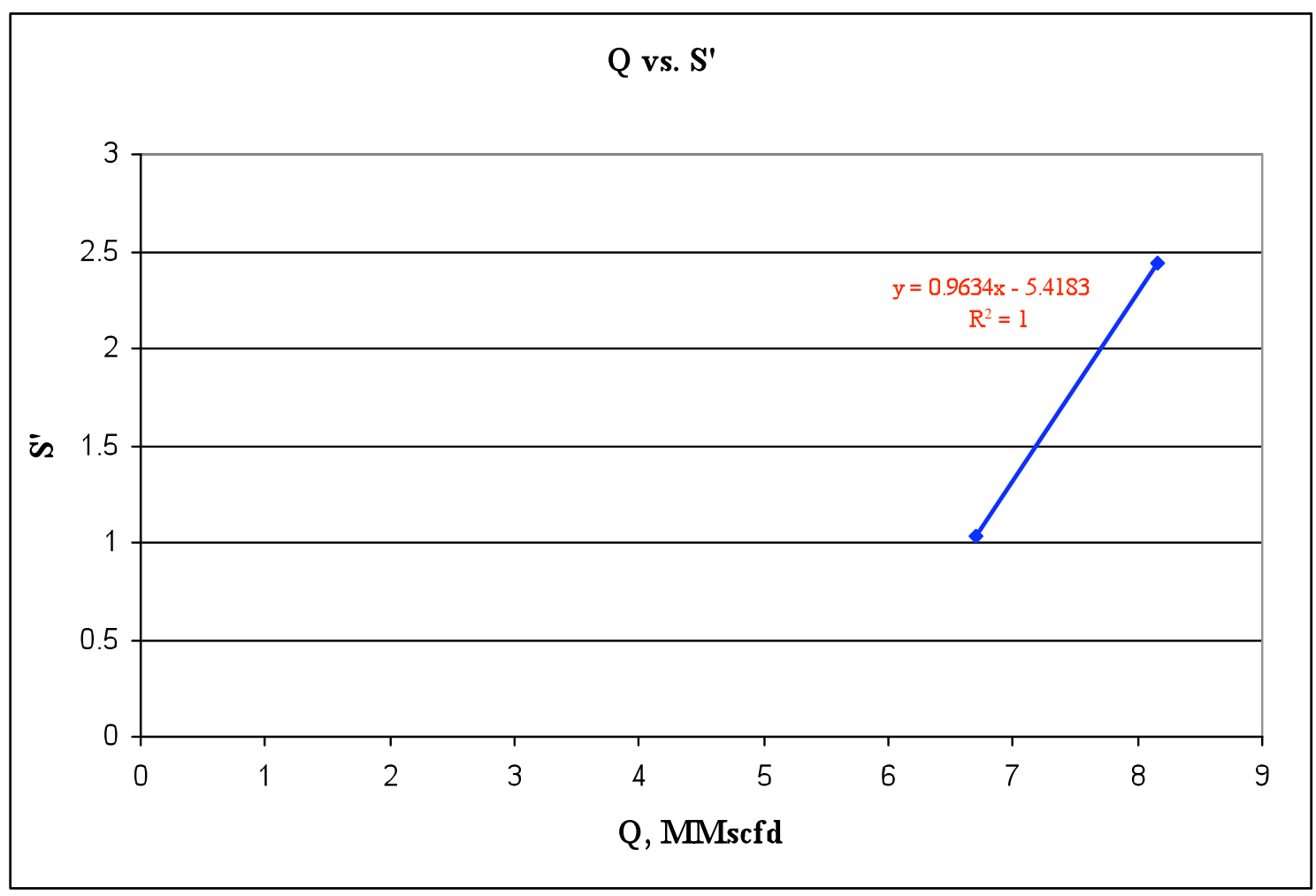

Figure B.13: Flow rates against skin factor (s') for well C-6 
From Trendline equ.

Slope $=$ Non-Darcy flow coefficient $D$

$D=$

0.9634

$\beta=$

$\beta=$

$\left(D^{*} \mu^{*} \mathrm{~h}^{*} \mathrm{rw}\right) /(2.223 \times 10-15 \mathrm{~g} \mathrm{~K})$

$9.95 \mathrm{E}+08$ 


\section{APPENDIX C}

\section{Reservoirs D Wells Data}

\section{Reservoir D Parameters:}

Table C.1 summarizes reservoir-D parameters and the calculated values of permeability $(K)$ and $(\beta)$ factor for each well.

Table C.1: Reservoir D Parameters Obtained from Multi-rate Tests

\begin{tabular}{|c|c|c|c|c|c|c|c|c|c|}
\hline \multicolumn{8}{|c|}{ Reservoir D Parameters Obtained from Multi-rate Tests } \\
\hline Well & h & rw & $\mu$ & $\gamma$ & D & k & $\beta$ & $\varphi$ & Kh \\
\hline D-1 & 90 & 0.167 & 0.018843521 & 0.593 & $1.32 \mathrm{E}-04$ & 0.81 & $3.50 \mathrm{E}+10$ & 0.1 & 72.9 \\
\hline D-2 & 101 & 0.167 & 0.018427464 & 0.593 & $1.35 \mathrm{E}-04$ & 4.775075 & $6.68 \mathrm{E}+09$ & 0.1 & 482.28262 \\
\hline D-3 & 101 & 0.167 & 0.018962395 & 0.593 & $1.08 \mathrm{E}-04$ & 9.370144 & $2.81 \mathrm{E}+09$ & 0.1 & 946.38451 \\
\hline
\end{tabular}

Figure C.1 shows the plot of permeability $(K)$ values vs. the coefficient of inertial resistance $(\beta)$ values for reservoirs $D$.

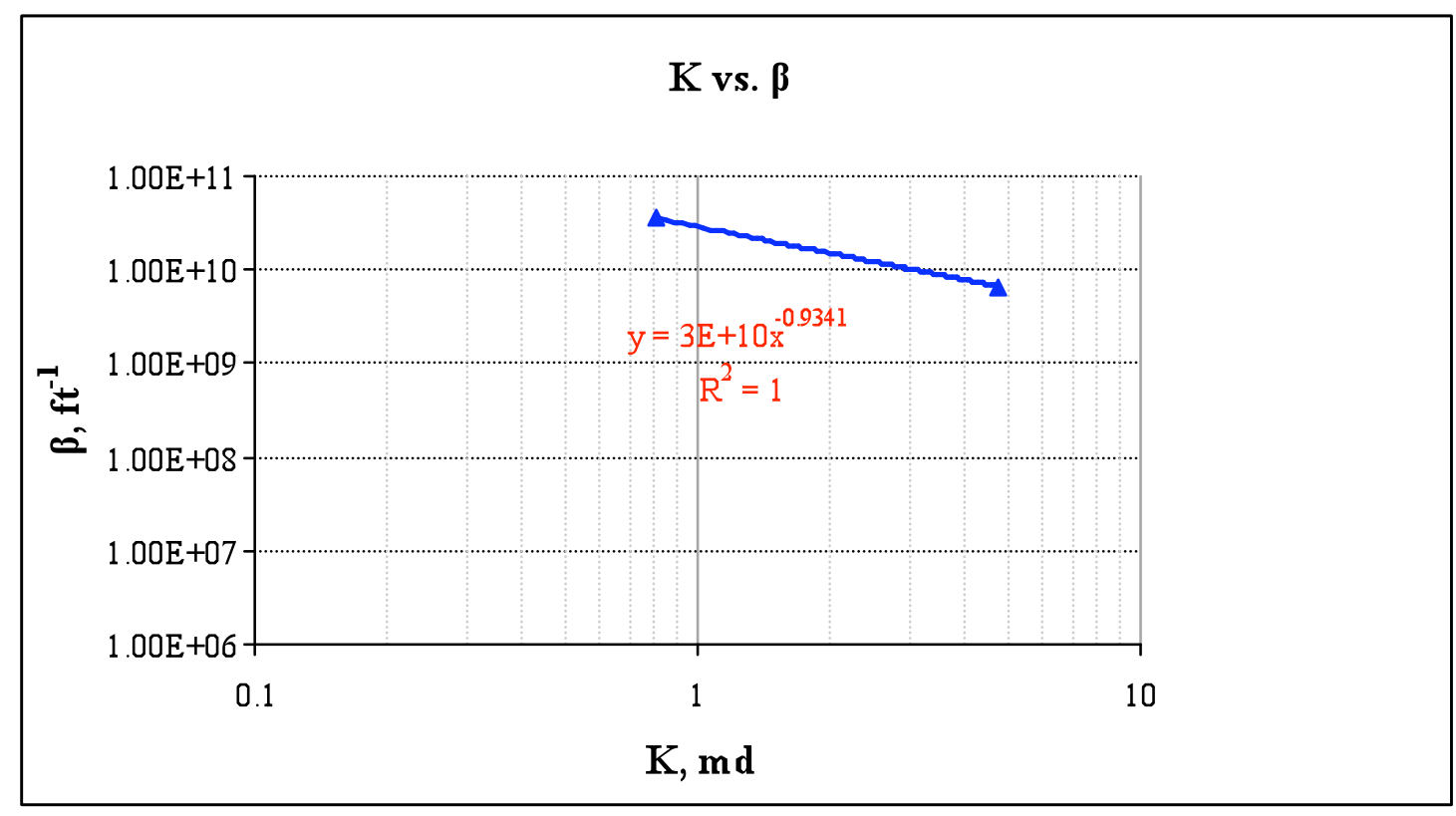

Figure C.1: $(\beta)$ Correlation for reservoir D 


\section{Reservoir-D Well Tests Data}

Multi-rate test data for wells D-1, D-2 and D-3 were available:

\section{Well D-1:}

Table C.2: Multi-rate test analysis for well D-1 (Rate-1)

\begin{tabular}{|c|c|c|c|c|c|c|c|c|c|c|}
\hline \multicolumn{10}{|c|}{ Well D-1 (Rate-1) } & \\
\hline Time (hrs) & Time (hrs) & $\Delta \mathrm{t}, \mathrm{hrs}$ & Log Time & $\begin{array}{c}\text { BHT Temp } \\
\text { (F) }\end{array}$ & $\begin{array}{c}\text { WH Pressure } \\
\text { (Psig) }\end{array}$ & $\begin{array}{c}\text { BHP Pressure } \\
\text { (Psig) Using } \\
\text { program }\end{array}$ & $\begin{array}{l}\text { BHP } \\
\text { Pressure } \\
\text { (Psia) }\end{array}$ & $\Delta \mathrm{P}(\mathrm{Psia})$ & $\begin{array}{c}\text { Q } \\
\text { (MMscfd) }\end{array}$ & \\
\hline $13: 20: 49$ & 0.033333 & & & 160 & 2524.61 & 3158.69 & 3173.39 & & 1891.13 & 1 \\
\hline $13: 21: 49$ & 0.050000 & 0.016667 & -1.778151 & 160 & 2529.61 & 3164.59 & 3179.29 & 5.9 & 1912 & 2 \\
\hline 13:22:49 & 0.066667 & 0.033333 & -1.477121 & 160 & 2534.61 & 3170.49 & 3185.19 & 11.8 & 1976.18 & \\
\hline $13: 23: 49$ & 0.083333 & 0.050000 & -1.30103 & 160 & 2537.11 & 3173.44 & 3188.14 & 14.75 & 1857.85 & 4 \\
\hline $13: 24: 49$ & 0.100000 & 0.066667 & -1.176091 & 160 & 2539.61 & 3176.39 & 3191.09 & 17.7 & 1894.13 & 5 \\
\hline $13: 25: 49$ & 0.116667 & 0.083333 & -1.079181 & 160 & 2543.36 & 3180.82 & 3195.52 & 22.13 & 1906.06 & \\
\hline 13:26:49 & 0.133333 & 0.100000 & -1 & 160 & 2544.61 & 3182.29 & 3196.99 & 23.6 & 1914.97 & \\
\hline 13:27:49 & 0.150000 & 0.116667 & -0.933053 & 160 & 2547.11 & 3185.24 & 3199.94 & 26.55 & 1914.97 & 8 \\
\hline 13:28:49 & 0.166667 & 0.133333 & -0.875061 & 160 & 2549.61 & 3188.19 & 3202.89 & 29.5 & 1912 & 9 \\
\hline 13:29:49 & 0.183333 & 0.150000 & -0.823909 & 160 & 2552.11 & 3191.13 & 3205.83 & 32.44 & 1903.09 & 10 \\
\hline 13:30:49 & 0.200000 & 0.166667 & -0.778151 & 160 & 2554.61 & 3194.08 & 3208.78 & 35.39 & 1920.88 & 11 \\
\hline 13:31:49 & 0.216667 & 0.183333 & -0.736759 & 160 & 2555.86 & 3195.55 & 3210.25 & 36.86 & 1920.88 & 12 \\
\hline 13:32:49 & 0.233333 & 0.200000 & -0.69897 & 160 & 2557.11 & 3197.02 & 3211.72 & 38.33 & 1920.88 & 13 \\
\hline 13:33:49 & 0.250000 & 0.216667 & -0.664208 & 160 & 2558.37 & 3198.51 & 3213.21 & 39.82 & 1917.93 & 14 \\
\hline 13:34:49 & 0.266667 & 0.233333 & -0.632023 & 160 & 2560.87 & 3201.45 & 3216.15 & 42.76 & 1909.04 & 15 \\
\hline $13: 35: 49$ & 0.283333 & 0.250000 & -0.60206 & 160 & 2562.12 & 3202.92 & 3217.62 & 44.23 & 1909.04 & 16 \\
\hline 13:36:49 & 0.300000 & 0.266667 & -0.574031 & 160 & 2563.37 & 3204.39 & 3219.09 & 45.7 & 1909.04 & 17 \\
\hline $13: 37: 49$ & 0.316667 & 0.283333 & -0.547702 & 160 & 2564.62 & 3205.86 & 3220.56 & 47.17 & 1909.04 & 18 \\
\hline 13:38:49 & 0.333333 & 0.300000 & -0.522879 & 160 & 2565.87 & 3207.33 & 3222.03 & 48.64 & 1903.09 & 19 \\
\hline 13:39:49 & 0.350000 & 0.316667 & -0.499398 & 160 & 2567.12 & 3208.81 & 3223.51 & 50.12 & 1903.09 & 20 \\
\hline 13:40:49 & 0.366667 & 0.333333 & -0.477121 & 160 & 2568.37 & 3210.28 & 3224.98 & 51.59 & 1961.78 & 21 \\
\hline 13:41:49 & 0.383333 & 0.350000 & -0.455932 & 160 & 2570.87 & 3213.22 & 3227.92 & 54.53 & 1950.18 & 22 \\
\hline 13:42:49 & 0.400000 & 0.366667 & -0.435729 & 160 & 2572.12 & 3214.69 & 3229.39 & 56 & 1909.04 & 23 \\
\hline 13:43:50 & 0.416944 & 0.383611 & -0.416109 & 160 & 2572.12 & 3214.69 & 3229.39 & 56 & 1909.04 & 24 \\
\hline 13:44:49 & 0.433333 & 0.400000 & -0.39794 & 160 & 2573.37 & 3216.16 & 3230.86 & 57.47 & 1906.06 & 25 \\
\hline 13:45:50 & 0.450278 & 0.416944 & -0.379922 & 160 & 2574.62 & 3217.63 & 3232.33 & 58.94 & 1909.04 & 26 \\
\hline 13:46:50 & 0.466944 & 0.433611 & -0.3629 & 160 & 2575.87 & 3219.1 & 3233.8 & 60.41 & 1903.09 & 27 \\
\hline 13:47:50 & 0.483611 & 0.450278 & -0.346519 & 160 & 2577.12 & 3220.57 & 3235.27 & 61.88 & 1938.51 & 28 \\
\hline 13:48:49 & 0.500000 & 0.466667 & -0.330993 & 160 & 2578.37 & 3222.04 & 3236.74 & 63.35 & 1897.12 & 29 \\
\hline 13:49:49 & 0.516667 & 0.483333 & \begin{tabular}{|c|}
-0.315753 \\
\end{tabular} & 160 & 2578.37 & 3222.04 & 3236.74 & 63.35 & 1906.06 & 30 \\
\hline \multicolumn{9}{|c|}{ Average Resevoir Pressure @ $\mathrm{t}=0$} & \begin{tabular}{|l|}
1913.1737 \\
1.9131737 \\
\end{tabular} & $\begin{array}{l}\text { Mscfd) } \\
\text { MMscfd }\end{array}$ \\
\hline
\end{tabular}

Since the calculated BHP is $>3000$ psia, we need to use the Pressure \& Time method $\left(P_{w f}\right.$ Vs. t $)$

- plotting the adjusted pressure against time in a semi-log paper as follow: 


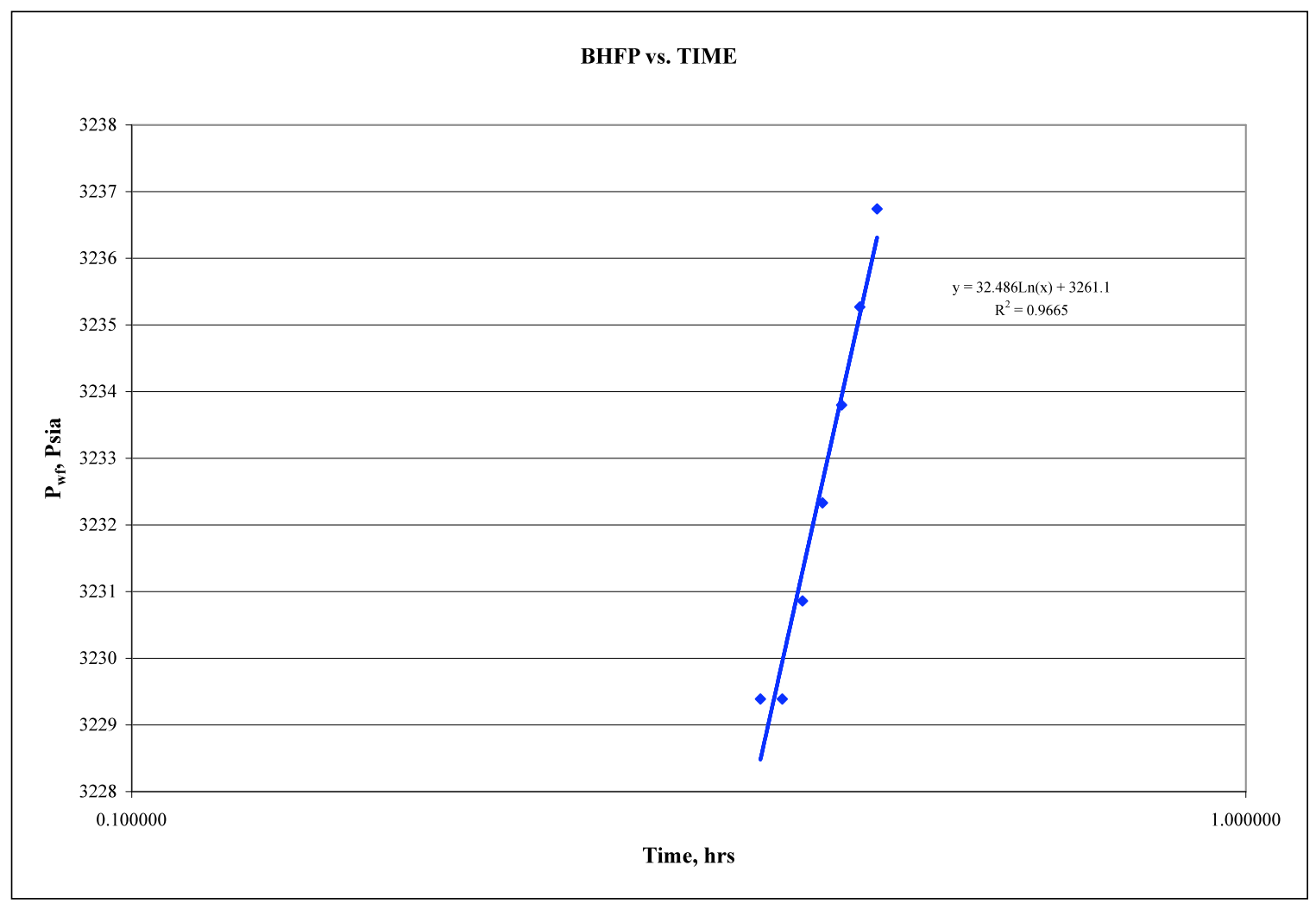

Figure C.2: Semi-log plot for well D-1 (Rate-1)

- Now, permeability (K) and apparent skin factor (s') can be calculated as follow:

From Regression

$$
\begin{aligned}
& m= \\
& \left(P_{w f}\right)_{1 h r}= \\
& 98.43258 \\
& 3261.1 \quad \text { psia } \\
& K=\frac{162.6 q_{g} B{ }_{g} \mu_{g}}{(m h)} \\
& \begin{array}{lrr}
K= & 0.58 \quad m d
\end{array} \\
& s^{\prime}=1.151\left[\frac{P_{1 h r}-\overline{P_{a}}}{m}-\log \left(\frac{k}{\phi \mu c_{t} r_{w}^{2}}\right)+3.23\right] \\
& s^{\prime}=\quad-3.776209433
\end{aligned}
$$

- By following the same procedures with the other two rates, the values of the permeability (K) and apparent skin factor (s') were obtained. Table C.3 summarizes the results of the multi-rate test analysis for well D-1 at each flow rate. 
Table C.3: $K$ and S' values for well D-1 at different rates

\begin{tabular}{|c|c|c|}
\hline \multicolumn{3}{|c|}{ Multi-Rate test Analysis for well D-1 } \\
\hline $\mathrm{q}(\mathrm{MMcf} / \mathrm{D})$ & $\mathrm{K}(\mathrm{md})$ & $\mathrm{S}^{\prime}$ \\
\hline 1.913173667 & 0.58 & -3.776209433 \\
\hline 2.699919667 & 1.08 & -3.672346876 \\
\hline 3.81419165 & 1.02 & -3.647289564 \\
\hline \\
Average $\mathrm{K}=$ & 2.68 \\
\end{tabular}

- By plotting the flow rate (Q) against the apparent skin factor (s') values, we had the following result:

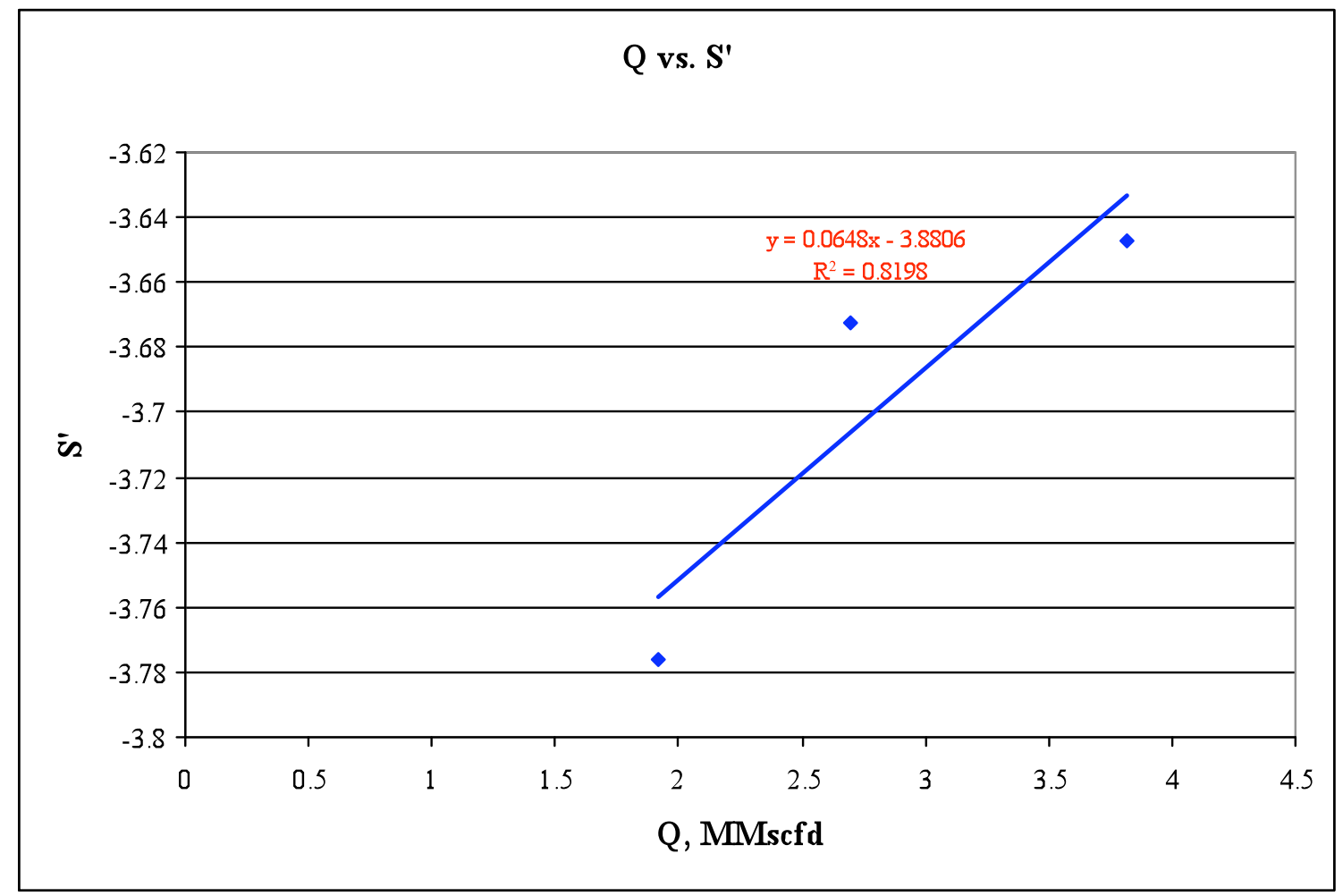

Figure C.3: Flow rates against skin factor (s') for well D-1

From Trendline equ.

Slope $=$ Non-Darcy flow coefficient $D$
$D=$
$0.0648 \quad 0.0000648$
$\beta=$
$\left(D^{*} \mu^{*} \mathrm{~h} * \mathrm{rw}\right) /(2.223 \times 10-15 \mathrm{~g} \mathrm{~K})$
$\beta=$
$3.01 \mathrm{E}+10$ 


\section{Well D-2:}

Table C.4: Multi-rate test analysis for well D-2 (Rate-1)

\begin{tabular}{|c|c|c|c|c|c|c|c|c|c|c|}
\hline \multicolumn{10}{|c|}{ Well D-2 (Rate-1) } & \\
\hline Time (hrs) & Time (hrs) & $\Delta \mathrm{t}, \mathrm{hrs}$ & Log Time & $\begin{array}{c}\text { BHT Temp } \\
\text { (F) }\end{array}$ & $\begin{array}{c}\text { WH Pressure } \\
\text { (Psig) }\end{array}$ & $\begin{array}{c}\text { BHP Pressure } \\
\text { (Psig) Using } \\
\text { program }\end{array}$ & $\begin{array}{c}\text { BHP Pressure } \\
\text { (Psia) }\end{array}$ & $\Delta \mathrm{P}$ (Psia) & $\begin{array}{c}\mathrm{Q} \\
\text { (MMscfd) }\end{array}$ & \\
\hline $14: 10: 39$ & 0.016667 & & & 160 & 2423.33 & 3041.5 & 3056.2 & & 2095.62 & 1 \\
\hline $14: 11: 39$ & 0.033333 & 0.016667 & -1.778151 & 160 & 2424.58 & 3042.99 & 3057.69 & 1.49 & 2114.62 & 2 \\
\hline $14: 12: 39$ & 0.050000 & 0.033333 & -1.477121 & 160 & 2425.83 & 3044.48 & 3059.18 & 2.98 & 2128.08 & 3 \\
\hline $14: 13: 39$ & 0.066667 & 0.050000 & -1.30103 & 160 & 2427.08 & 3045.97 & 3060.67 & 4.47 & 2130.76 & 4 \\
\hline 14:14:39 & 0.083333 & 0.066667 & -1.176091 & 160 & 2428.33 & 3047.46 & 3062.16 & 5.96 & 2130.76 & 5 \\
\hline $14: 15: 40$ & 0.100278 & 0.083611 & -1.077736 & 160 & 2428.33 & 3047.46 & 3062.16 & 5.96 & 2138.79 & 6 \\
\hline $14: 16: 39$ & 0.116667 & 0.100000 & -1 & 160 & 2429.58 & 3048.95 & 3063.65 & 7.45 & 2141.46 & 7 \\
\hline $14: 17: 39$ & 0.133333 & 0.116667 & -0.933053 & 160 & 2429.58 & 3048.95 & 3063.65 & 7.45 & 2128.08 & 8 \\
\hline $14: 18: 39$ & 0.150000 & 0.133333 & -0.875061 & 160 & 2430.83 & 3050.45 & 3065.15 & 8.95 & 2152.11 & 9 \\
\hline $14: 19: 40$ & 0.166944 & 0.150278 & -0.823105 & 160 & 2430.83 & 3050.45 & 3065.15 & 8.95 & 2152.11 & 10 \\
\hline $14: 20: 39$ & 0.183333 & 0.166667 & -0.778151 & 160 & 2430.83 & 3050.45 & 3065.15 & 8.95 & 2144.13 & 11 \\
\hline $14: 21: 39$ & 0.200000 & 0.183333 & -0.736759 & 160 & 2432.08 & 3051.94 & 3066.64 & 10.44 & 2146.79 & 12 \\
\hline $14: 22: 40$ & 0.216944 & 0.200278 & -0.698367 & 160 & 2432.08 & 3051.94 & 3066.64 & 10.44 & 2144.13 & 13 \\
\hline $14: 23: 39$ & 0.233333 & 0.216667 & -0.664208 & 160 & 2432.08 & 3051.94 & 3066.64 & 10.44 & 2122.7 & 14 \\
\hline $14: 24: 39$ & 0.250000 & 0.233333 & -0.632023 & 160 & 2432.08 & 3051.94 & 3066.64 & 10.44 & 2120.01 & 15 \\
\hline $14: 25: 39$ & 0.266667 & 0.250000 & -0.60206 & 160 & 2433.33 & 3053.43 & 3068.13 & 11.93 & 2095.62 & 16 \\
\hline $14: 26: 39$ & 0.283333 & 0.266667 & -0.574031 & 160 & 2433.33 & 3053.43 & 3068.13 & 11.93 & 2114.62 & 17 \\
\hline $14: 27: 39$ & 0.300000 & 0.283333 & -0.547702 & 160 & 2433.33 & 3053.43 & 3068.13 & 11.93 & 2081.94 & 18 \\
\hline $14: 28: 40$ & 0.316944 & 0.300278 & -0.522477 & 160 & 2433.33 & 3053.43 & 3068.13 & 11.93 & 2098.34 & 19 \\
\hline $14: 29: 39$ & 0.333333 & 0.316667 & -0.499398 & 160 & 2433.33 & 3053.43 & 3068.13 & 11.93 & 2084.69 & 20 \\
\hline $14: 30: 39$ & 0.350000 & 0.333333 & -0.477121 & 160 & 2434.59 & 3054.93 & 3069.63 & 13.43 & 2070.94 & 21 \\
\hline $14: 31: 39$ & 0.366667 & 0.350000 & -0.455932 & 160 & 2434.59 & 3054.93 & 3069.63 & 13.43 & 2092.89 & 22 \\
\hline $14: 32: 39$ & 0.383333 & 0.366667 & -0.435729 & 160 & 2434.59 & 3054.93 & 3069.63 & 13.43 & 2084.69 & 23 \\
\hline $14: 33: 39$ & 0.400000 & 0.383333 & -0.416423 & 160 & 2434.59 & 3054.93 & 3069.63 & 13.43 & 2073.7 & 24 \\
\hline $14: 34: 39$ & 0.416667 & 0.400000 & -0.39794 & 160 & 2434.59 & 3054.93 & 3069.63 & 13.43 & 2073.7 & 25 \\
\hline $14: 35: 40$ & 0.433611 & 0.416944 & -0.379922 & 160 & 2435.84 & 3056.42 & 3071.12 & 14.92 & 2084.69 & 26 \\
\hline $14: 36: 39$ & 0.450000 & 0.433333 & -0.363178 & 160 & 2435.84 & 3056.42 & 3071.12 & 14.92 & 2084.69 & 27 \\
\hline $14: 37: 39$ & 0.466667 & 0.450000 & -0.346787 & 160 & 2435.84 & 3056.42 & 3071.12 & 14.92 & 2065.41 & 28 \\
\hline $14: 38: 39$ & 0.483333 & 0.466667 & -0.330993 & 160 & 2435.84 & 3056.42 & 3071.12 & 14.92 & 2048.75 & 29 \\
\hline $14: 39: 39$ & 0.500000 & 0.483333 & -0.315753 & 160 & 2435.84 & 3056.42 & 3071.12 & 14.92 & 2095.62 & 30 \\
\hline & erage Resev & Pressure @ & & 160 & 2419.58 & 3037.44 & 3052.14 & & \begin{tabular}{|l|}
2108.0147 \\
2.1080147
\end{tabular} & $\begin{array}{l}\text { Avg q (Mscfd) } \\
\text { Avg q (MMscfd) }\end{array}$ \\
\hline
\end{tabular}

Since the calculated BHP is $>3000$ psia, we need to use the Pressure \& Time method (P $\mathrm{P}_{\mathrm{wf}}$ Vs. t).

- By plotting the adjusted pressure against time in a semi-log paper as follow: 


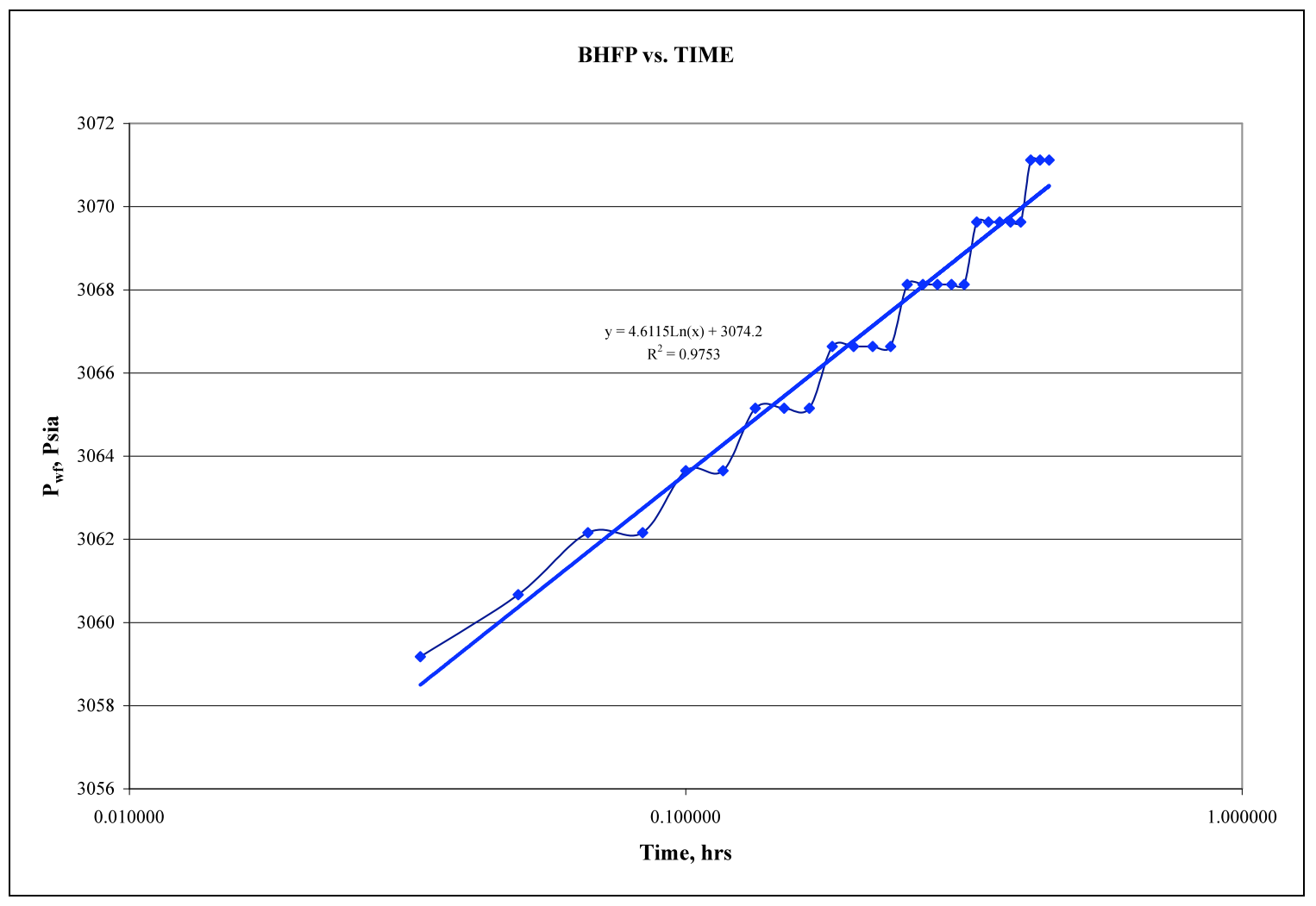

Figure C.4: Semi-log plot for well D-2 (Rate-1)

- Now, permeability (K) and apparent skin factor (s') can be calculated as follow:

From Regression

$$
\begin{aligned}
& m= \\
& \left(P_{w f}\right)_{1 h r},=\quad 3074.2 \quad \text { psia } \\
& K=\frac{162.6 q_{g} B{ }_{g} \mu_{g}}{(m h)} \\
& K=\quad 4.08 \quad m d \\
& s^{\prime}=1.151\left[\frac{P_{1 h r}-\overline{P_{a}}}{m}-\log \left(\frac{k}{\phi \overline{\mu c_{t}} r_{w}^{2}}\right)+3.23\right] \\
& s^{\prime}=\quad-4.170691
\end{aligned}
$$

- By following the same procedures with the other two rates, the values of the permeability (K) and apparent skin factor (s') were obtained. Table C.5 summarizes the results of the multi-rate test analysis for well D-2 at each flow rate. 
Table C.5: $K$ and S' values for well D-2 at different rates

\begin{tabular}{|c|c|c|}
\hline \multicolumn{3}{|c|}{ Multi-Rate test Analysis for well D-2 } \\
\hline q(MMcf/D) & $\mathrm{K} \mathrm{md}$ & $\mathrm{S}^{\prime}$ \\
\hline 2.108014667 & 4.08 & -4.1706908 \\
\hline 3.203857667 & 4.96 & -3.913617718 \\
\hline 4.681542466 & 5.28 & -3.812443879 \\
\hline \multicolumn{3}{|c|}{14.33} \\
\hline
\end{tabular}

- By plotting the flow rate (Q) against the apparent skin factor (s') values, we had the following result:

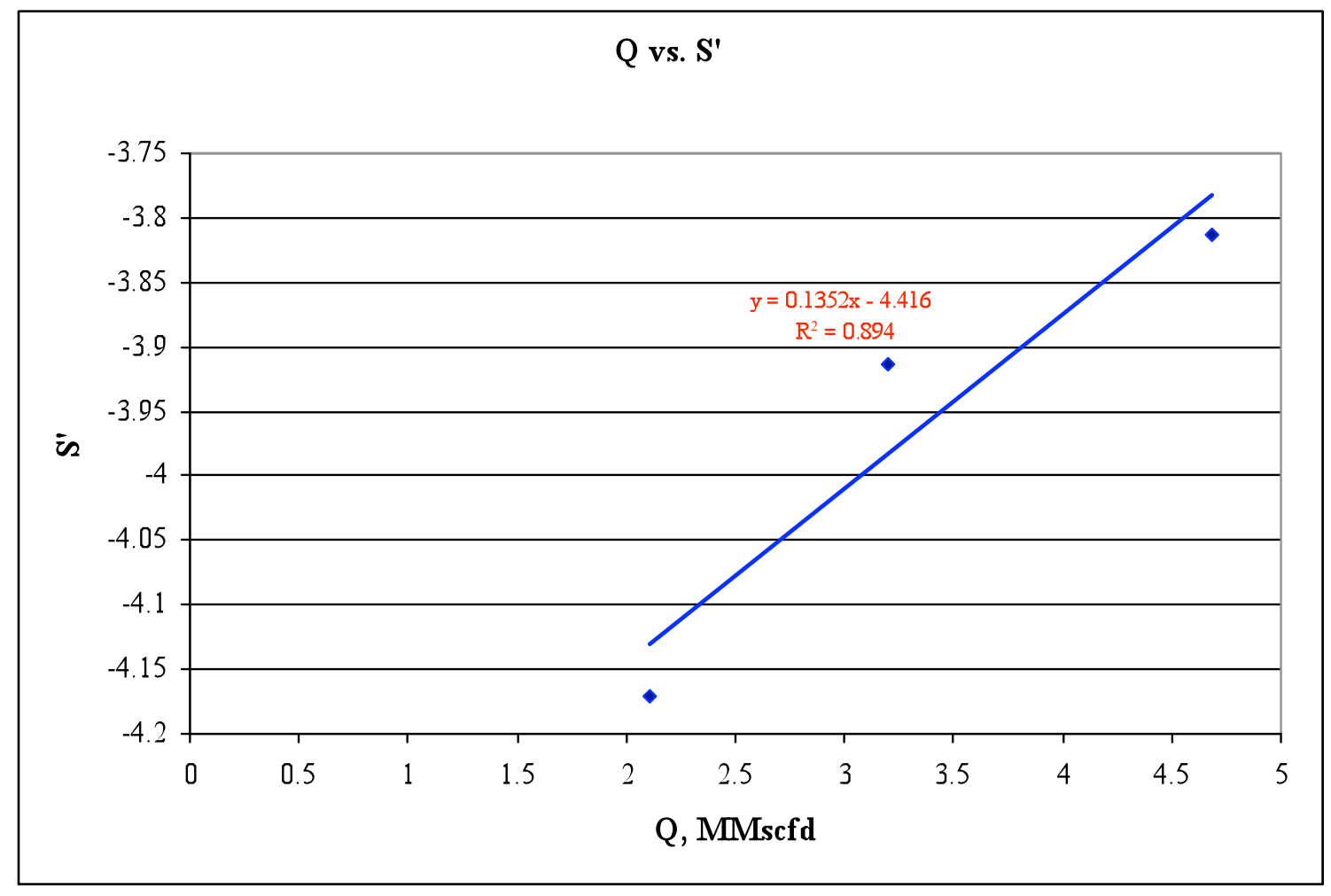

Figure C.5: Flow rates against skin factor (s') for well D-2

From Trendline equ.

Slope $=$ Non-Darcy flow coefficient $D$
$D=$
$0.1352 \quad 0.0001352$
$\beta=$
$\left(D^{*} \mu^{*} \mathrm{~h}^{*} \mathrm{rw}\right) /(2.223 \times 10-15 \mathrm{~g} \mathrm{~K})$
$\beta=$
$6.68 \mathrm{E}+09$ 


\section{Well D-3: (It was selected to be Reservoir D test well)}

Table C.6: Multi-rate test analysis for well D-3 (Rate-1)

\begin{tabular}{|c|c|c|c|c|c|c|c|c|c|c|}
\hline \multicolumn{10}{|c|}{ Well D-3 (Rate-1) } & \\
\hline Time (hrs) & Time (hrs) & $\Delta \mathrm{t}, \mathrm{hrs}$ & Log Time & BHT Temp (F) & $\begin{array}{c}\text { WH Pressure } \\
\text { (Psig) }\end{array}$ & $\begin{array}{c}\text { BHP Pressure } \\
\text { (Psig) Using } \\
\text { program }\end{array}$ & $\begin{array}{l}\text { BHP } \\
\text { Pressure } \\
\text { (Psia) }\end{array}$ & $\Delta \mathrm{P}$ (Psia) & $\begin{array}{c}\text { Q } \\
\text { (MMscfd) }\end{array}$ & \\
\hline $13: 30: 38$ & 0.066667 & & & 160 & 2619.63 & 3227.46 & 3242.16 & & 1803.85 & 1 \\
\hline 13:31:38 & 0.083333 & 0.016667 & -1.778151 & 160 & 2620.88 & 3228.92 & 3243.62 & 1.46 & 1991.82 & 2 \\
\hline 13:32:39 & 0.100278 & 0.033611 & -1.473517 & 160 & 2620.88 & 3228.92 & 3243.62 & 1.46 & 1889.7 & 3 \\
\hline $13: 33: 38$ & 0.116667 & 0.050000 & -1.30103 & 160 & 2622.13 & 3230.37 & 3245.07 & 2.91 & 1925.32 & 4 \\
\hline 13:34:39 & 0.133611 & 0.066944 & -1.174285 & 160 & 2622.13 & 3230.37 & 3245.07 & 2.91 & 1904.63 & 5 \\
\hline $13: 35: 38$ & 0.150000 & 0.083333 & -1.079181 & 160 & 2622.13 & 3230.37 & 3245.07 & 2.91 & 1939.97 & 6 \\
\hline 13:36:38 & 0.166667 & 0.100000 & -1 & 160 & 2622.13 & 3230.37 & 3245.07 & 2.91 & 1942.89 & 7 \\
\hline $13: 37: 38$ & 0.183333 & 0.116667 & -0.933053 & 160 & 2622.13 & 3230.37 & 3245.07 & 2.91 & 1934.13 & 8 \\
\hline $13: 38: 38$ & 0.200000 & 0.133333 & -0.875061 & 160 & 2623.38 & 3231.82 & 3246.52 & 4.36 & 1913.52 & 9 \\
\hline 13:39:38 & 0.216667 & 0.150000 & -0.823909 & 160 & 2623.38 & 3231.82 & 3246.52 & 4.36 & 1907.6 & 10 \\
\hline $13: 40: 38$ & 0.233333 & 0.166667 & -0.778151 & 160 & 2623.38 & 3231.82 & 3246.52 & 4.36 & 1922.38 & 11 \\
\hline 13:41:38 & 0.250000 & 0.183333 & -0.736759 & 160 & 2623.38 & 3231.82 & 3246.52 & 4.36 & 1904.63 & 12 \\
\hline $13: 42: 38$ & 0.266667 & 0.200000 & -0.69897 & 160 & 2623.38 & 3231.82 & 3246.52 & 4.36 & 1880.69 & 13 \\
\hline 13:43:39 & 0.283611 & 0.216944 & -0.663651 & 160 & 2623.38 & 3231.82 & 3246.52 & 4.36 & 1844.21 & 14 \\
\hline 13:44:39 & 0.300278 & 0.233611 & -0.631507 & 160 & 2623.38 & 3231.82 & 3246.52 & 4.36 & 1904.63 & 15 \\
\hline $13: 45: 38$ & 0.316667 & 0.250000 & -0.60206 & 160 & 2623.38 & 3231.82 & 3246.52 & 4.36 & 1901.65 & 16 \\
\hline 13:46:38 & 0.333333 & 0.266667 & -0.574031 & 160 & 2624.63 & 3233.27 & 3247.97 & 5.81 & 2000.33 & 17 \\
\hline $13: 47: 38$ & 0.350000 & 0.283333 & -0.547702 & 160 & 2624.63 & 3233.27 & 3247.97 & 5.81 & 1931.2 & 18 \\
\hline $13: 48: 38$ & 0.366667 & 0.300000 & -0.522879 & 160 & 2624.63 & 3233.27 & 3247.97 & 5.81 & 1898.67 & 19 \\
\hline $13: 49: 38$ & 0.383333 & 0.316667 & -0.499398 & 160 & 2624.63 & 3233.27 & 3247.97 & 5.81 & 1904.63 & 20 \\
\hline $13: 50: 38$ & 0.400000 & 0.333333 & -0.477121 & 160 & 2624.63 & 3233.27 & 3247.97 & 5.81 & 1862.54 & 21 \\
\hline 13:51:39 & 0.416944 & 0.350278 & -0.455587 & 160 & 2624.63 & 3233.27 & 3247.97 & 5.81 & 1916.48 & 22 \\
\hline $13: 52: 38$ & 0.433333 & 0.366667 & -0.435729 & 160 & 2624.63 & 3233.27 & 3247.97 & 5.81 & 1856.45 & 23 \\
\hline 13:53:38 & 0.450000 & 0.383333 & -0.416423 & 160 & 2624.63 & 3233.27 & 3247.97 & 5.81 & 1925.32 & 24 \\
\hline $13: 54: 38$ & 0.466667 & 0.400000 & -0.39794 & 160 & 2624.63 & 3233.27 & 3247.97 & 5.81 & 1904.63 & 25 \\
\hline $13: 55: 38$ & 0.483333 & 0.416667 & -0.380211 & 160 & 2624.63 & 3233.27 & 3247.97 & 5.81 & 1939.97 & 26 \\
\hline $13: 56: 39$ & 0.500278 & 0.433611 & -0.3629 & 160 & 2624.63 & 3233.27 & 3247.97 & 5.81 & 1913.52 & 27 \\
\hline 13:57:38 & 0.516667 & 0.450000 & -0.346787 & 160 & 2624.63 & 3233.27 & 3247.97 & 5.81 & 1856.45 & 28 \\
\hline $13: 58: 38$ & 0.533333 & 0.466667 & -0.330993 & 160 & 2624.63 & 3233.27 & 3247.97 & 5.81 & 1898.67 & 29 \\
\hline $13: 59: 38$ & 0.550000 & 0.483333 & -0.315753 & 160 & 2624.63 & 3233.27 & 3247.97 & 5.81 & 1898.67 & 30 \\
\hline \multicolumn{4}{|c|}{ Average Resevoir Pressure @ $\mathrm{t}=0$} & 160 & 2615.88 & 3223.4 & \multicolumn{2}{|l|}{3238.1} & 1907.305 & Avg q (Mscfd) \\
\hline
\end{tabular}

Since the calculated BHP is $>3000$ psia, we need to use the Pressure \& Time method $\left(\mathrm{P}_{\mathrm{wf}}\right.$ VS. t $)$.

- plotting the adjusted pressure against time in a semi-log paper as follow: 


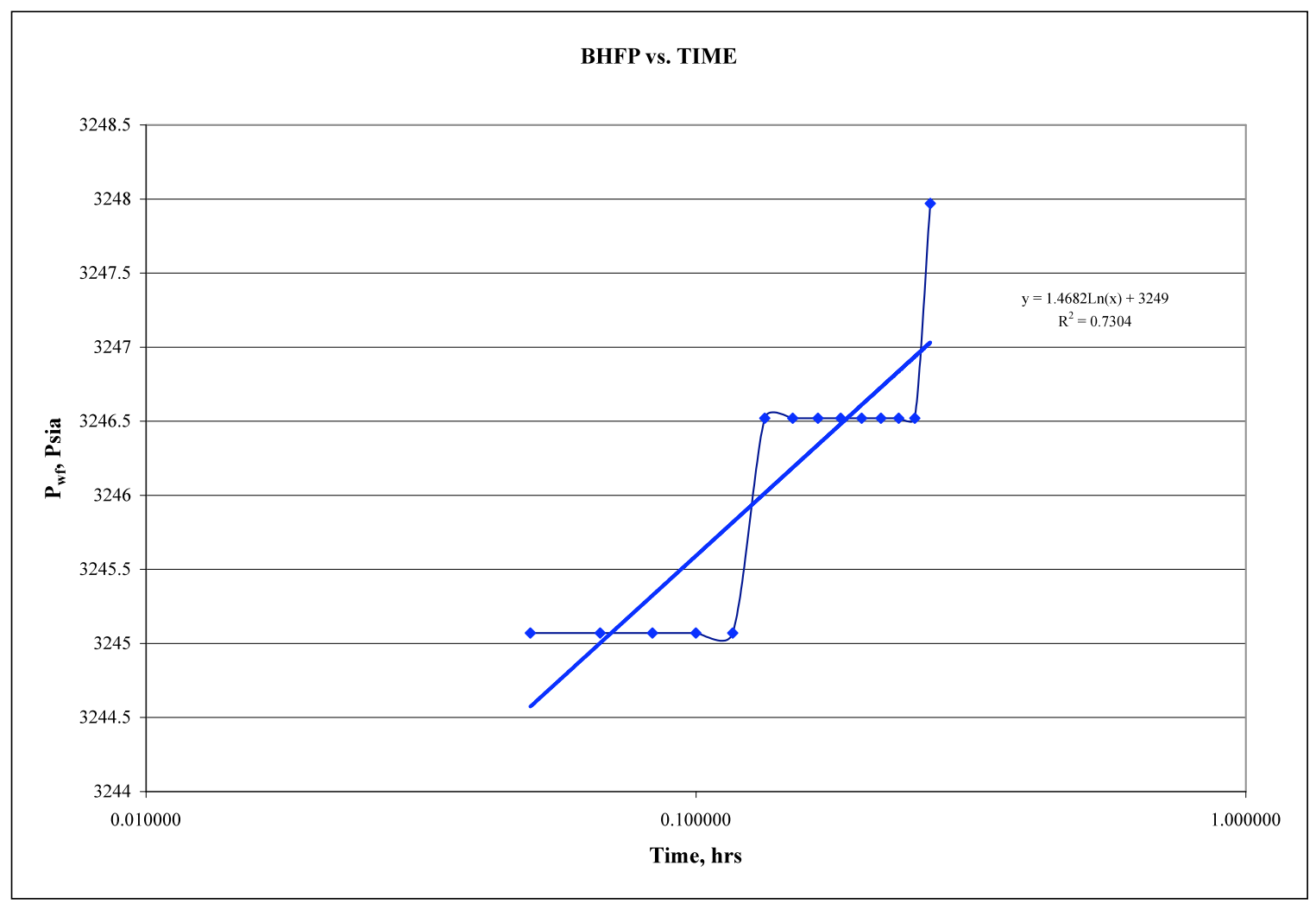

Figure C.6: Semi-log plot for well D-3 (Rate-1)

- Now, permeability (K) and apparent skin factor (s') can be calculated as follow:

From Regression

$$
\begin{aligned}
& m= \\
& \left(P_{w f}\right)_{1 h r}=\quad 3249 \quad \text { psia } \\
& K=\frac{162.6 q_{g} B{ }_{g} \mu_{g}}{(m h)} \\
& s^{\prime}=1.151\left[\frac{P_{1 h r}-\overline{P_{a}}}{m}-\log \left(\frac{k}{\phi \overline{\mu c_{t}} r_{w}^{2}}\right)+3.23\right] \\
& s^{\prime}=\quad-3.708794
\end{aligned}
$$

- By following the same procedures with the other two rates, the values of the permeability (K) and apparent skin factor (s') were obtained. Table C.7 summarizes the results of the multi-rate test analysis for well D-3 at each flow rate. 
Table C.7: K and S' values for well D-3 at different rates

\begin{tabular}{|c|c|c|}
\hline \multicolumn{3}{|c|}{ Multi-Rate test Analysis for well D-3 } \\
\hline $\mathrm{q}(\mathrm{MMcf} / \mathrm{D})$ & $\mathrm{K} \mathrm{md}$ & $\mathrm{S}^{\prime}$ \\
\hline 1.907305 & 11.34 & -3.708793933 \\
\hline 3.087374333 & 9.29 & -3.676093889 \\
\hline 4.435217031 & 7.47 & -3.438769082 \\
\hline \multicolumn{3}{|c|}{} \\
Average $\mathrm{K}=$ & 28.11 \\
\hline
\end{tabular}

- By plotting the flow rate (Q) against the apparent skin factor (s') values, we had the following result:

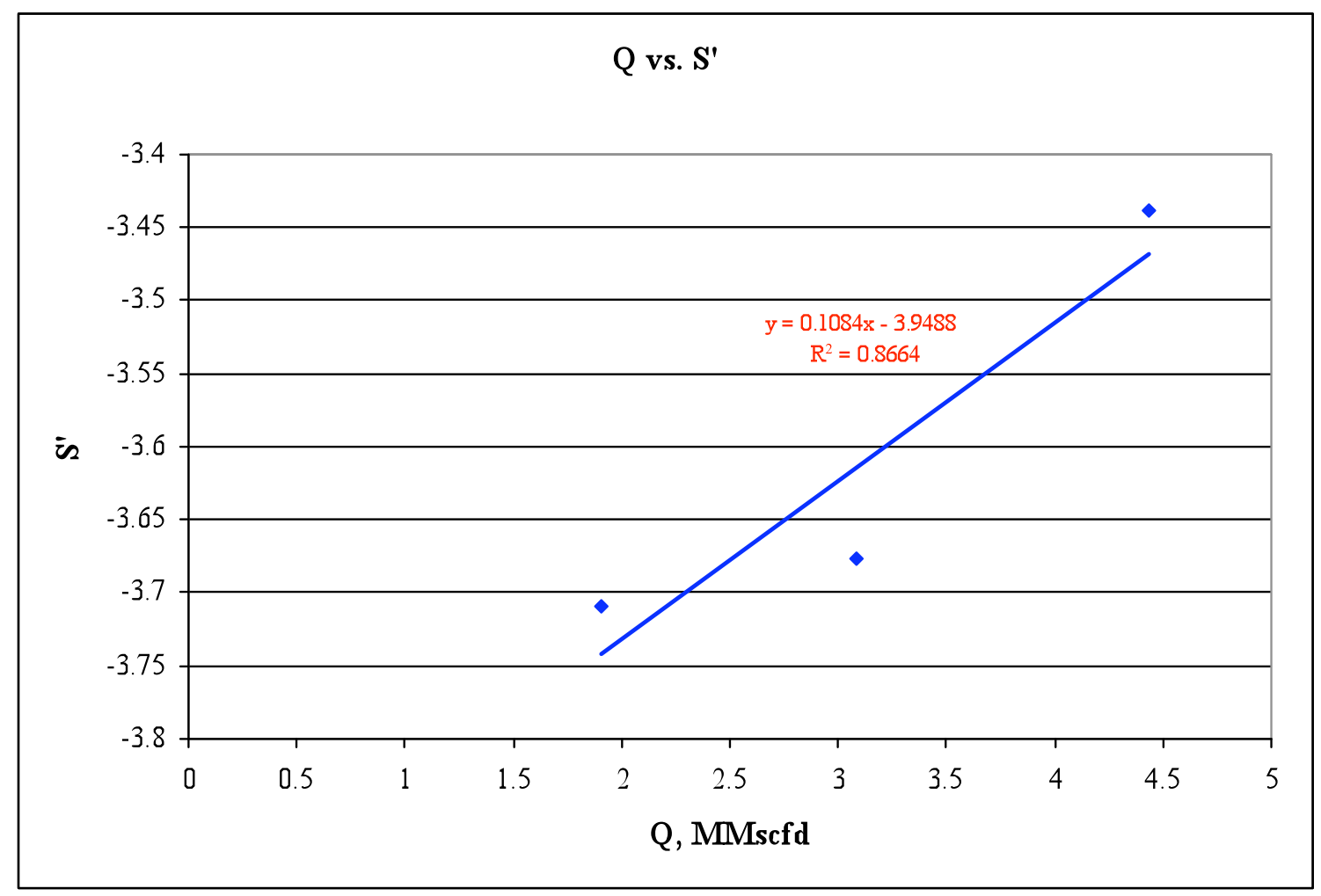

Figure C.7: Flow rates against skin factor (s') for well D-3

From Trendline equ.

Slope $=$ Non-Darcy flow coefficient $D$
$D=$
0.1084
0.0001084
$\beta=$
$\left(D^{*} \mu^{*} \mathrm{~h}^{*} \mathrm{rw}\right) /(2.223 \times 10-15 \mathrm{~g} \mathrm{~K})$
$\beta=$
$2.81 \mathrm{E}+09$ 